\title{
A Terminally Bound Niobium Methylidyne
}

\author{
Takashi Kurogi, ${ }^{\ddagger}$ Patrick J. Carroll, ${ }^{\ddagger}$ and Daniel J. Mindiola* ${ }^{*}$ \\ ${ }^{\ddagger}$ Department of Chemistry, University of Pennsylvania, 231 South 34th Street, \\ Philadelphia, Pennsylvania 19104
}

\section{Table of contents}

General Procedure

S3

Synthesis of complex 1-6

$\left[(\mathrm{PNP}) \mathrm{NbCl}_{2}(\mathrm{OAr})\right](\mathbf{1})$

S4

$\left[(\mathrm{PNP}) \mathrm{Nb}\left(\mathrm{CH}_{3}\right)_{2}(\mathrm{OAr})\right](2)$

S4-S5

$\left[(\mathrm{PNP}) \mathrm{Nb}\left({ }^{13} \mathrm{CH}_{3}\right)_{2}(\mathrm{OAr})\right]\left(\mathbf{2 -}{ }^{\mathbf{1 3}} \mathbf{C}\right)$

S5

$\left[(\mathrm{PNP}) \mathrm{Nb}\left(\mathrm{CH}_{3}\right)_{2}(\mathrm{OAr})(\mathrm{OTf})\right](\mathbf{3})$

S5-S6

$\left[(\mathrm{PNP}) \mathrm{Nb}\left({ }^{13} \mathrm{CH}_{3}\right)_{2}(\mathrm{OAr})(\mathrm{OTf})\right]\left(\mathbf{3}-{ }^{\mathbf{1 3}} \mathbf{C}\right)$

S6

$\left[(\mathrm{PNP}) \mathrm{Nb}\left(=\mathrm{CH}_{2}\right)(\mathrm{OAr})(\mathrm{OTf})\right](4)$

S7-S8

$\left[(\mathrm{PNP}) \mathrm{Nb}\left(={ }^{13} \mathrm{CH}_{2}\right)(\mathrm{OAr})(\mathrm{OTf})\right]\left(\mathbf{4 -}{ }^{\mathbf{1 3}} \mathbf{C}\right)$

S8

$[(\mathrm{PNP}) \mathrm{Nb}(\equiv \mathrm{CH})(\mathrm{OAr})](\mathbf{5})$

S8-S10

$\left[(\mathrm{PNP}) \mathrm{Nb}\left(\equiv{ }^{13} \mathrm{CH}\right)(\mathrm{OAr})\right]\left(\mathbf{5 -}^{\mathbf{1 3}} \mathbf{C}\right)$

$\mathrm{S} 10$

$[(\mathrm{PNP}) \mathrm{Nb}(\equiv \mathrm{N})(\mathrm{OAr})](\mathbf{6})$

S10-S11

$\left[(\mathrm{PNP}) \mathrm{Nb}\left(\equiv^{15} \mathrm{~N}\right)(\mathrm{OAr})\right]\left(\mathbf{6}-{ }^{15} \mathbf{N}\right)$

S11

NMR spectroscopic data

Complex 1

$\mathrm{S} 12$

Complex 2

S12

Complex 3 and $\mathbf{3 -}{ }^{\mathbf{1 3}} \mathbf{C}$

S13-S15

Complex 4 and $4-{ }^{13} \mathrm{C}$

S16-S19

Complex 5 and $5-{ }^{13} \mathbf{C}$

S20-S22

Complex 6 and $6-{ }^{15} \mathbf{N}$

S23-S24 
Reaction of $\mathbf{3}$ with $\mathbf{H}_{\mathbf{2}} \mathbf{C P P h} \mathbf{P H}_{3} \quad \mathrm{~S} 25-\mathrm{S} 26$

Reaction of 4 with $\mathrm{H}_{3} \mathrm{CMgCl} \quad$ S27-S28

Reaction of 5 with ${ }^{15}$ NC[1-Ad] $\quad$ S29

Reaction of 5- ${ }^{13} \mathbf{C}$ with ${ }^{15}$ NC[1-Ad] $\quad$ S30-S31

UV-Vis Spectra

$\begin{array}{ll}\text { Complex (1) } & \text { S32 }\end{array}$

$\begin{array}{ll}\text { Complex (2) } & \text { S32 }\end{array}$

$\begin{array}{ll}\text { Complex (3) } & \text { S33 }\end{array}$

$\begin{array}{ll}\text { Complex (4) } & \text { S33 }\end{array}$

$\begin{array}{ll}\text { Complex (5) } & \text { S34 }\end{array}$

$\begin{array}{lr}\text { Complex (6) } & \text { S34 }\end{array}$

$\begin{array}{ll}\text { Cyclic Voltammetry } & \text { S35 }\end{array}$

$\begin{array}{ll}\text { Cyclic Voltammogram of } 2 & \text { S35 }\end{array}$

$\begin{array}{lr}\text { X-ray Crystallography } & \text { S36-S37 }\end{array}$

$\begin{array}{ll}\text { Molecular Structure of } 1 & \text { S37 }\end{array}$

$\begin{array}{ll}\text { Crystallographic data of } \mathbf{1} & \text { S38 }\end{array}$

$\begin{array}{ll}\text { Crystallographic data of } 2 & \text { S39 }\end{array}$

$\begin{array}{ll}\text { Crystallographic data of } 3 & \text { S40 }\end{array}$

$\begin{array}{ll}\text { Crystallographic data of } \mathbf{4} & \text { S41 }\end{array}$

$\begin{array}{ll}\text { Crystallographic data of } 5 & \text { S42 }\end{array}$

$\begin{array}{ll}\text { References } & \text { S43 }\end{array}$ 


\section{General Procedure}

All operations were performed in a M. Braun glove box or using standard Schlenk techniques under a nitrogen atmosphere unless otherwise stated. Anhydrous solvents were purchased from Fisher Scientific or Aldrich. All anhydrous solvents were purified and dried by passage through two columns of activated alumina and Q-5 drying agent in a Grubbs-type solvent system. Stabilizer-free $\mathrm{Et}_{2} \mathrm{O}$ and $\mathrm{THF}$ were purchased from Fisher Scientific and dried by passage through two columns of activated alumina. All bulk solvents were kept over sodium and $4 \AA$ molecular sieves. A benzene- $d_{6}$ (Cambridge Isotope Laboratories) was dried and degassed over a potassium mirror prior to use. Celite and $4 \AA$ molecular sieves were activated under vacuum overnight at $200{ }^{\circ} \mathrm{C}$. Li(PNP), ${ }^{1}$ $\mathrm{NaOAr},{ }^{2}$ [FeCp$\left.p_{2}\right][\mathrm{OTf}],{ }^{3} \mathrm{NbCl}_{4}(\mathrm{THF})_{2},{ }^{4}$ and $\mathrm{H}_{2} \mathrm{CPPh}_{3}{ }^{5}$ were prepared according to the reported procedures. Labeled $\mathrm{Mg}\left({ }^{13} \mathrm{CH}_{3}\right)_{2}$ was prepared according to the reported procedure ${ }^{6}$ of $\mathrm{Mg}\left(\mathrm{CH}_{3}\right)_{2}$ by ${ }^{13} \mathrm{CH}_{3} \mathrm{I}$ (99 atom $\%{ }^{13} \mathrm{C}$, Aldrich). Labeled ${ }^{15} \mathrm{NC}[1-\mathrm{Ad}]$ (40 atom $\%{ }^{15} \mathrm{~N}$ ) was prepared according to the reported procedure. ${ }^{7}$ All other chemicals were purchased from commercial sources and degassed before being used. ${ }^{1} \mathrm{H},{ }^{13} \mathrm{C},{ }^{15} \mathrm{~N},{ }^{19} \mathrm{~F}$, ${ }^{31} \mathrm{P}$, and HMQC NMR spectra were recorded on a Bruker AV-II $500 \mathrm{MHz}$, AVIII 400 $\mathrm{MHz}$ or DMX $300 \mathrm{MHz}$ spectrometers. ${ }^{1} \mathrm{H},{ }^{13} \mathrm{C}$ NMR chemical shifts are reported referenced to the internal residual proton or carbon resonances of $\mathrm{C}_{6} \mathrm{D}_{6}(\delta=7.16 \mathrm{ppm}$ or $128.06 \mathrm{ppm}) .{ }^{19} \mathrm{~F}$ and ${ }^{31} \mathrm{P} \mathrm{NMR}$ chemical shifts are reported with respect to external $\mathrm{CF}_{3} \mathrm{CO}_{2} \mathrm{H}(\delta-78.5 \mathrm{ppm})$ and $\mathrm{H}_{3} \mathrm{PO}_{4}(\delta \quad 0.0 \mathrm{ppm}) .{ }^{15} \mathrm{~N}$ NMR chemical shifts were referenced to ${ }^{15} \mathrm{NC}[1-\mathrm{Ad}]\left(\delta=242 \mathrm{ppm}\right.$ vs. $\mathrm{NH}_{3}(l)$ at $\left.0 \mathrm{ppm}\right)$. Solution state magnetic susceptibility was measured by the Evans' $\operatorname{method}^{8}$ in benzene- $d_{6} /$ tetramethylsilane solution. Corrections were applied for diamagnetism calculated for Pascal constants. ${ }^{9}$ The $\mathrm{UV}-\mathrm{Vis}$ absorption spectrums were obtained in a J-Young valve $1 \mathrm{~cm}$ quartz cell on a Cary 5000 UV-Vis-NIR spectrophotometer (Agilent Technologies). Photolysis experiments were performed by a MAX-303 Xe-lamp photoreactor (Asahi Spectra Company) equipped with a UV mirror module (250-385 nm) 


\section{Synthesis of [(PNP)NbCl 2 (OAr)] (1)}

To a suspension of $\mathrm{NbCl}_{4}(\mathrm{THF})_{2}(1.00 \mathrm{~g}, 2.64 \mathrm{mmol})$ in toluene $(10 \mathrm{~mL})$ was added $\operatorname{Li}(\mathrm{PNP})(1.15 \mathrm{~g}, 2.64 \mathrm{mmol})$ as a solid at room temperature and additional toluene (10 $\mathrm{mL}$ ) was used to add the remainder of $\operatorname{Li}(\mathrm{PNP})$. After stirring for $12 \mathrm{~h}$, the reaction mixture changed color to a dark purple suspension/solution containing (PNP) $\mathrm{NbCl}_{3} \cdot{ }^{10} \mathrm{To}$ the purple mixture of (PNP) $\mathrm{NbCl}_{3}$ and $\mathrm{LiCl}$ was added $\mathrm{NaOAr}(530 \mathrm{mg}, 2.65 \mathrm{mmol})$ as solid at room temperature and additional toluene $(10 \mathrm{~mL})$ was used to add the rest of the $\mathrm{NaOAr}$. The reaction mixture gradually turned dark green in color over the duration of 2 h. After this time, the volatiles were removed under vacuum, and the dark green residue was extracted into toluene $(10 \mathrm{~mL})$ and the solution filtered through a medium porosity glass frit containing celite. The celite was washed twice with toluene $(2 \times 10 \mathrm{~mL})$. The dark green filtrate was evaporated to dryness and the residue was triturated twice with pentane $(2 \times 3 \mathrm{~mL})$ to yield $\mathbf{1}$ as green powder (1.86 g, $2.42 \mathrm{mmol}, 92 \%$ yield). Green crystals suitable for X-ray analysis were grown from a concentrated hexane solution at $-35^{\circ} \mathrm{C}$.

${ }^{1} \mathrm{H}$ NMR (400 MHz, Benzene- $d_{6}, 300 \mathrm{~K}$ ): $\delta 13.78$ (br), 10.52 (br), 6.53 (br), 3.65 (br), 2.03 (br), 1.47 (br), -0.28 (br). Broadening and overlapping of the ${ }^{1} \mathrm{H}$ NMR spectrum prevent us from measuring accurate integrations. $\mu_{\text {eff }}$ (Evans' Method, Benzene- $d_{6}, 300$ $\mathrm{K}): 1.83 \mu_{\mathrm{B}}$. UV-Vis (hexane, $\left.\lambda_{\max } / \mathrm{nm}\left(\varepsilon / \mathrm{M}^{-1} \mathrm{~cm}^{-1}\right)\right): 281$ (8650), 328 (sh, 17600), 459 (br, 4650), 608 (br, 1750).

\section{Synthesis of [(PNP)Nb(CH3) $(\mathrm{OAr})](2)$}

To a dark green solution of $1(900 \mathrm{mg}, 1.17 \mathrm{mmol})$ in toluene $(10 \mathrm{~mL})$ were added $\mathrm{H}_{3} \mathrm{CMgCl}$ in THF (3.0 M, $\left.0.80 \mathrm{~mL}, 2.4 \mathrm{mmol}\right)$ and 1,4-dioxane $(0.70 \mathrm{~mL})$ via syringe at $-35{ }^{\circ} \mathrm{C}$, resulting in a color change to reddish brown. After stirring for $30 \mathrm{~min}$, the reaction mixture was evaporated to dryness under reduced pressure. The brown residue was dissolved in toluene $(5 \mathrm{~mL})$ and filtered through a medium porosity glass frit 
containing celite, which was then washed with toluene $(5 \mathrm{~mL})$. The brown filtrate was evaporated to dryness under reduced pressure and the residue was triturated twice with cold pentane $\left(-35^{\circ} \mathrm{C}, 2 \times 2 \mathrm{~mL}\right)$ to yield 2 as reddish brown powder $(638 \mathrm{mg}, 875 \mu \mathrm{mol}$, $75 \%$ yield). Reddish brown crystals suitable for X-ray analysis were grown from concentrated pentane solution at $-35^{\circ} \mathrm{C}$.

${ }^{1} \mathrm{H}$ NMR (400 MHz, Benzene- $d_{6}, 300 \mathrm{~K}$ ): $\delta 11.20$ (br), 9.66 (br), 5.23 (br), 4.64 (br), 3.09

(br), 1.92 (br). Broadening and overlapping of the ${ }^{1} \mathrm{H}$ NMR spectrum prevent us from measuring accurate integrations. $\mu_{\text {eff }}$ (Evans' Method, Benzene- $\left.d_{6}, 300 \mathrm{~K}\right): 1.76 \mu_{\mathrm{B}}$.

\section{Synthesis of $\left[(\mathrm{PNP}) \mathrm{Nb}\left({ }^{13} \mathrm{CH}_{3}\right)_{2}(\mathrm{OAr})\right]\left(2-{ }^{13} \mathrm{C}\right)$}

To a dark green solution of $1(800 \mathrm{mg}, 1.04 \mathrm{mmol})$ in toluene $(20 \mathrm{~mL})$ was added $\operatorname{Mg}\left({ }^{13} \mathrm{CH}_{3}\right)_{2}(76.2 \mathrm{mg}, 1.35 \mathrm{mmol})$ in THF $(5 \mathrm{~mL})$ and 1,4-dioxane $(0.4 \mathrm{~mL})$ via syringe at $-35^{\circ} \mathrm{C}$, resulting in a color change to reddish brown. After stirring for $3 \mathrm{~h}$, the reaction mixture was evaporated to dryness under reduced pressure. The brown residue was dissolved in toluene $(10 \mathrm{~mL})$ and filtered through a medium porosity glass frit containing celite, which was then washed with toluene $(15 \mathrm{~mL})$. The brown filtrate was evaporated to dryness under reduced pressure and the residue was triturated twice with cold pentane $\left(-35^{\circ} \mathrm{C}, 2 \times 2 \mathrm{~mL}\right)$ to give $2-{ }^{13} \mathrm{C}$ as reddish brown powder $(672 \mathrm{mg}, 919 \mu \mathrm{mol}, 88 \%$ yield). Paramagnetic broadening prevents us from observing any significant differences of the ${ }^{1} \mathrm{H}$ NMR spectrum to that of 2 .

\section{Synthesis of $\left[(\mathrm{PNP}) \mathrm{Nb}\left(\mathrm{CH}_{3}\right)_{2}(\mathrm{OAr})(\mathrm{OTf})\right](3)$}

To a reddish brown solution of $3(400 \mathrm{mg}, 549 \mu \mathrm{mol})$ in toluene $(10 \mathrm{~mL})$ was added [FeCp 2$][\mathrm{OTf}](200 \mathrm{mg}, 563 \mu \mathrm{mol})$ as solid at room temperature and additional toluene (5 $\mathrm{mL}$ ) was used to add the remaining of the $\left[\mathrm{FeCp}_{2}\right][\mathrm{OTf}]$ in the vial. After stirring for $4 \mathrm{~h}$, the reaction mixture was filtered through a medium porosity glass frit, which was rinsed with THF $(3 \mathrm{~mL})$. The dark brown filtrate was evaporated to dryness under reduced 
pressure at room temperature. The residue was heated at $50-60{ }^{\circ} \mathrm{C}$ under vacuum (ca. 0.1-0.2 $\mathrm{mmHg}$ ) to remove $\mathrm{FeCp}_{2}$ via sublimation. The residue was then washed three times with pentane $(3 \times 5 \mathrm{~mL})$ to yield 3 as dark reddish brown powder $(325 \mathrm{mg}, 382$ $\mu$ mol, $70 \%$ yield). Brown crystals suitable for X-ray analysis were grown from concentrated toluene solution at $-35^{\circ} \mathrm{C}$.

${ }^{1} \mathrm{H}$ NMR (400 MHz, Benzene- $\left.d_{6}, 300 \mathrm{~K}\right): \delta 7.16\left(3 \mathrm{H}, \mathrm{Ar}-\mathrm{CH}\right.$ overlapped with $\mathrm{C}_{6} \mathrm{D}_{5} \mathrm{H}$ ), 6.85 (br, 4H, Ar-CH), 6.77 (br, 2H, Ar-CH), 2.89 (br, 2H, OArCH( $\left.\left(\mathrm{CH}_{3}\right)_{2}\right), 2.37$ (br, 4H, $\left.\mathrm{PC} H\left(\mathrm{CH}_{3}\right)_{2}\right), 2.21$ (br, 3H, $\mathrm{NbCH}_{3}$ ), 2.08 (br, 6H, $\mathrm{ArCH}_{3}$ ), 2.06 - 0.80 (overlapped br, $\mathrm{PCH}\left(\mathrm{CH}_{3}\right)_{2}$ and $\left.\left.\mathrm{NbCH}\right)_{3}\right) .{ }^{31} \mathrm{P}\left\{{ }^{1} \mathrm{H}\right\}$ NMR $\left(162 \mathrm{MHz}\right.$, Benzene- $\left.d_{6}, 300 \mathrm{~K}\right) \delta 50.33$ (br, $\left.\Delta v_{1 / 2}=365 \mathrm{~Hz}, \mathrm{PNP}\right), 38.93$ (br, $\left.\Delta v_{1 / 2}=352 \mathrm{~Hz}, \mathrm{PNP}\right) .{ }^{19} \mathrm{~F}\left\{{ }^{1} \mathrm{H}\right\}$ NMR $(282 \mathrm{MHz}$, Benzene- $\left.d_{6}, 300 \mathrm{~K}\right) \delta-76.35$ (s, OTf). UV-Vis (THF, $\left.\lambda_{\max } / \mathrm{nm}\left(\varepsilon / \mathrm{M}^{-1} \mathrm{~cm}^{-1}\right)\right): 302$ (13900). Solubility constraints prevented us from acquiring the ${ }^{13} \mathrm{C}$ NMR spectrum and VT NMR spectral data.

\section{Synthesis of $\left[(\mathrm{PNP}) \mathrm{Nb}\left({ }^{13} \mathrm{CH}_{3}\right)_{2}(\mathrm{OAr})(\mathrm{OTf})\right]\left(3-{ }^{13} \mathrm{C}\right)$}

The same procedure as used for 3 was followed. Addition of [ $\left.\mathrm{FeCp}_{2}\right][\mathrm{OTf}]$ (242 mg, 722 $\mu \mathrm{mol})$ in toluene $(5 \mathrm{~mL})$ to a toluene solution $(10 \mathrm{~mL})$ of $2-{ }^{13} \mathbf{C}(500 \mathrm{mg}, 684 \mu \mathrm{mol})$ afforded $3-{ }^{13} \mathbf{C}$ (452 mg, $514 \mu \mathrm{mol}, 75 \%$ yield) as dark reddish brown powder. Overlapping and broadening prevent us from observing any significant differences of the ${ }^{1} \mathrm{H}$ NMR spectrum when compared to 3. Four cross peaks of four doublets for $\left[\mathrm{Nb}\left({ }^{13} \mathrm{CH}_{3}\right)_{2}\right]$ corresponding to two isomers of $3-{ }^{13} \mathrm{C}$ were observed by ${ }^{1} \mathrm{H}^{13}{ }^{13} \mathrm{C} \mathrm{HMQC}$ (Figure S8.).

${ }^{13} \mathrm{C}$ NMR $\left(126 \mathrm{MHz}\right.$, Benzene- $d_{6}, 300 \mathrm{~K}$, selected data): $\delta 50.56\left(\mathrm{br}, \mathrm{NbCH}_{3}\right)$. Selected ${ }^{1} \mathrm{H}-{ }^{13} \mathrm{C}$ HMQC NMR chemical shifts (500 MHz, Benzene- $\left.d_{6}, 300 \mathrm{~K}\right): \delta{ }^{1} \mathrm{H}\left(\delta^{13} \mathrm{C}\right) 2.25$ $\left(58.99, \mathrm{~d},{ }^{2} J_{\mathrm{CC}}=440 \mathrm{~Hz}\right), 2.21\left(50.98, \mathrm{~d},{ }^{2} J_{\mathrm{CC}}=440 \mathrm{~Hz}\right), 1.60\left(60.04, \mathrm{~d},{ }^{2} J_{\mathrm{CC}}=440 \mathrm{~Hz}\right)$, $1.30\left(48.19, \mathrm{~d},{ }^{2} J_{\mathrm{CC}}=440 \mathrm{~Hz}\right)$. 


\section{Synthesis of $\left[(\mathrm{PNP}) \mathrm{Nb}=\mathrm{CH}_{2}(\mathrm{OAr})(\mathrm{OTf})\right](4)$}

A dark reddish brown solution of 3 (300 mg, $342 \mu \mathrm{mol})$ in benzene $(20 \mathrm{~mL})$ was placed in a $100 \mathrm{~mL}$ J-Young tube (Pyrex glass). The solution was degassed under reduced pressure. The reaction mixture was photoirradiated with a Xe-lamp at room temperature for $18 \mathrm{~h}$. The reaction mixture was degassed again after $1 \mathrm{~h}, 2 \mathrm{~h}, 3 \mathrm{~h}$; in this period the color changed from reddish brown to dark yellow. After photoirradiation, all volatile materials were removed in vacuo. The residue was triturated twice with cold pentane $\left(-35{ }^{\circ} \mathrm{C}, 2 \times 2 \mathrm{~mL}\right)$ to give 4 as dark yellow powder (352 $\mathrm{mg}, 875 \mu \mathrm{mol}, 77 \%$ yield).

Dark brown crystals suitable for X-ray analysis were grown from concentrated pentane solution at $-35^{\circ} \mathrm{C}$.

${ }^{1} \mathrm{H}$ NMR (400 MHz, Benzene- $d_{6}, 300 \mathrm{~K}$ ): $\delta 12.22\left(\mathrm{br}, 1 \mathrm{H}, \mathrm{NbCH}_{2}\right), 11.41(\mathrm{br}, 1 \mathrm{H}$, $\mathrm{NbCH}_{2}$ ), 7.16 - 7.07 (overlapped m, 4H, Ar-CH), 7.00-6.97 (overlapped m, 2H, Ar-CH), $6.94-6.86(\mathrm{~m}, 3 \mathrm{H}, \mathrm{Ar}-\mathrm{CH}), 4.38$ (virtual-quint, $\left.{ }^{3} J_{\mathrm{HH}}=6.4 \mathrm{~Hz}, 2 \mathrm{H}, \mathrm{OArCH}\left(\mathrm{CH}_{3}\right)_{2}\right), 3.21$ (br m, 1H, PCH( $\left.\left(\mathrm{CH}_{3}\right)_{2}\right), 2.67$ (br m, 1H, $\left.\mathrm{PCH}\left(\mathrm{CH}_{3}\right)_{2}\right), 2.15$ (s, 3H, $\left.\mathrm{ArCH}_{3}\right), 2.13$ (s, 3H, $\mathrm{ArCH}_{3}$ ), $2.25-2.10$ (overlapped m, 1H, $\left.\mathrm{PCH}\left(\mathrm{CH}_{3}\right)_{2}\right), 2.01$ (m, 1H, $\left.\mathrm{PCH}\left(\mathrm{CH}_{3}\right)_{2}\right), 1.57$ $\left(\mathrm{dd},{ }^{1} J_{\mathrm{HH}}=7.2 \mathrm{~Hz},{ }^{3} J_{\mathrm{PH}}=17.2 \mathrm{~Hz}, 3 \mathrm{H}, \mathrm{PCH}\left(\mathrm{CH}_{3}\right)_{2}\right), 1.45\left(\mathrm{dd},{ }^{1} J_{\mathrm{HH}}=6.8 \mathrm{~Hz},{ }^{3} J_{\mathrm{PH}}=15.6\right.$ $\left.\mathrm{Hz}, 3 \mathrm{H}, \mathrm{PCH}\left(\mathrm{CH}_{3}\right)_{2}\right), 1.38\left(\mathrm{br}, 12 \mathrm{H}, \mathrm{OArCH}\left(\mathrm{CH}_{3}\right)_{2}\right), 1.15\left(\mathrm{dd},{ }^{1} J_{\mathrm{HH}}=6.8 \mathrm{~Hz},{ }^{3} J_{\mathrm{PH}}=16.0\right.$ $\left.\mathrm{Hz}, 3 \mathrm{H}, \mathrm{PCH}\left(\mathrm{CH}_{3}\right)_{2}\right), 1.05\left(\mathrm{dd},{ }^{1} J_{\mathrm{HH}}=6.8 \mathrm{~Hz},{ }^{3} J_{\mathrm{PH}}=14.4 \mathrm{~Hz}, 6 \mathrm{H}, \mathrm{PCH}\left(\mathrm{CH}_{3}\right)_{2}\right), 0.95-$ 0.77 (overlapped m, 9H, $\left.\mathrm{PCH}\left(\mathrm{CH}_{3}\right)_{2}\right) .{ }^{13} \mathrm{C}\left\{{ }^{1} \mathrm{H}\right\}$ NMR $\left(126 \mathrm{MHz}\right.$, Benzene- $\left.d_{6}, 300 \mathrm{~K}\right) \delta$. 157.70 (OAr), 133.00 (OAr), 132.05 (OAr), 130.80 (OAr), 124.83 (OAr), 124.19 (br, PNP-Ar), $121.15\left(\mathrm{~d},{ }^{3} J_{\mathrm{CP}}=9.1 \mathrm{~Hz}\right.$, PNP-Ar), $118.63\left(\mathrm{~d},{ }^{2} J_{\mathrm{CP}}=9.2 \mathrm{~Hz}\right.$, PNP-Ar), 26.73 (br, $\left.\mathrm{PCH}\left(\mathrm{CH}_{3}\right)_{2}\right), 26.46\left(\mathrm{OAr}\left(\mathrm{CH}\left(\mathrm{CH}_{3}\right)_{2}\right)_{2}\right), 26.26\left(\mathrm{~d},{ }^{1} J_{\mathrm{CP}}=12.7 \mathrm{~Hz}, \mathrm{PCH}\left(\mathrm{CH}_{3}\right)_{2}\right), 24.03$ (br, $\left.\mathrm{OAr}\left(\mathrm{CH}\left(\mathrm{CH}_{3}\right)_{2}\right)_{2}\right), 23.53$ (br, $\left.\mathrm{PCH}\left(\mathrm{CH}_{3}\right)_{2}\right), 22.30$ (br, $\left.\mathrm{PCH}\left(\mathrm{CH}_{3}\right)_{2}\right), 22.12\left(\mathrm{~d},{ }^{1} J_{\mathrm{CP}}=\right.$ $\left.15.5 \mathrm{~Hz}, \mathrm{PCH}\left(\mathrm{CH}_{3}\right)_{2}\right), 21.49\left(\mathrm{~d},{ }^{1} J_{\mathrm{CP}}=12.7 \mathrm{~Hz}, \mathrm{PCH}\left(\mathrm{CH}_{3}\right)_{2}\right), 20.77\left(\mathrm{ArCH}_{3}\right), 20.66$ $\left(\mathrm{ArCH}_{3}\right), 19.46\left(\mathrm{~d},{ }^{2} J_{\mathrm{CP}}=7.3 \mathrm{~Hz}, \operatorname{PCH}\left(\mathrm{CH}_{3}\right)_{2}\right), 19.08\left(\mathrm{~d},{ }^{2} J_{\mathrm{CP}}=7.3 \mathrm{~Hz}, \operatorname{PCH}\left(\mathrm{CH}_{3}\right)_{2}\right)$, 18.11 (br, $\left.\mathrm{PCH}\left(\mathrm{CH}_{3}\right)_{2}\right), 17.70$ (br, $\left.\mathrm{PCH}\left(\mathrm{CH}_{3}\right)_{2}\right)$. Broadening and overlapping of the ${ }^{13} \mathrm{C}$ NMR spectrum prevent us from measuring ${ }^{13} \mathrm{C}$ signals of apical positions on PNP and 
$\mathrm{CF}_{3}{ }^{31} \mathrm{P}\left\{{ }^{1} \mathrm{H}\right\}$ NMR (162 MHz, Benzene- $\left.d_{6}, 300 \mathrm{~K}\right) \delta 50.25$ (br, PNP), 45.20 (br, PNP). ${ }^{19} \mathrm{~F}\left\{{ }^{1} \mathrm{H}\right\}$ NMR $\left(282 \mathrm{MHz}\right.$, Benzene- $\left.d_{6}, 300 \mathrm{~K}\right) \delta-77.26$ (s, OTf). UV-Vis $\left(\mathrm{THF}, \lambda_{\max } / \mathrm{nm}\right.$ $\left.\left(\varepsilon / \mathrm{M}^{-1} \mathrm{~cm}^{-1}\right)\right): 317$ (19700), 430 (br, 4640), 570 (br, 2030).

\section{Synthesis of $\left[(\mathrm{PNP}) \mathrm{Nb}\left(={ }^{13} \mathrm{CH}\right)(\mathrm{OAr})(\mathrm{OTf})\right]\left(4-{ }^{13} \mathrm{C}\right)$ by Photolysis of $3-{ }^{13} \mathrm{C}$}

In a J-Young valve NMR tube, a benzene- $d_{6}$ solution $(0.5 \mathrm{~mL})$ of $\mathbf{3 -}^{\mathbf{1 3}} \mathbf{C}(11.2 \mathrm{mg}, 12.7$ $\mu \mathrm{mol})$ was degassed under reduced pressure and photoirradiated with a Xe-lamp at room temperature for $18 \mathrm{~h}$. After photoirradiation, formation of $\mathbf{4 -}^{\mathbf{1 3}} \mathbf{C}$ and ${ }^{13} \mathrm{CH}_{4}$ was observed by ${ }^{1} \mathrm{H}$ NMR, ${ }^{13} \mathrm{C}\left\{{ }^{1} \mathrm{H}\right\}$ NMR and ${ }^{1} \mathrm{H}-{ }^{13} \mathrm{C}$ HMQC.

${ }^{1} \mathrm{H}$ NMR (400 MHz, Benzene- $d_{6}, 300 \mathrm{~K}$, selected data): $\delta 12.20\left(\mathrm{~d},{ }^{1} J_{\mathrm{CH}}=129 \mathrm{~Hz}, 1 \mathrm{H}\right.$, $\left.\mathrm{Nb}^{13} \mathrm{C} H_{2}\right), 11.44\left(\mathrm{~d},{ }^{1} J_{\mathrm{CH}}=134 \mathrm{~Hz}, 1 \mathrm{H}, \mathrm{Nb}^{13} \mathrm{CH}_{2}\right), 0.16\left(\mathrm{~d},{ }^{1} J_{\mathrm{CH}}=126 \mathrm{~Hz},{ }^{13} \mathrm{CH}_{4}\right) .{ }^{13} \mathrm{C}$ NMR (126 MHz, Benzene- $d_{6}$, selected data): $\delta 281.70$ (br, $\left.\mathrm{NbCH}_{2}\right),-4.29\left(\mathrm{~s}, \mathrm{CH}_{4}\right)$. Selected ${ }^{1} \mathrm{H}_{-}{ }^{13} \mathrm{C}$ HMQC NMR chemical shifts $\left(500 \mathrm{MHz}\right.$, Benzene- $\left.d_{6}, 300 \mathrm{~K}\right): \delta^{1} \mathrm{H}(\delta$ ${ }^{13}$ C) $12.20(281.70), 11.44(281.70)$.

\section{Synthesis of $[(\mathrm{PNP}) \mathrm{Nb} \equiv \mathrm{CH}(\mathrm{OAr})](5)$}

\section{Route A:}

To a dark reddish brown solution of $\mathbf{3}(350 \mathrm{mg}, 401 \mu \mathrm{mol})$ in toluene $(10 \mathrm{~mL})$ was added $\mathrm{H}_{2} \mathrm{CPPh}_{3}(115 \mathrm{mg}, 531 \mu \mathrm{mol})$ in toluene $(5 \mathrm{~mL})$ at room temperature and additional toluene ( $3 \mathrm{~mL}$ ) was used to add $\mathrm{H}_{2} \mathrm{CPPh}_{3}$ completely, resulting in a gradual color change to green and formation of colorless precipitate. After stirring for $2 \mathrm{~h}$, the reaction mixture was evaporated to dryness. The green residue was dissolved in hexane $(5 \mathrm{~mL})$ and filtered through a medium porosity glass frit containing celite, which was triturated with hexane $(10 \mathrm{~mL})$. The green filtrate was evaporated to dryness. The green residue was dissolved in pentane $(3 \mathrm{~mL})$ and stored at $-35{ }^{\circ} \mathrm{C}$ to give $\mathbf{5}$ as green solid (201 mg, 282 $\mu$ mol, $72 \%$ yield). Green crystals suitable for X-ray analysis were grown from concentrated pentane solution at $-35^{\circ} \mathrm{C}$. 


\section{Route B:}

To a dark yellow solution of $4(150 \mathrm{mg}, 184 \mu \mathrm{mol})$ in toluene $(5 \mathrm{~mL})$ was added $\mathrm{Li}\left[\mathrm{N}\left(\mathrm{SiMe}_{3}\right)_{2}\right](33.8 \mathrm{mg}, 202 \mu \mathrm{mol})$ also dissolved in toluene $(3 \mathrm{~mL})$ at room temperature. Additional toluene $(5 \mathrm{~mL})$ was used to add the remainder of the $\mathrm{Li}\left[\mathrm{N}\left(\mathrm{SiMe}_{3}\right)_{2}\right]$ in the vial, resulting in a gradual color change to green concurrent with formation of a precipitate. After stirring for $2 \mathrm{~h}$, the reaction mixture was evaporated to dryness. The green residue was dissolved in hexane $(3 \mathrm{~mL})$ and filtered through a medium porosity glass frit containing celite, which was then triturated with hexane (5 $\mathrm{mL}$ ). The green filtrate was evaporated to dryness. The green residue was dissolved in pentane $(3 \mathrm{~mL})$ and stored at $-35{ }^{\circ} \mathrm{C}$ to give 5 as green solid $(79.1 \mathrm{mg}, 111 \mu \mathrm{mol}, 60 \%$ yield).

${ }^{1} \mathrm{H}$ NMR (400 MHz, Benzene- $d_{6}, 300 \mathrm{~K}$ ): $\delta 7.30$ (m, 3H, Ar-CH), 7.23 (br, $1 \mathrm{H}, \mathrm{Ar}-\mathrm{C} H$ ), $7.20-7.10$ (overlapped with $\left.\mathrm{C}_{6} \mathrm{D}_{5} \mathrm{H}, 2 \mathrm{H}, \mathrm{Ar}-\mathrm{CH}\right), 7.01\left(\mathrm{t},{ }^{3} \mathrm{~J}_{\mathrm{HH}}=7.5 \mathrm{~Hz}, 1 \mathrm{H}, \mathrm{OAr}-\mathrm{CH}\right.$ ), $6.87\left(\mathrm{dd},{ }^{3} J_{\mathrm{HH}}=6.2,{ }^{3} J_{\mathrm{PH}}=17.1 \mathrm{~Hz}, 1 \mathrm{H}, \mathrm{Ar}-\mathrm{CH}\right), 6.82\left(\right.$ overlapped dd, ${ }^{3} J_{\mathrm{HH}}=7.4,{ }^{3} J_{\mathrm{PH}}=$ $20.4 \mathrm{~Hz}, 1 \mathrm{H}, \mathrm{Ar}-\mathrm{CH}), 6.02(\mathrm{br}, 1 \mathrm{H}, \mathrm{NbCH}), 5.50-3.00\left(\mathrm{br}, 2 \mathrm{H}, \mathrm{OArCH}\left(\mathrm{CH}_{3}\right)_{2}\right), 2.37$ (m, 1H, PCH( $\left.\left(\mathrm{CH}_{3}\right)_{2}\right), 2.30\left(\mathrm{~m}, 1 \mathrm{H}, \mathrm{PCH}\left(\mathrm{CH}_{3}\right)_{2}\right), 2.18\left(\mathrm{~s}, 3 \mathrm{H}, \mathrm{ArCH}_{3}\right), 2.09(\mathrm{~s}, 3 \mathrm{H}$, $\left.\mathrm{ArCH} H_{3}\right), 2.20-2.11\left(\mathrm{~m}, 1 \mathrm{H}, \mathrm{PC}\left(\mathrm{CH}_{3}\right)_{2}\right), 1.97\left(\mathrm{~m}, 1 \mathrm{H}, \mathrm{PC}\left(\mathrm{CH}_{3}\right)_{2}\right), 1.75-0.89$ (overlapped m, $\mathrm{PCH}\left(\mathrm{CH}_{3}\right)_{2}$ and $\left.\mathrm{OArCH}\left(\mathrm{CH}_{3}\right)_{2}\right) .{ }^{13} \mathrm{C}\left\{{ }^{1} \mathrm{H}\right\}$ NMR (126 MHz, Benzene- $d_{6}$, 300 K) ․ 162.08 (PNP-Ar), 161.93 (PNP-Ar) 158.48 (OAr), 133.08 (OAr), 131.97 (d, $\left.{ }^{2} J_{\mathrm{CP}}=10.3 \mathrm{~Hz}, \mathrm{PNP}-\mathrm{Ar}\right), 131.50(\mathrm{OAr}), 127.55(\mathrm{OAr}), 126.52\left(\mathrm{~d},{ }^{3} J_{\mathrm{CP}}=5.1 \mathrm{~Hz}\right.$, PNP-Ar), 123.38 (br, OAr), 120.87 (OAr), 119.93 (d, $\left.{ }^{3} J_{\mathrm{CP}}=6.9 \mathrm{~Hz}, \mathrm{PNP}-\mathrm{Ar}\right), 119.64$ (d, ${ }^{1} J_{\mathrm{CP}}=13.8 \mathrm{~Hz}$, PNP-Ar), $119.10\left(\mathrm{~d},{ }^{2} J_{\mathrm{CP}}=8.7 \mathrm{~Hz}, \mathrm{PNP}-\mathrm{Ar}\right), 117.32\left(\mathrm{~d},{ }^{2} J_{\mathrm{CP}}=8.7 \mathrm{~Hz}\right.$, PNP-Ar), $26.63\left(\mathrm{~d},{ }^{1} J_{\mathrm{CP}}=17.2 \mathrm{~Hz}, \mathrm{PCH}\left(\mathrm{CH}_{3}\right)_{2}\right), 26.10\left(\mathrm{br}, \mathrm{OAr}\left(\mathrm{CH}\left(\mathrm{CH}_{3}\right)_{2}\right)_{2}\right), 24.42(\mathrm{~d}$, $\left.{ }^{1} J_{\mathrm{CP}}=10.3 \mathrm{~Hz}, \mathrm{PCH}\left(\mathrm{CH}_{3}\right)_{2}\right), 23.78\left(\mathrm{br}, \mathrm{OAr}\left(\mathrm{CH}\left(\mathrm{CH}_{3}\right)_{2}\right)_{2}\right), 20.94\left(\mathrm{ArCH}_{3}\right), 20.92\left(\mathrm{~d},{ }^{1} J_{\mathrm{CP}}\right.$ $\left.=14.0 \mathrm{~Hz}, \mathrm{PCH}\left(\mathrm{CH}_{3}\right)_{2}\right), 20.70\left(\mathrm{ArCH}_{3}\right), 20.55\left(\mathrm{~d},{ }^{2} J_{\mathrm{CP}}=6.9 \mathrm{~Hz}, \mathrm{PCH}\left(\mathrm{CH}_{3}\right)_{2}\right), 19.57$ (br, $\left.\operatorname{PCH}\left(\mathrm{CH}_{3}\right)_{2}\right), 19.37\left(\mathrm{br}, \operatorname{PCH}\left(\mathrm{CH}_{3}\right)_{2}\right), 18.99\left(\mathrm{~d},{ }^{2} J_{\mathrm{CP}}=8.7 \mathrm{~Hz}, \operatorname{PCH}\left(\mathrm{CH}_{3}\right)_{2}\right), 18.87$ (br, 
$\left.\operatorname{PCH}\left(\mathrm{CH}_{3}\right)_{2}\right), 18.66\left(\mathrm{~d},{ }^{2} J_{\mathrm{CP}}=7.0 \mathrm{~Hz}, \operatorname{PCH}\left(\mathrm{CH}_{3}\right)_{2}\right), 18.33\left(\mathrm{~d},{ }^{2} J_{\mathrm{CP}}=8.7 \mathrm{~Hz}, \operatorname{PCH}\left(\mathrm{CH}_{3}\right)_{2}\right)$, $16.43\left(\mathrm{br}, \mathrm{PCH}\left(\mathrm{CH}_{3}\right)_{2}\right), 15.92\left(\mathrm{~d},{ }^{2} J_{\mathrm{CP}}=6.9 \mathrm{~Hz}, \mathrm{PCH}\left(\mathrm{CH}_{3}\right)_{2}\right) .{ }^{31} \mathrm{P}\left\{{ }^{1} \mathrm{H}\right\} \mathrm{NMR}(162 \mathrm{MHz}$, Benzene- $\left.d_{6}, 300 \mathrm{~K}\right) \delta 52.89$ (br, $\left.\Delta v_{1 / 2}=420 \mathrm{~Hz}, \mathrm{PNP}\right), 42.17$ (br, $\Delta v_{1 / 2}=350 \mathrm{~Hz}, \mathrm{PNP}$ ). UV-Vis (hexane, $\left.\lambda_{\max } / \mathrm{nm}\left(\varepsilon / \mathrm{M}^{-1} \mathrm{~cm}^{-1}\right)\right): 335$ (16400), 609 (br, 727).

\section{Synthesis of $\left[(\mathrm{PNP}) \mathrm{Nb} \equiv{ }^{13} \mathrm{CH}(\mathrm{OAr})\right]\left(5-{ }^{13} \mathrm{C}\right)$}

The same procedure as used for 5 (route A) was followed. Addition of $\mathrm{H}_{2} \mathrm{CPPh}_{3}(66.1$ $\mathrm{mg}, 239 \mu \mathrm{mol})$ in toluene $(5 \mathrm{~mL})$ to a toluene solution $(10 \mathrm{~mL})$ of $\mathbf{3 -}^{13} \mathbf{C}(200 \mathrm{mg}, 227$ $\mu \mathrm{mol}$ ) afforded $\mathbf{5}{ }^{13} \mathbf{C}$ (114 mg, $382 \mu \mathrm{mol}, 70 \%$ yield) as green powder.

${ }^{1} \mathrm{H}$ NMR (400 MHz, Benzene- $d_{6}, 300 \mathrm{~K}$, selected data): $\delta 6.02\left(\mathrm{~d},{ }^{1} J_{\mathrm{CH}}=134 \mathrm{~Hz}\right.$, $\mathrm{Nb}^{13} \mathrm{CH}$ ). ${ }^{13} \mathrm{C}$ NMR (126 MHz, Benzene- $d_{6}, 300 \mathrm{~K}$, selected data): $\delta 293.77$ (br, $\mathrm{NbCH}$ ). Selected ${ }^{1} \mathrm{H}-{ }^{13} \mathrm{C}$ HMQC NMR chemical shifts $\left(500 \mathrm{MHz}\right.$, Benzene- $\left.d_{6}, 300 \mathrm{~K}\right): \delta{ }^{1} \mathrm{H}(\delta$ $\left.{ }^{13} \mathrm{C}\right) 6.02$ (293.77).

\section{Synthesis of $[(\mathrm{PNP}) \mathrm{Nb} \equiv \mathrm{N}(\mathrm{OAr})](6)$}

To a green solution of $\mathbf{6}(40.0 \mathrm{mg}, 56.2 \mu \mathrm{mol})$ in toluene $(10 \mathrm{~mL})$ was added $\mathrm{NC}^{\mathrm{t}} \mathrm{Bu}(12.0$ $\mu \mathrm{L}, 109 \mu \mathrm{mol}$ ) by a syringe at room temperature, resulting in a gradual color change to reddish brown. After stirring for $2 \mathrm{~h}$, the reaction mixture was evaporated to dryness. The reddish brown residue was dissolved in pentane $(2 \mathrm{~mL})$ and stored at $-35^{\circ} \mathrm{C}$ to give 6 as reddish brown solid (29.8 mg, $41.9 \mu \mathrm{mol}, 75 \%$ yield).

${ }^{1} \mathrm{H}$ NMR $\left(400 \mathrm{MHz}\right.$, Benzene- $\left.d_{6}, 300 \mathrm{~K}\right): \delta 7.34\left(\mathrm{dd}, J_{\mathrm{HH}}=4.0,8.4 \mathrm{~Hz}, 1 \mathrm{H}, \mathrm{Ar}-\mathrm{CH}\right), 7.28$ (br, $1 \mathrm{H}, \mathrm{Ar}-\mathrm{CH}$ ), $7.16-7.11$ (overlapped with $\mathrm{C}_{6} \mathrm{D}_{5} \mathrm{H}, 2 \mathrm{H}, \mathrm{Ar}-\mathrm{CH}$ ), 7.04 (t, $J_{\mathrm{HH}}=7.6 \mathrm{~Hz}$, $1 \mathrm{H}, \mathrm{OAr}-\mathrm{C} H), 6.89\left(\mathrm{~d}, J_{\mathrm{HH}}=2.4, J_{\mathrm{PH}}=11.6 \mathrm{~Hz}, 2 \mathrm{H}, \mathrm{Ar}-\mathrm{C} H\right), 6.80\left(\mathrm{~d}, J_{\mathrm{HH}}=8.4,1 \mathrm{H}\right.$, $\operatorname{Ar}-\mathrm{CH}), 6.75\left(\mathrm{~d}, J_{\mathrm{HH}}=8.4,5.6 \mathrm{~Hz}, 1 \mathrm{H}, \mathrm{Ar}-\mathrm{CH}\right), 5.15\left(\mathrm{br}, 1 \mathrm{H}, \mathrm{OArCH}\left(\mathrm{CH}_{3}\right)_{2}\right), 3.55(\mathrm{br}$, $\left.1 \mathrm{H}, \mathrm{OArCH}\left(\mathrm{CH}_{3}\right)_{2}\right), 2.26\left(\mathrm{~m}, 1 \mathrm{H}, \mathrm{PCH}\left(\mathrm{CH}_{3}\right)_{2}\right), 2.16\left(\mathrm{~s}, 3 \mathrm{H}, \mathrm{ArCH}_{3}\right), 2.07(\mathrm{~s}, 3 \mathrm{H}$, $\mathrm{ArCH}_{3}$ ), $2.20-1.90$ (overlapped m, 3H, $\left.\mathrm{PCH}\left(\mathrm{CH}_{3}\right)_{2}\right), 1.67\left(\mathrm{dd},{ }^{1} J_{\mathrm{HH}}=7.2 \mathrm{~Hz},{ }^{3} J_{\mathrm{PH}}=\right.$ $\left.17.2 \mathrm{~Hz}, 3 \mathrm{H}, \mathrm{PCH}\left(\mathrm{CH}_{3}\right)_{2}\right), 1.59\left(\mathrm{dd},{ }^{1} J_{\mathrm{HH}}=6.8 \mathrm{~Hz},{ }^{3} J_{\mathrm{PH}}=16.0 \mathrm{~Hz}, 3 \mathrm{H}, \mathrm{PCH}(\mathrm{CH})_{2}\right), 1.36$ 
(br, $\left.12 \mathrm{H}, \mathrm{OArCH}\left(\mathrm{CH}_{3}\right)_{2}\right), 1.15-0.84$ (overlapped m, $\left.15 \mathrm{H}, \mathrm{PCH}\left(\mathrm{CH}_{3}\right)_{2}\right), 1.59\left(\mathrm{dd},{ }^{1} J_{\mathrm{HH}}=\right.$ $\left.6.8 \mathrm{~Hz},{ }^{3} J_{\mathrm{PH}}=16.8 \mathrm{~Hz}, 3 \mathrm{H}, \mathrm{PCH}\left(\mathrm{CH}_{3}\right)_{2}\right) .{ }^{13} \mathrm{C}\left\{{ }^{1} \mathrm{H}\right\}$ NMR $\left(126 \mathrm{MHz}\right.$, Benzene- $\left.d_{6}, 300 \mathrm{~K}\right)$ ઈ. 133.00 (OAr), 132.28 (OAr), 121.20 (OAr), 119.69 (br, PNP-Ar), 118.68 (br Hz, PNP-Ar), 118.20 (PNP-Ar), $\left.27.30-25.32\left(\mathrm{CH}\left(\mathrm{CH}_{3}\right)_{2} \text { and } \mathrm{CH}\left(\mathrm{CH}_{3}\right)_{2}\right)_{2}\right), 20.86-18.50$ $\left(\mathrm{CH}\left(\mathrm{CH}_{3}\right)_{2}\right)_{2}$ and $\left.\mathrm{ArCH}_{3}\right)$. Broadening and overlapping of the ${ }^{13} \mathrm{C}$ NMR spectrum prevent us from measuring ${ }^{13} \mathrm{C}$ signals of apical positions on the aromatic rings. ${ }^{31} \mathrm{P}\left\{{ }^{1} \mathrm{H}\right\} \mathrm{NMR}$ (162 MHz, Benzene- $\left.d_{6}, 300 \mathrm{~K}\right) \delta 43.05$ (br, $\left.\Delta v_{1 / 2}=352 \mathrm{~Hz}, \mathrm{PNP}\right), 37.05$ (br, $\Delta v_{1 / 2}=346$ $\mathrm{Hz}, \mathrm{PNP})$. UV-Vis (hexane, $\left.\lambda_{\max } / \mathrm{nm}\left(\varepsilon / \mathrm{M}^{-1} \mathrm{~cm}^{-1}\right)\right): 305$ (13700), 495 (br, 1100).

\section{Synthesis of $\left[(\mathrm{PNP}) \mathrm{Nb}\left(\equiv^{15} \mathrm{~N}\right)(\mathrm{OAr})\right]\left(6-{ }^{15} \mathrm{~N}\right)$}

To a green solution of $6(110 \mathrm{mg}, 155 \mu \mathrm{mol})$ in toluene $(5 \mathrm{~mL})$ was added ${ }^{15} \mathrm{NC}$ [1-Ad] (28.1 $\mathrm{mg}, 174 \mu \mathrm{mol})$ in toluene $(5 \mathrm{~mL})$ at $-35{ }^{\circ} \mathrm{C}$, resulting in a gradual color change to reddish brown. After stirring for $2 \mathrm{~h}$ at room temperature, the reaction mixture was evaporated to dryness. The reddish brown residue was dissolved in pentane $(5 \mathrm{~mL})$ and filtered through a medium porosity glass frit. The reddish brown filtrate was evaporated to dryness. The residue was dissolved in $\mathrm{Et}_{2} \mathrm{O}(2 \mathrm{~mL})$ and stored at $-35^{\circ} \mathrm{C}$ to give $6-{ }^{15} \mathbf{N}$ as reddish brown solid (31.6 mg, 29\% crude yield). The similar solubility of Ad-C $\equiv \mathrm{CH}$ and some impurities to $6-{ }^{15} \mathbf{N}$ prevents us from isolating $6-{ }^{15} \mathbf{N}$. No significant differences to 6 were observed by ${ }^{31} \mathrm{P}$ NMR.

${ }^{15} \mathrm{~N}$ NMR (40.5 MHz, Benzene- $d_{6}, 300 \mathrm{~K}$, selected data): $\delta 833\left(\mathrm{~s}, \Delta v_{1 / 2}=10 \mathrm{~Hz}, \mathrm{Nb} N\right.$ ). 


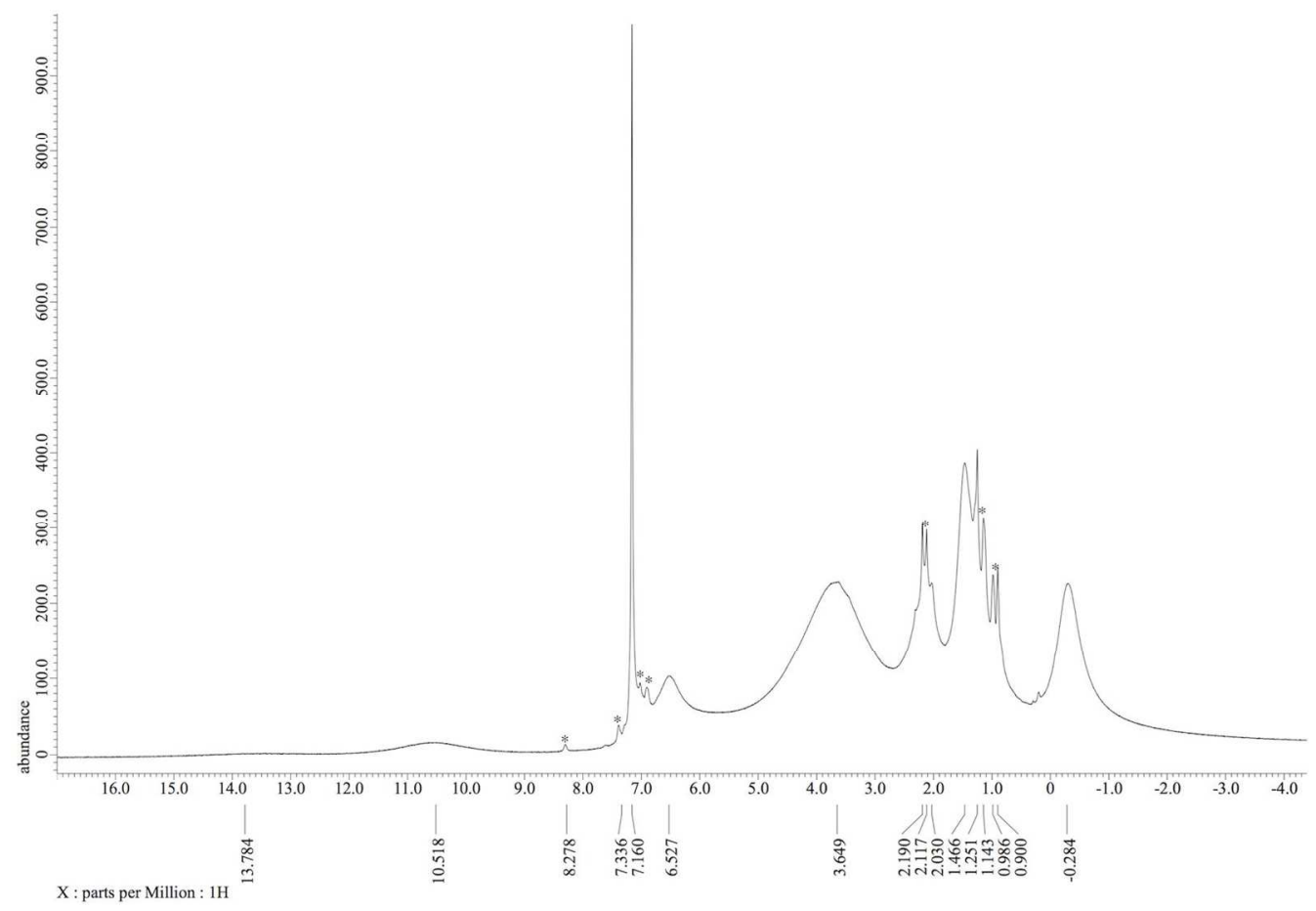

Figure S1. ${ }^{1} \mathrm{H}$ NMR spectrum of $1\left(400 \mathrm{MHz}\right.$, in Benzene- $d_{6}$, at $\left.300 \mathrm{~K}\right)$. *: Solvent residue and impurity.

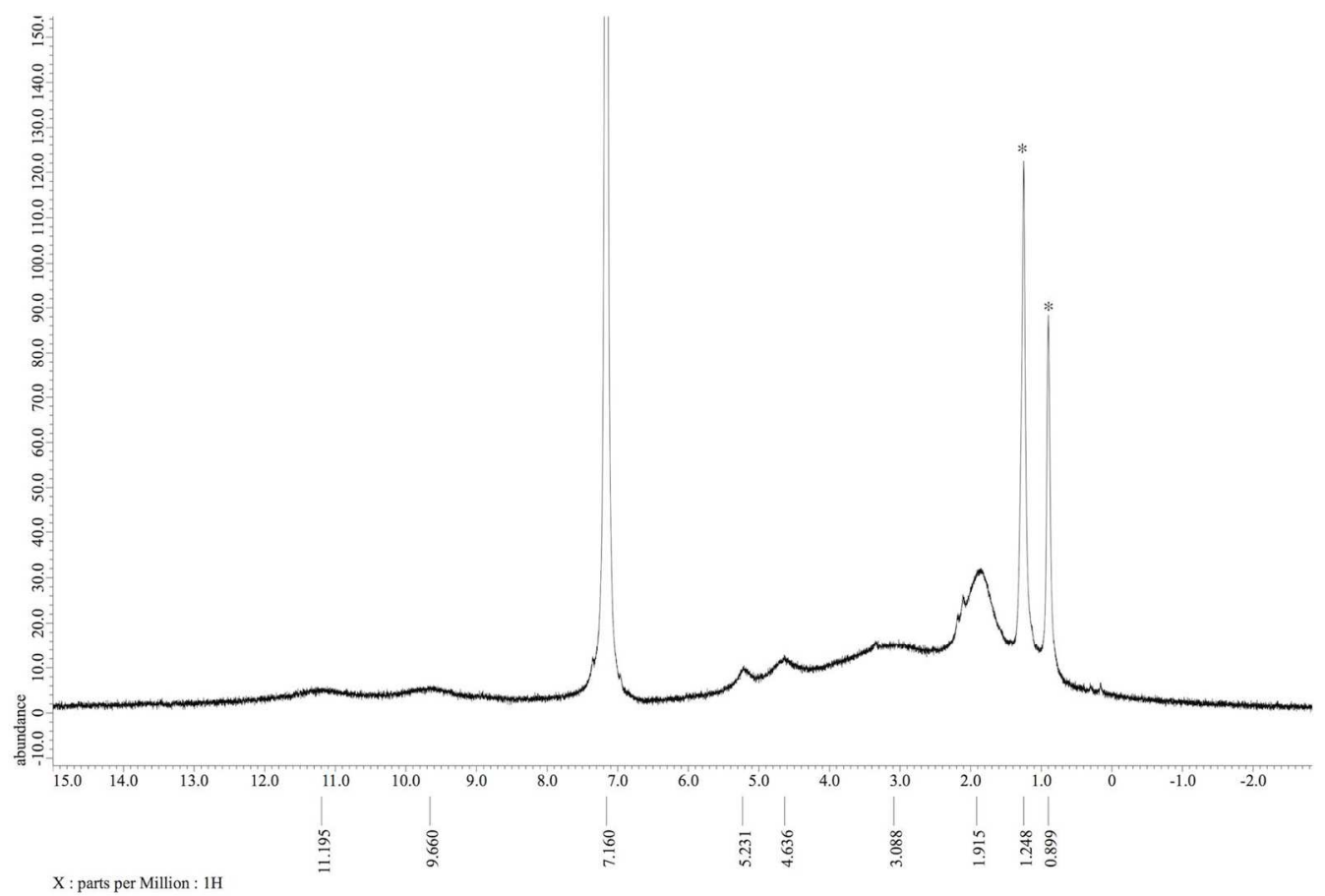

Figure S2. ${ }^{1} \mathrm{H}$ NMR spectrum of $2\left(400 \mathrm{MHz}\right.$, in Benzene- $d_{6}$, at $\left.300 \mathrm{~K}\right)$. *: Solvent residue. 


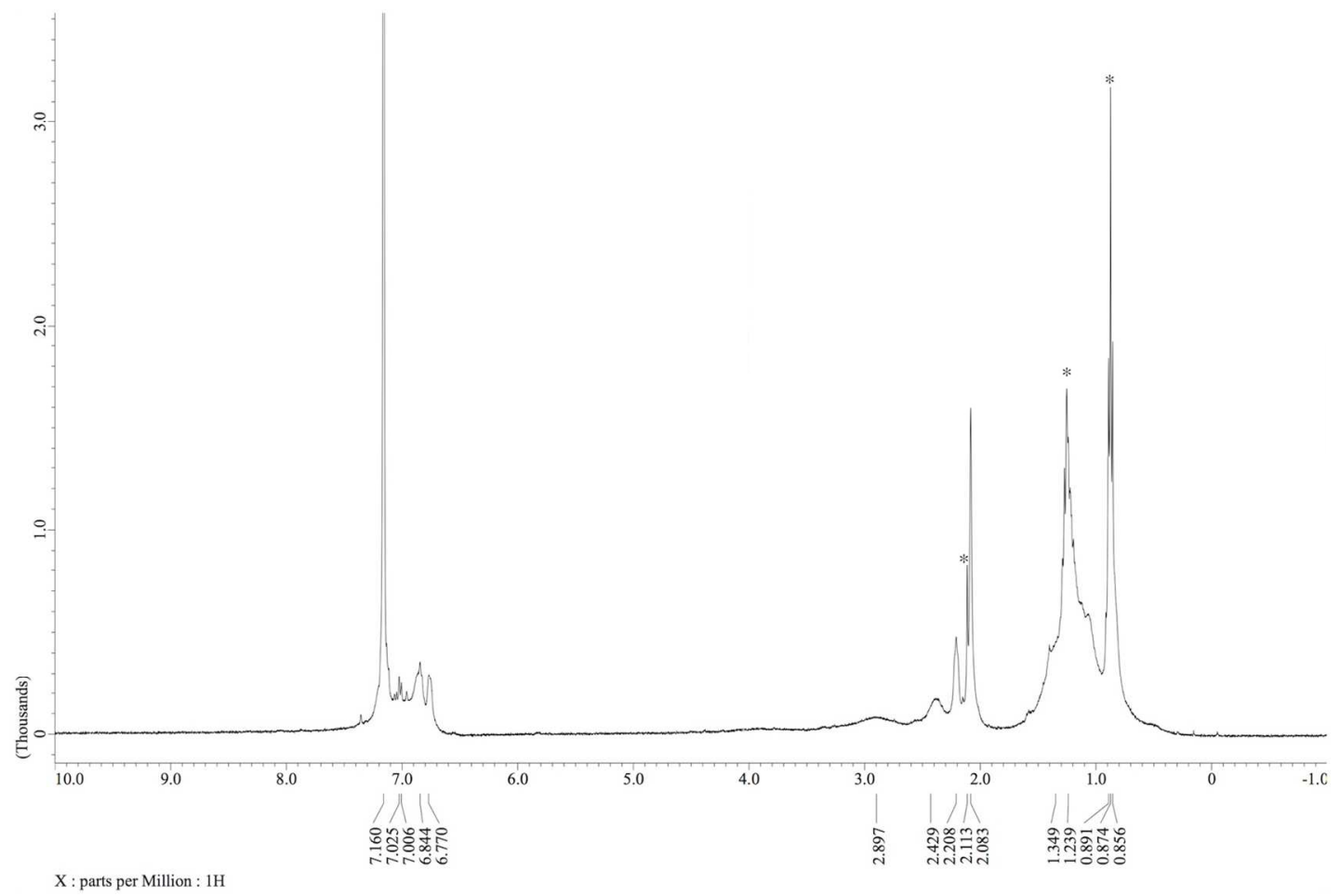

Figure S3. ${ }^{1} \mathrm{H}$ NMR spectrum of $3\left(400 \mathrm{MHz}\right.$, in Benzene- $d_{6}$, at $\left.300 \mathrm{~K}\right)$. *: Solvent residue.

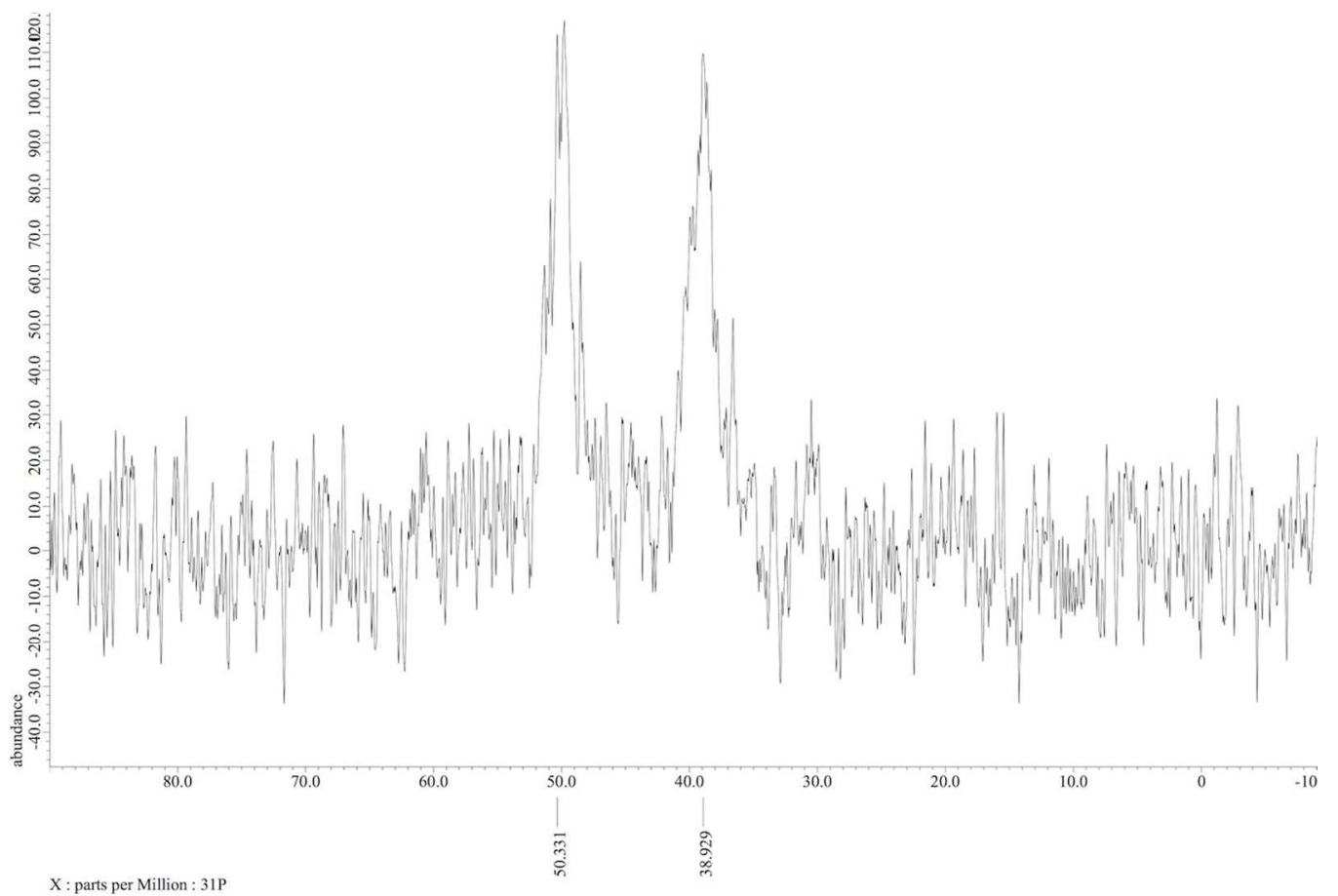

Figure S4. ${ }^{31} \mathrm{P}\left\{{ }^{1} \mathrm{H}\right\}$ NMR spectrum of $3\left(162 \mathrm{MHz}\right.$, in Benzene- $d_{6}$, at $\left.300 \mathrm{~K}\right)$. 


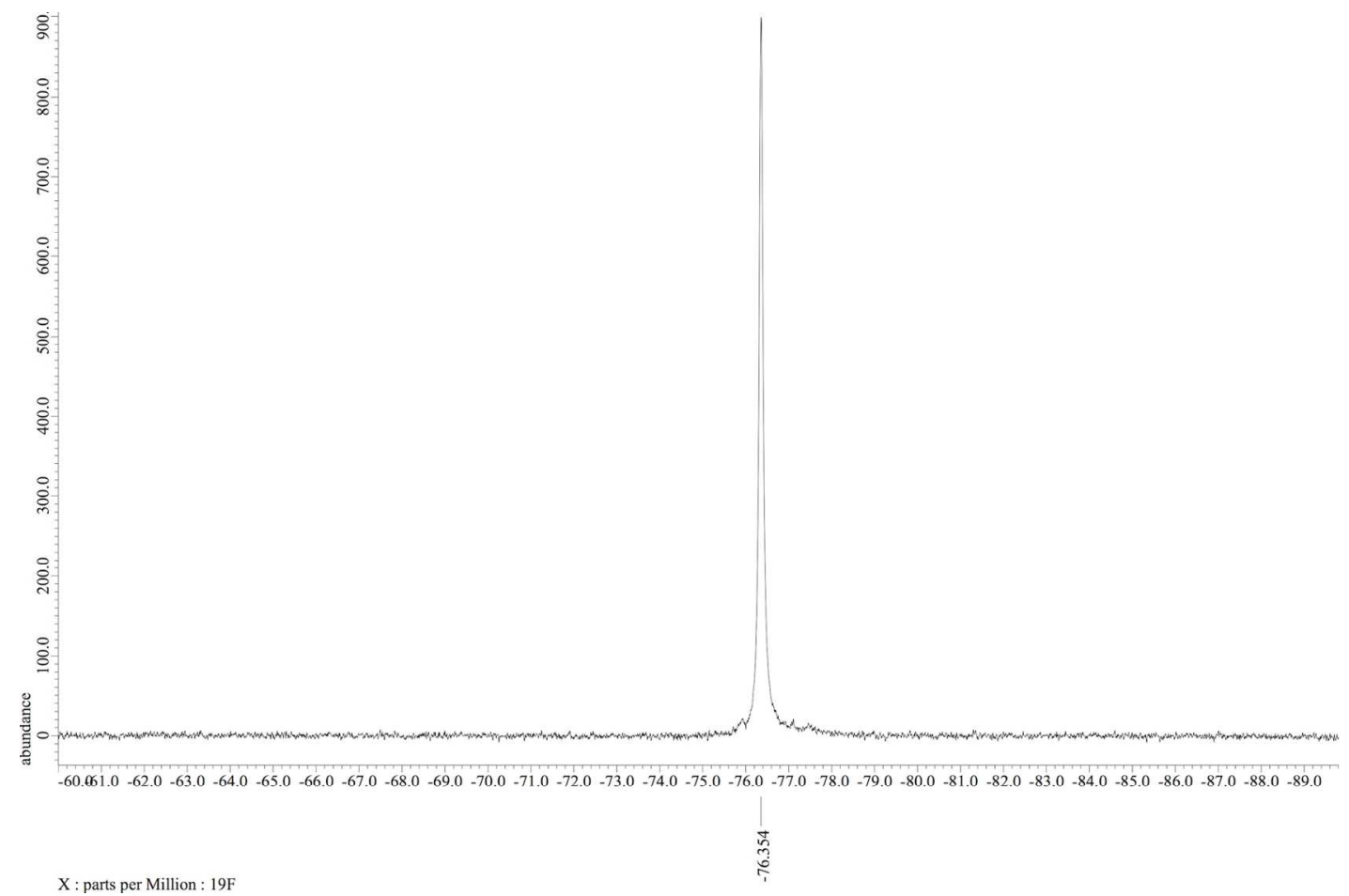

Figure S5. ${ }^{19} \mathrm{~F}\left\{{ }^{1} \mathrm{H}\right\}$ NMR spectrum of $3\left(282 \mathrm{MHz}\right.$, in Benzene- $d_{6}$, at $\left.300 \mathrm{~K}\right)$.

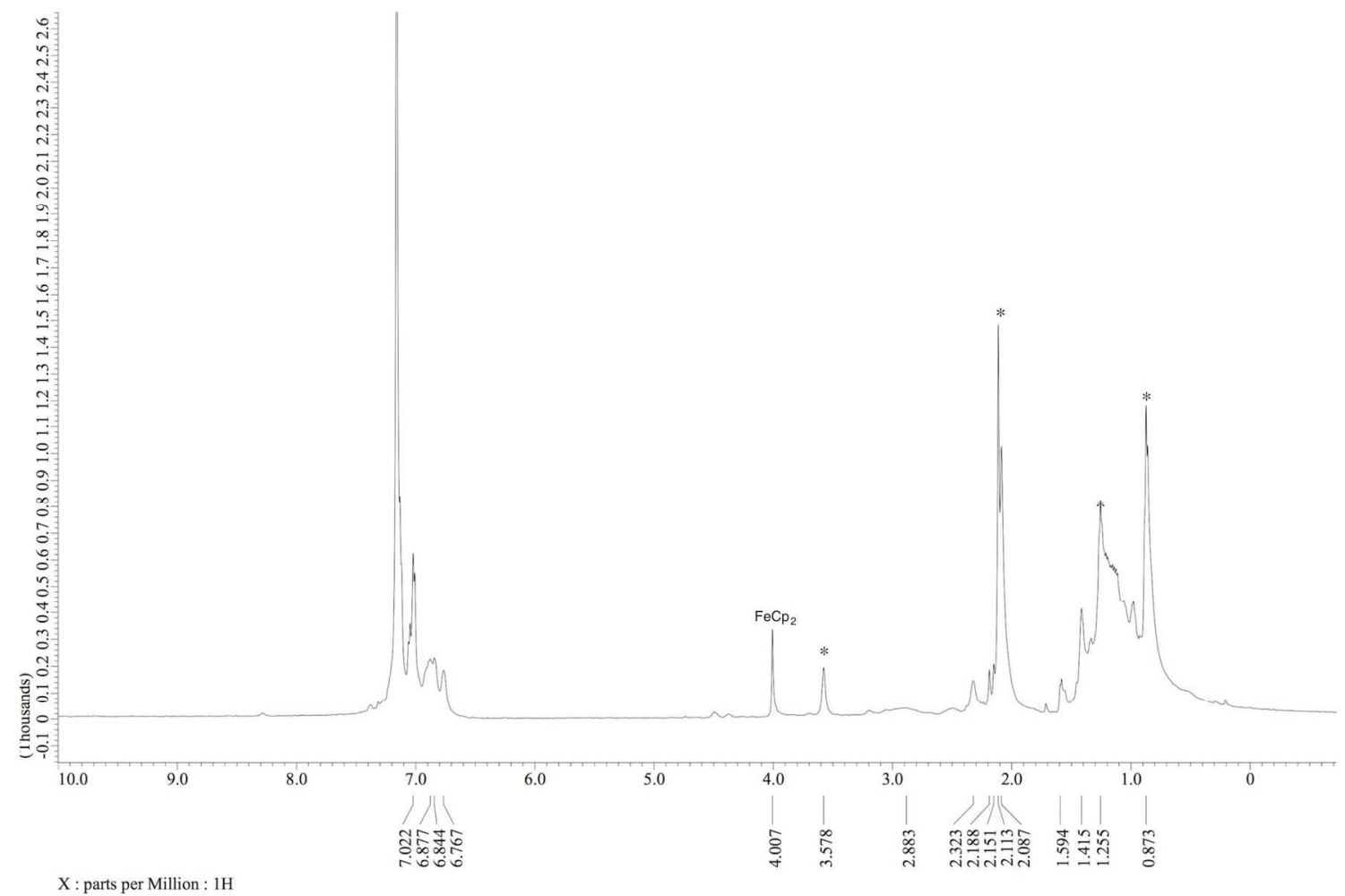

Figure S6. ${ }^{1} \mathrm{H}$ NMR spectrum of $\mathbf{3 -}^{13} \mathbf{C}\left(500 \mathrm{MHz}\right.$, in Benzene- $d_{6}$, at $\left.300 \mathrm{~K}\right)$. *: Solvent residue. 


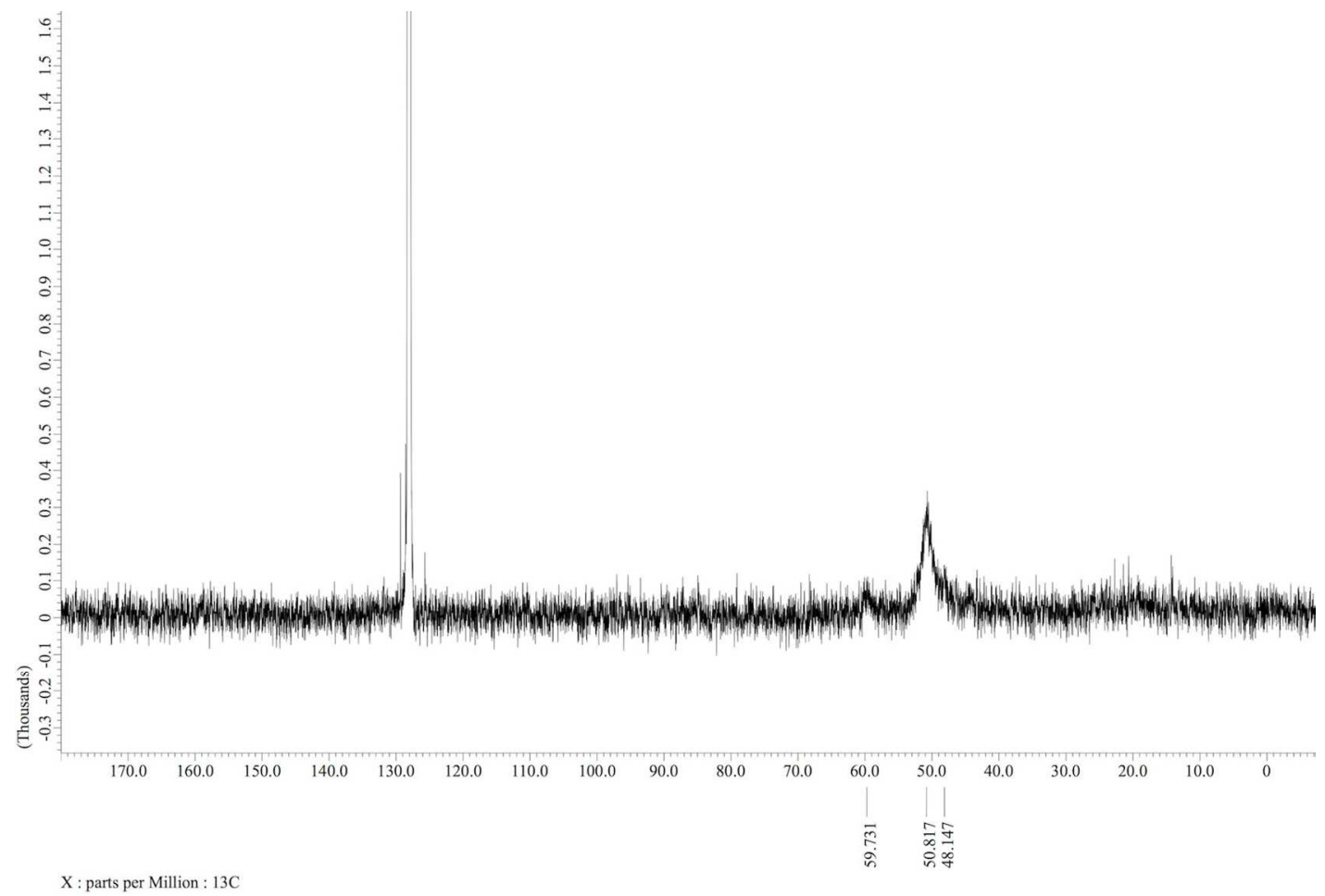

Figure S7. ${ }^{13} \mathrm{C}\left\{{ }^{1} \mathrm{H}\right\}$ NMR spectrum of $3-{ }^{\mathbf{1 3}} \mathbf{C}\left(126 \mathrm{MHz}\right.$, in Benzene- $d_{6}$, at $\left.300 \mathrm{~K}\right)$.

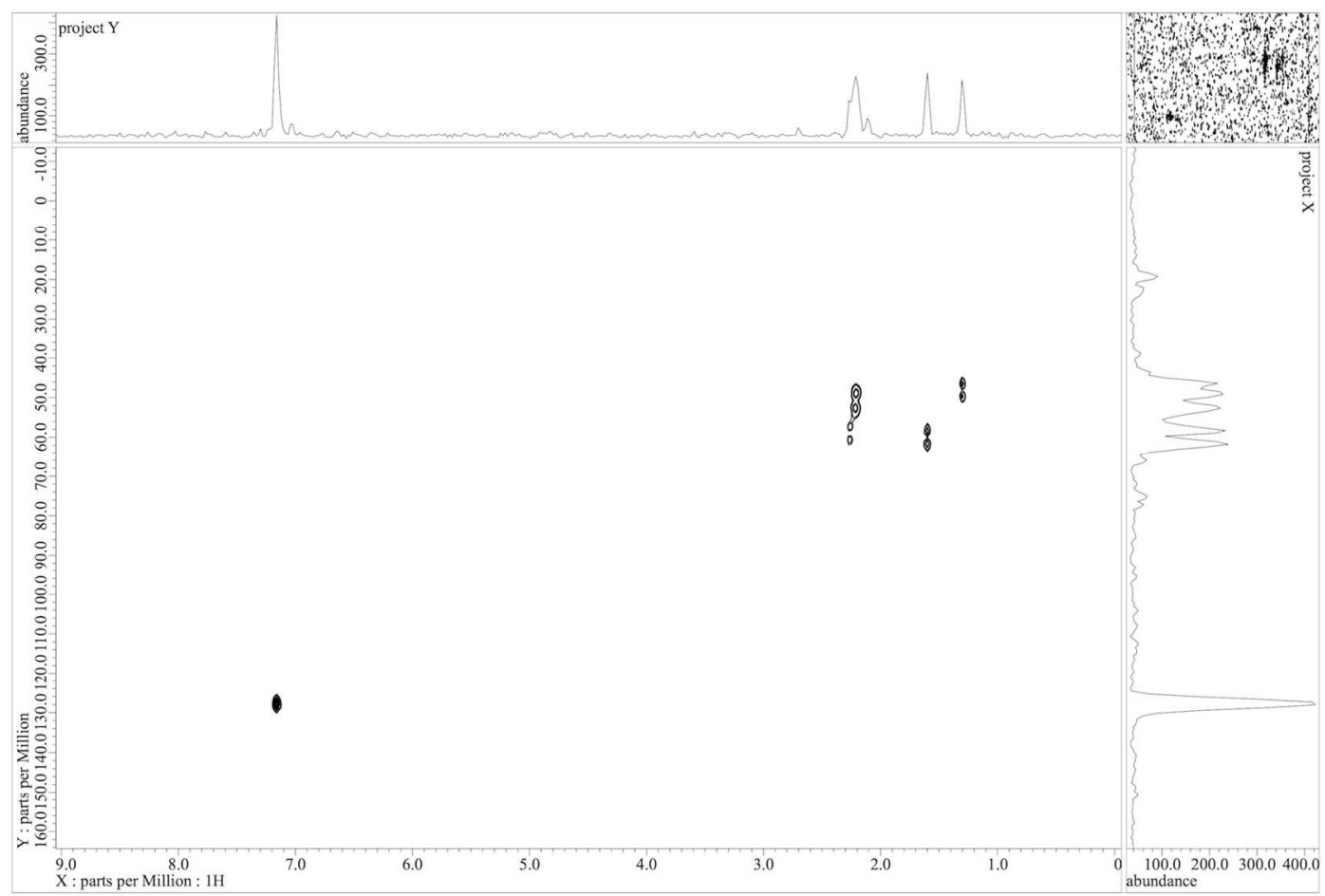

Figure S8. ${ }^{1} \mathrm{H}-{ }^{13} \mathrm{C}$ HMQC spectrum of $3-{ }^{13} \mathbf{C}\left(500 \mathrm{MHz}\right.$ in Benzene- $d_{6}$, at $300 \mathrm{~K}, \mathrm{X}$ axis: ${ }^{1} \mathrm{H}$, Y axis: ${ }^{13} \mathrm{C}$ NMR). 


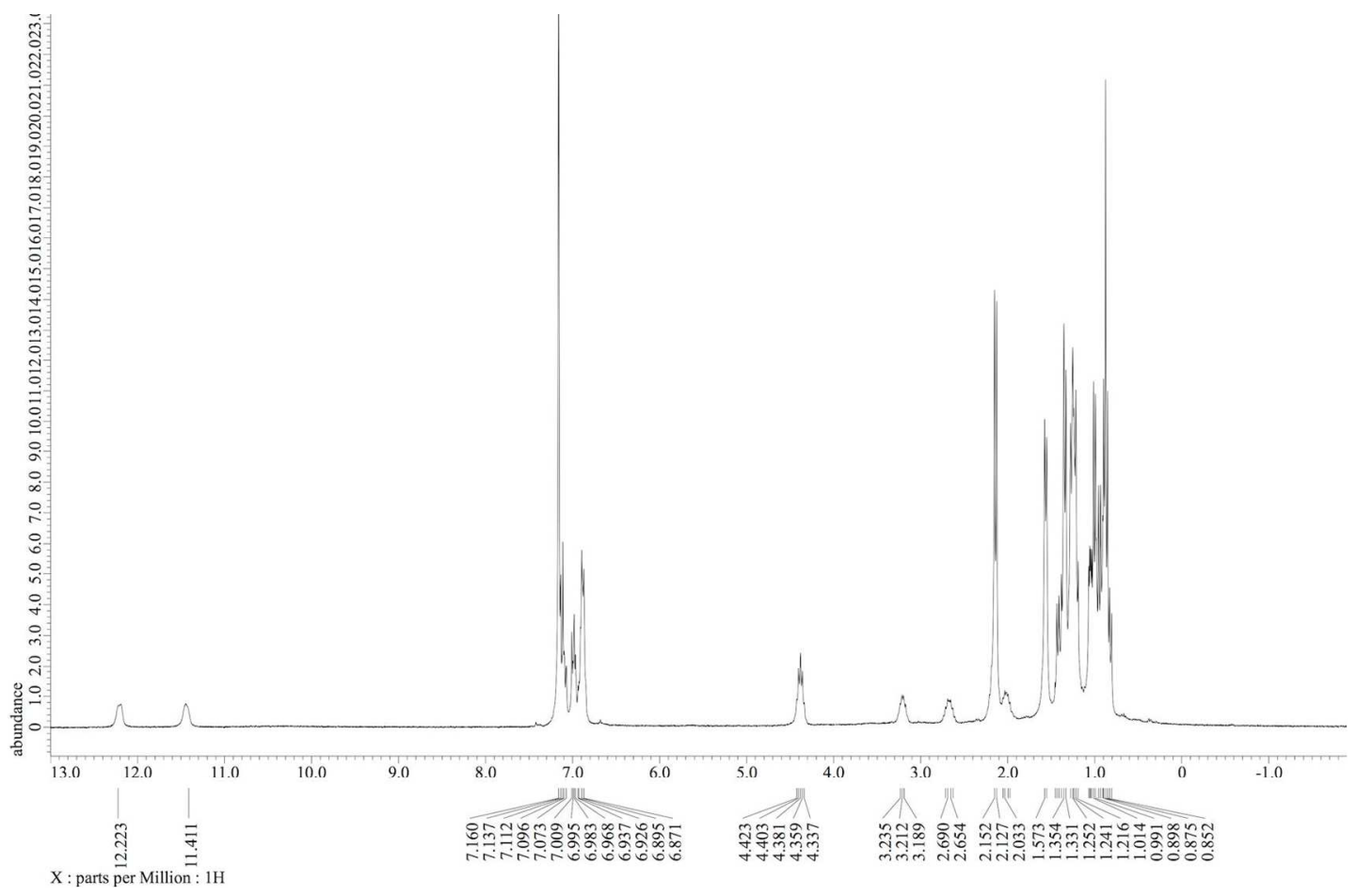

Figure S9. ${ }^{1} \mathrm{H}$ NMR spectrum of 4 (400 MHz, in Benzene- $d_{6}$, at $300 \mathrm{~K}$ ).

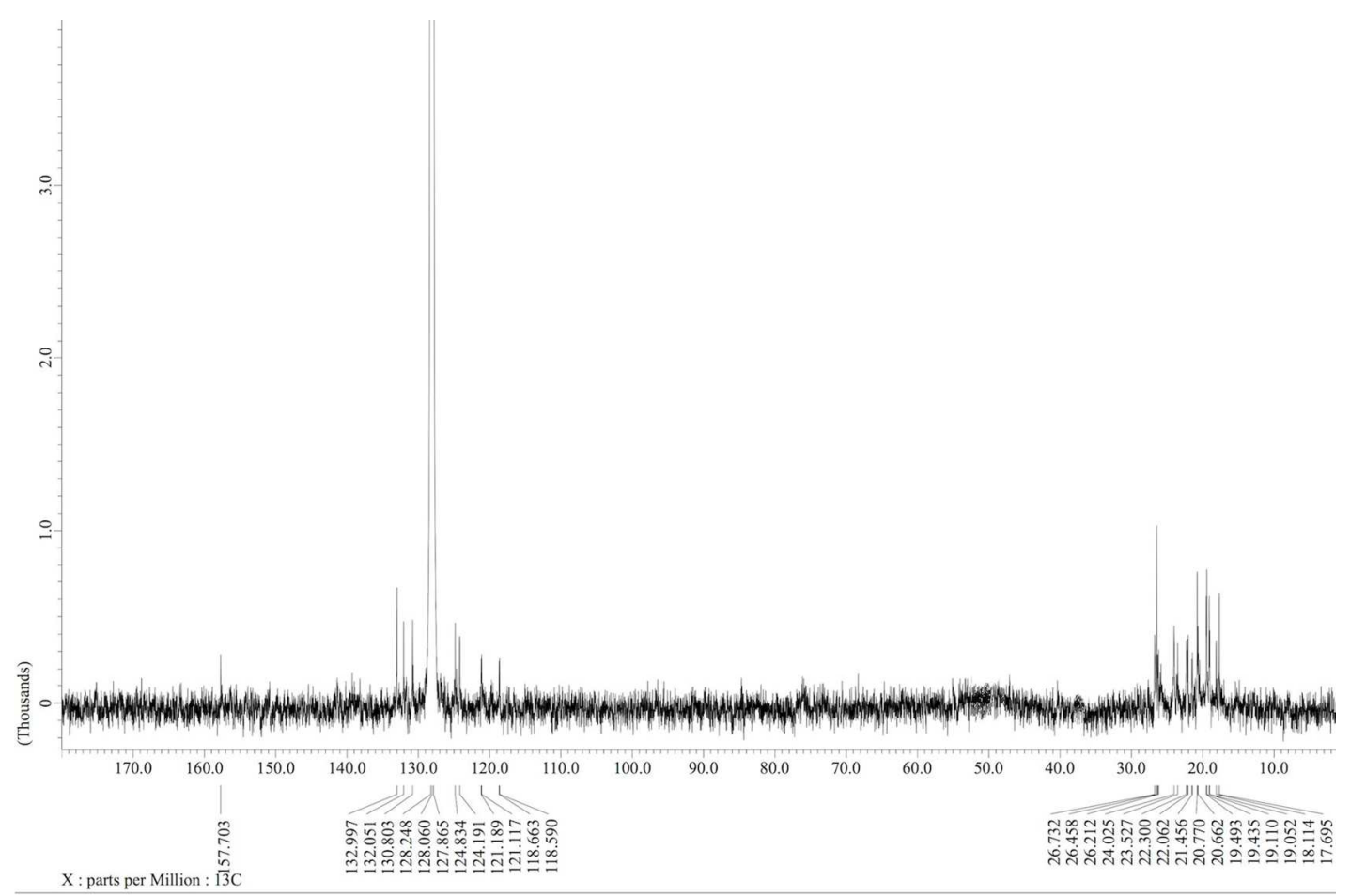

Figure S10. ${ }^{13} \mathrm{C}\left\{{ }^{1} \mathrm{H}\right\}$ NMR spectrum of $4\left(126 \mathrm{MHz}\right.$, in Benzene- $d_{6}$, at $\left.300 \mathrm{~K}\right)$. 


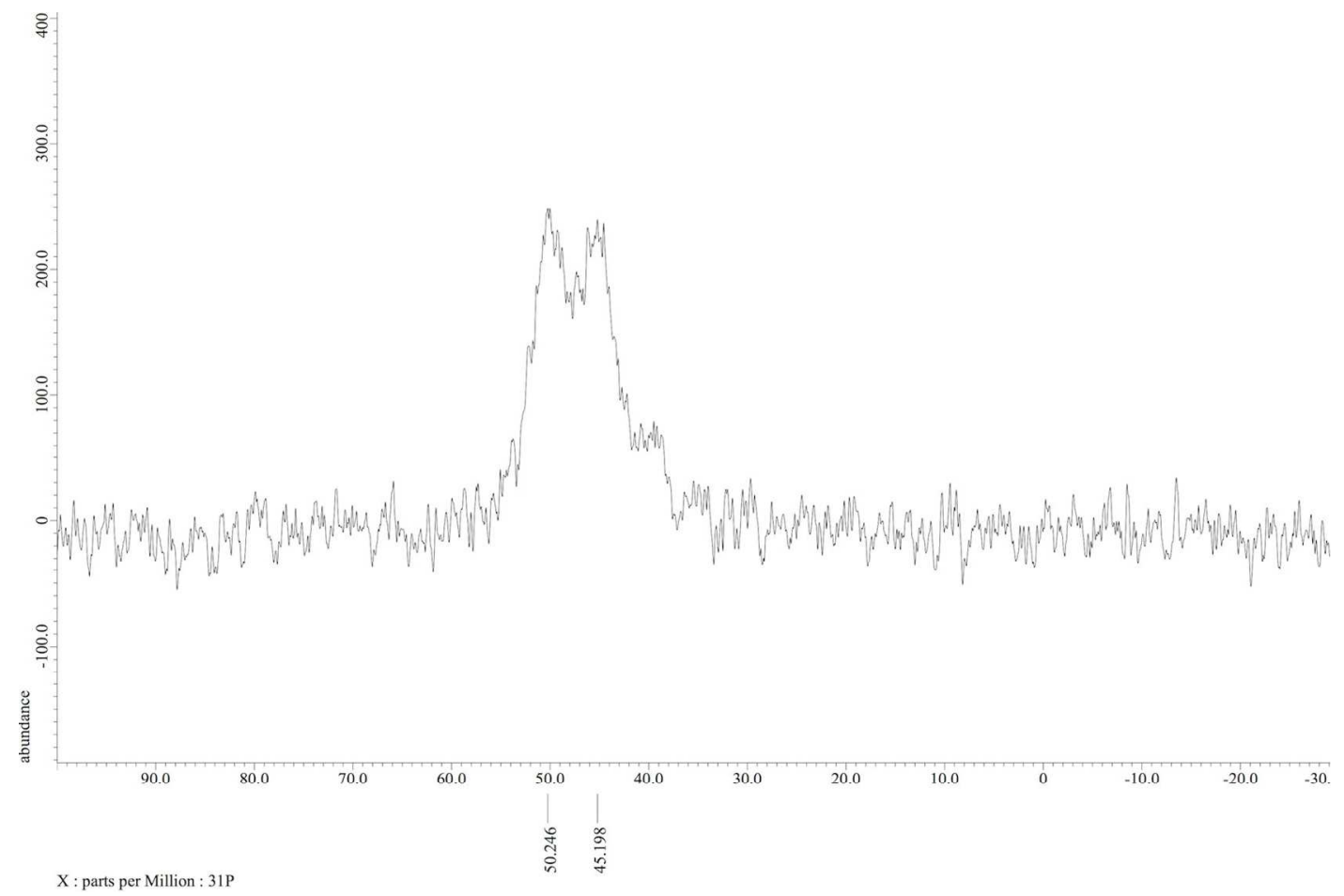

Figure S11. ${ }^{31} \mathrm{P}\left\{{ }^{1} \mathrm{H}\right\}$ NMR spectrum of $4\left(162 \mathrm{MHz}\right.$, in Benzene- $d_{6}$, at $\left.300 \mathrm{~K}\right)$.

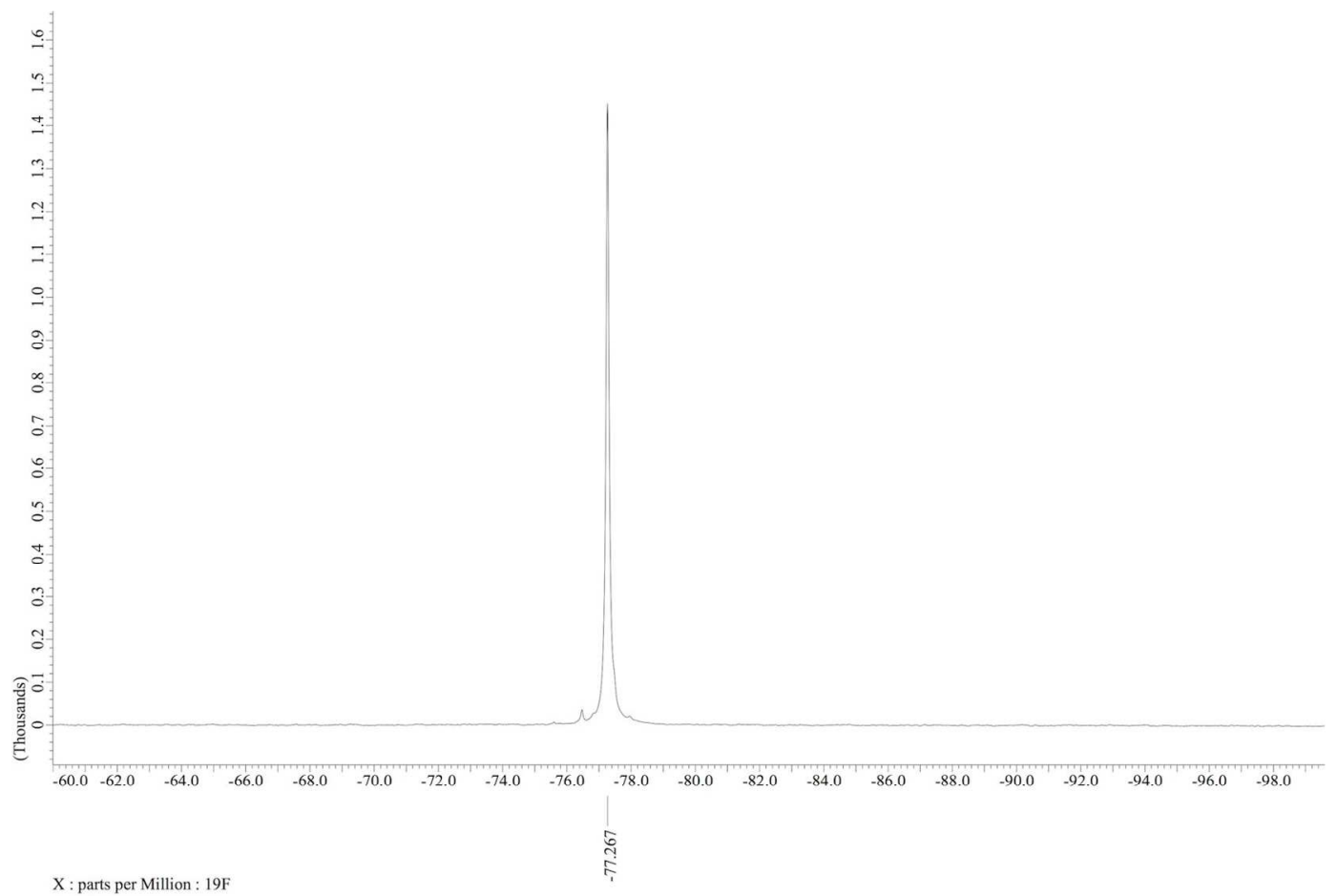

Figure S12. ${ }^{19} \mathrm{~F}\left\{{ }^{1} \mathrm{H}\right\}$ NMR spectrum of $4\left(282 \mathrm{MHz}\right.$, in Benzene- $d_{6}$, at $\left.300 \mathrm{~K}\right)$. 


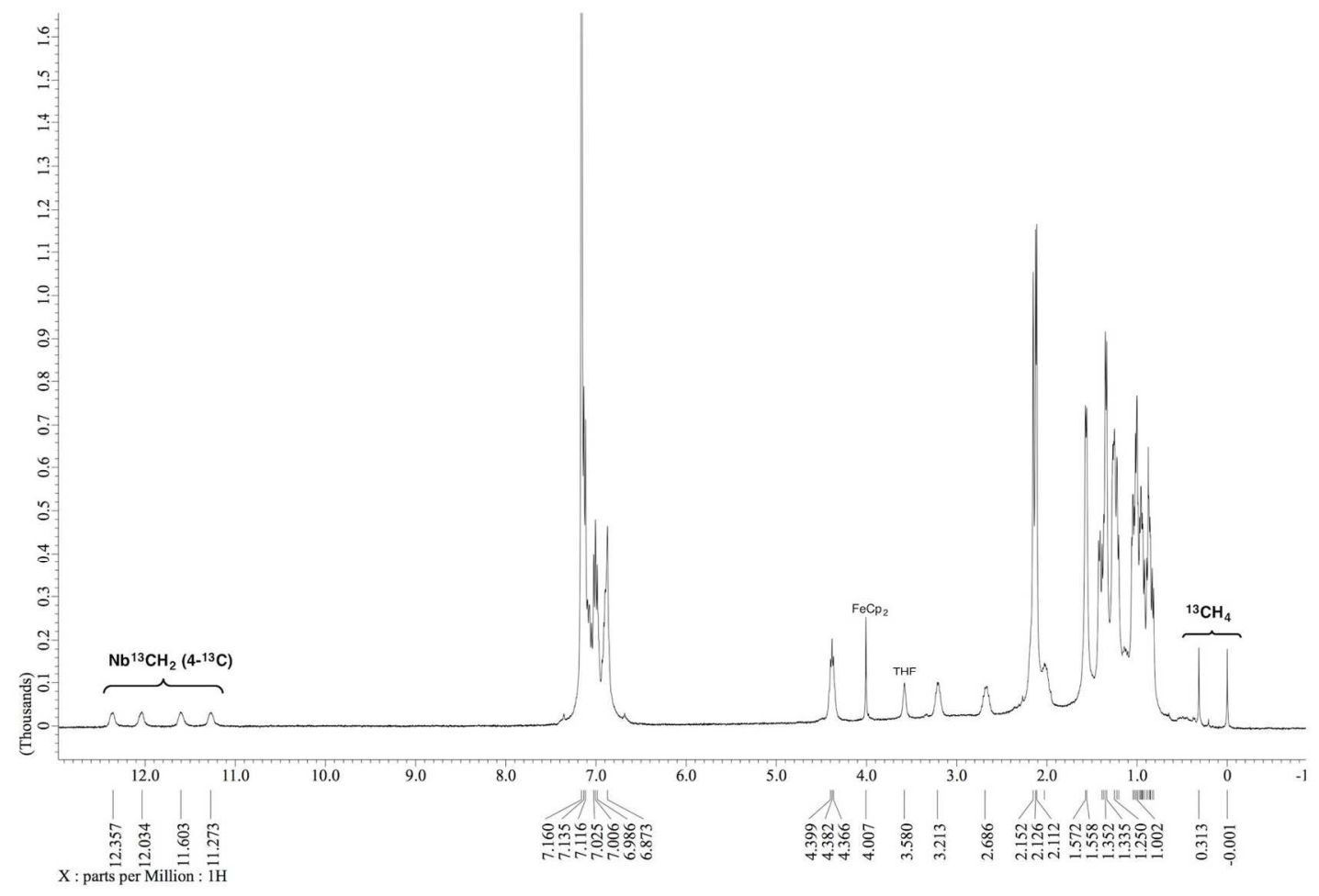

Figure S13. ${ }^{1} \mathrm{H}$ NMR spectrum of $4-{ }^{13} \mathbf{C}\left(400 \mathrm{MHz}\right.$, in Benzene- $d_{6}$, at $\left.300 \mathrm{~K}\right)$.

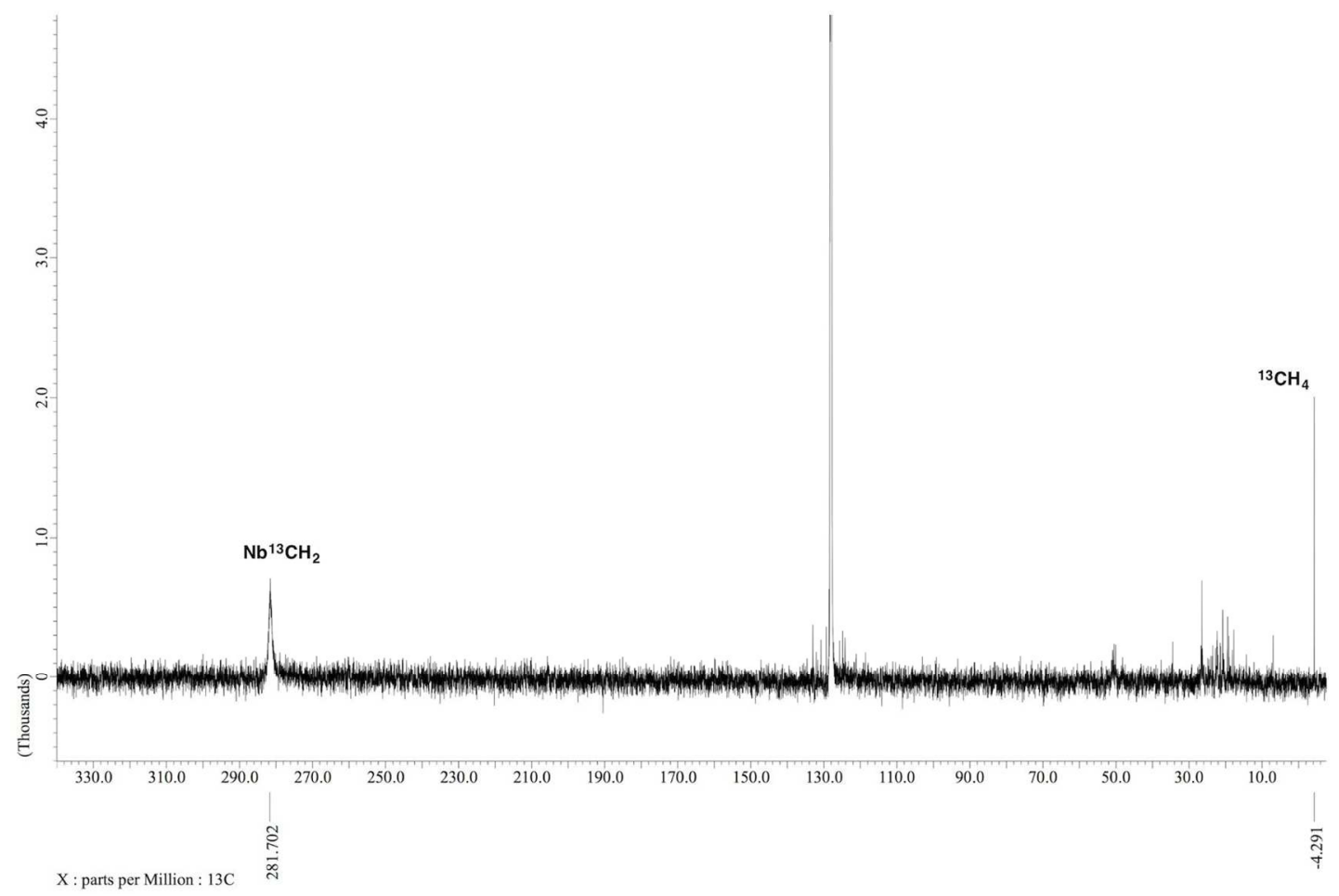

Figure S14. ${ }^{13} \mathrm{C}\left\{{ }^{1} \mathrm{H}\right\}$ NMR spectrum of $4-{ }^{13} \mathbf{C}\left(126 \mathrm{MHz}\right.$, in Benzene- $d_{6}$, at $\left.300 \mathrm{~K}\right)$. 


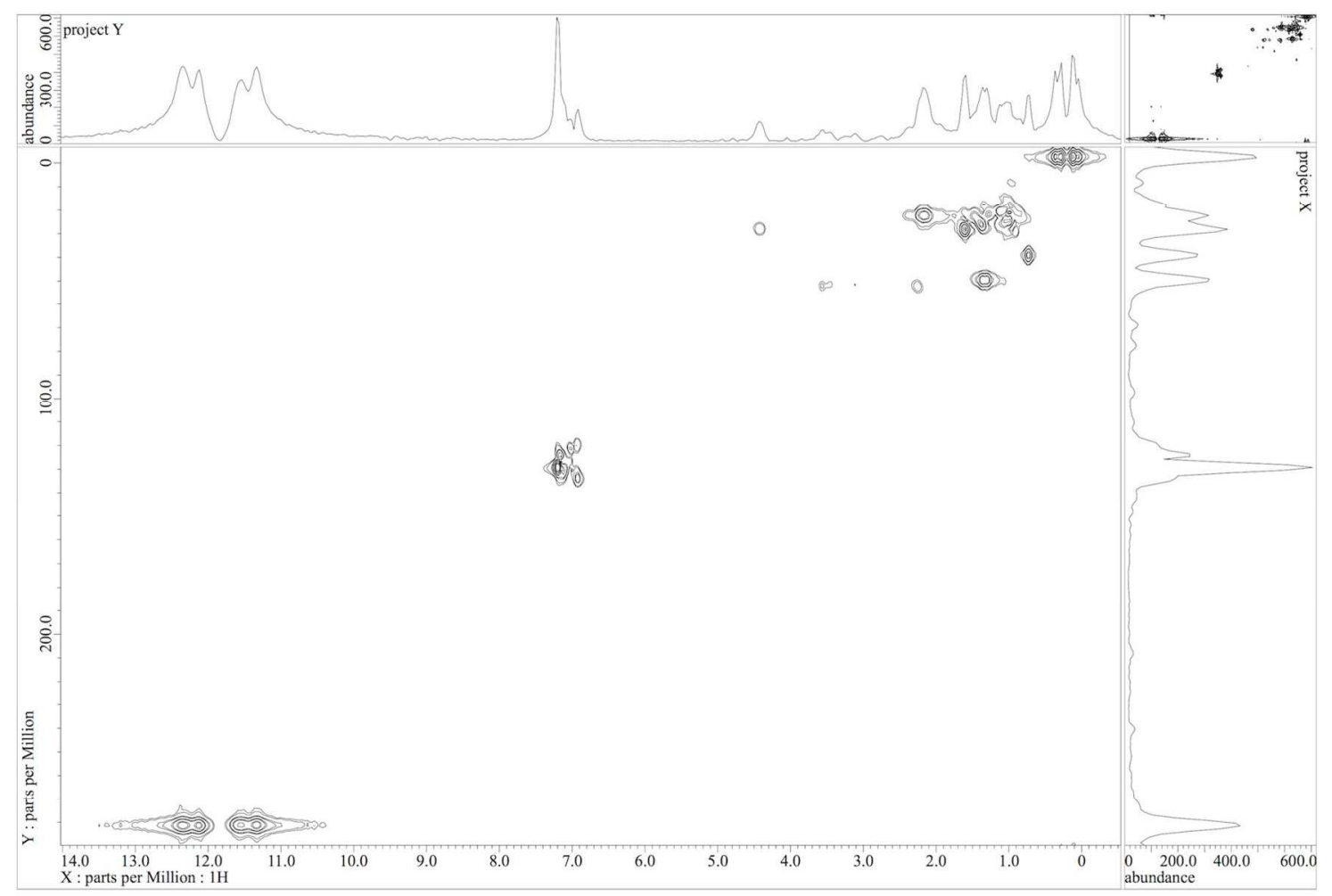

Figure S15. ${ }^{1} \mathrm{H}-{ }^{13} \mathrm{C}$ HMQC spectrum of ${ }^{4-}{ }^{13} \mathbf{C}\left(500 \mathrm{MHz}\right.$ in Benzene- $d_{6}$, at $300 \mathrm{~K}, \mathrm{X}$ axis: ${ }^{1} \mathrm{H}, \mathrm{Y}$ axis: ${ }^{13} \mathrm{C}$ NMR). 


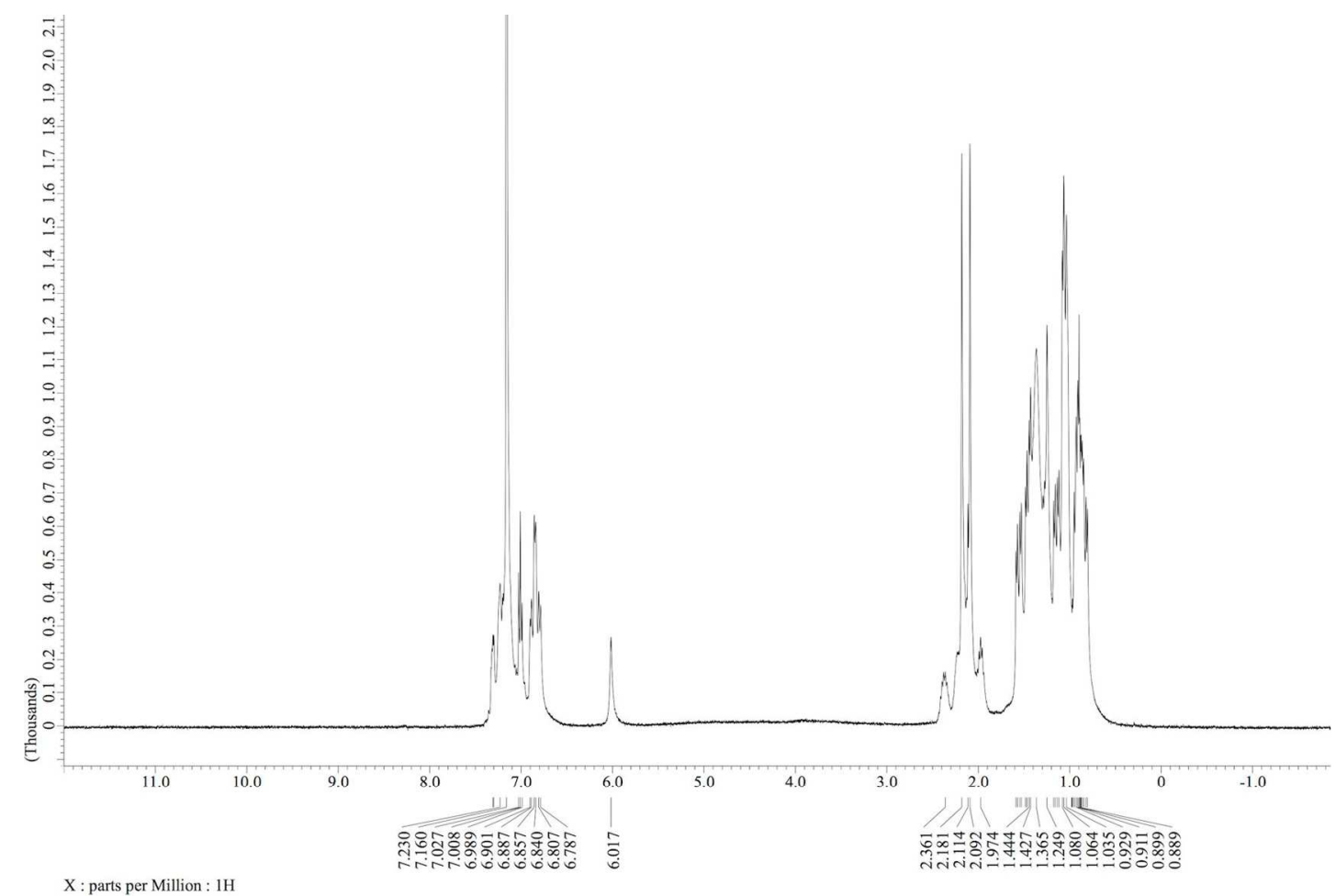

Figure S16. ${ }^{1} \mathrm{H}$ NMR spectrum of $5\left(400 \mathrm{MHz}\right.$, in Benzene- $d_{6}$, at $\left.300 \mathrm{~K}\right)$.

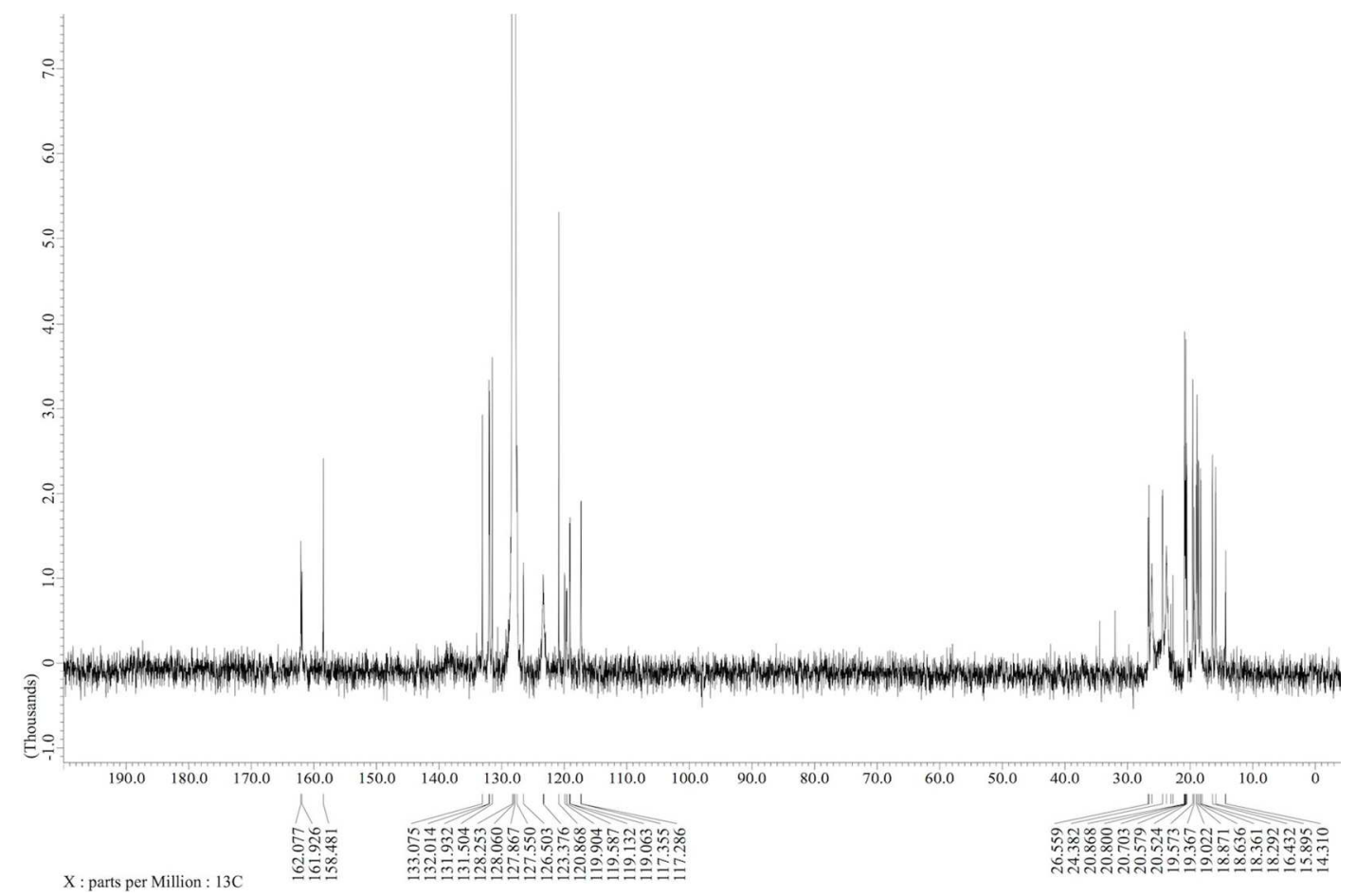

Figure S17. ${ }^{13} \mathrm{C}\left\{{ }^{1} \mathrm{H}\right\} \mathrm{NMR}$ spectrum of $5\left(126 \mathrm{MHz}\right.$, in Benzene- $d_{6}$, at $\left.300 \mathrm{~K}\right)$. 


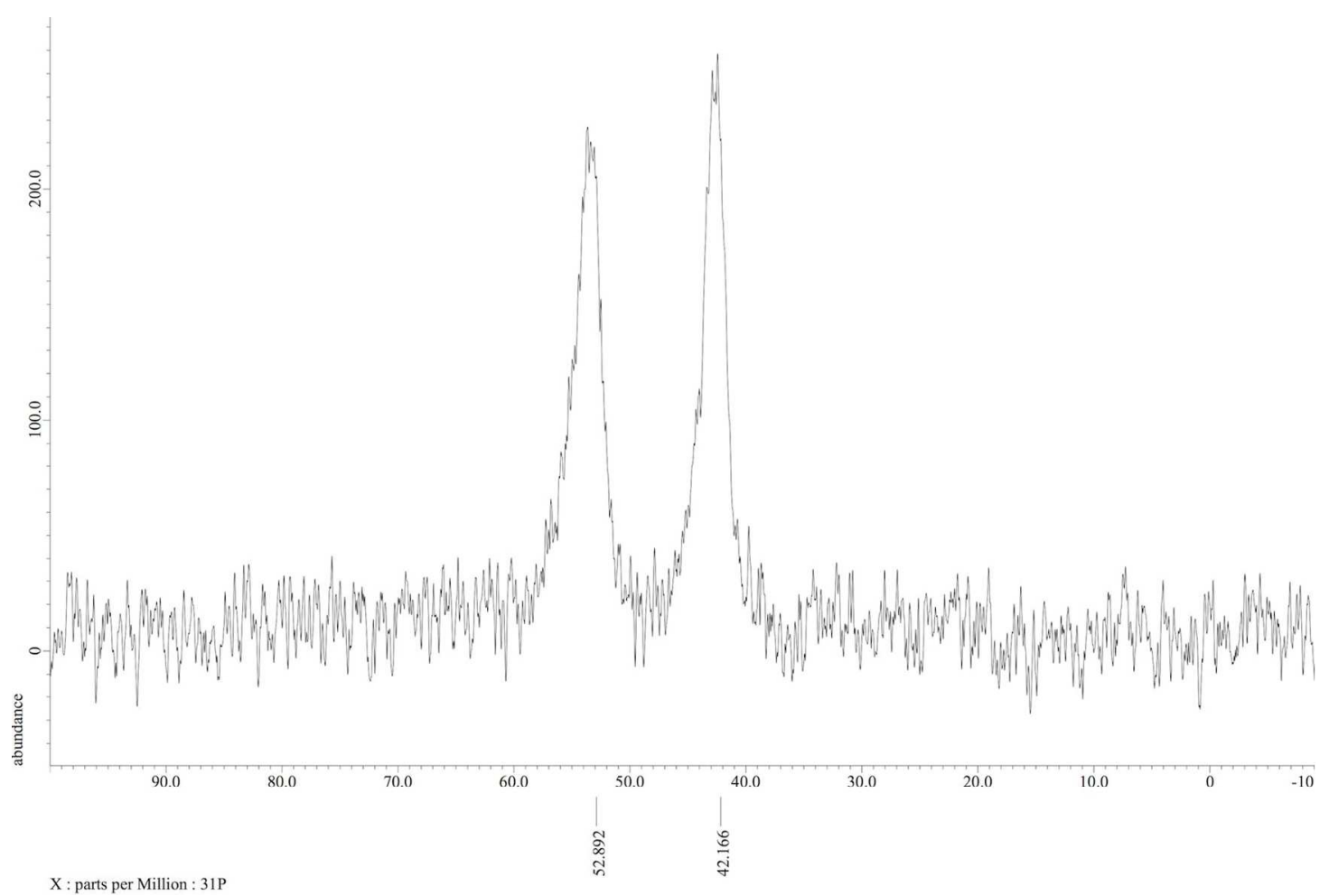

Figure S18. ${ }^{31} \mathrm{P}\left\{{ }^{1} \mathrm{H}\right\}$ NMR spectrum of $5\left(162 \mathrm{MHz}\right.$, in Benzene- $d_{6}$, at $\left.300 \mathrm{~K}\right)$.

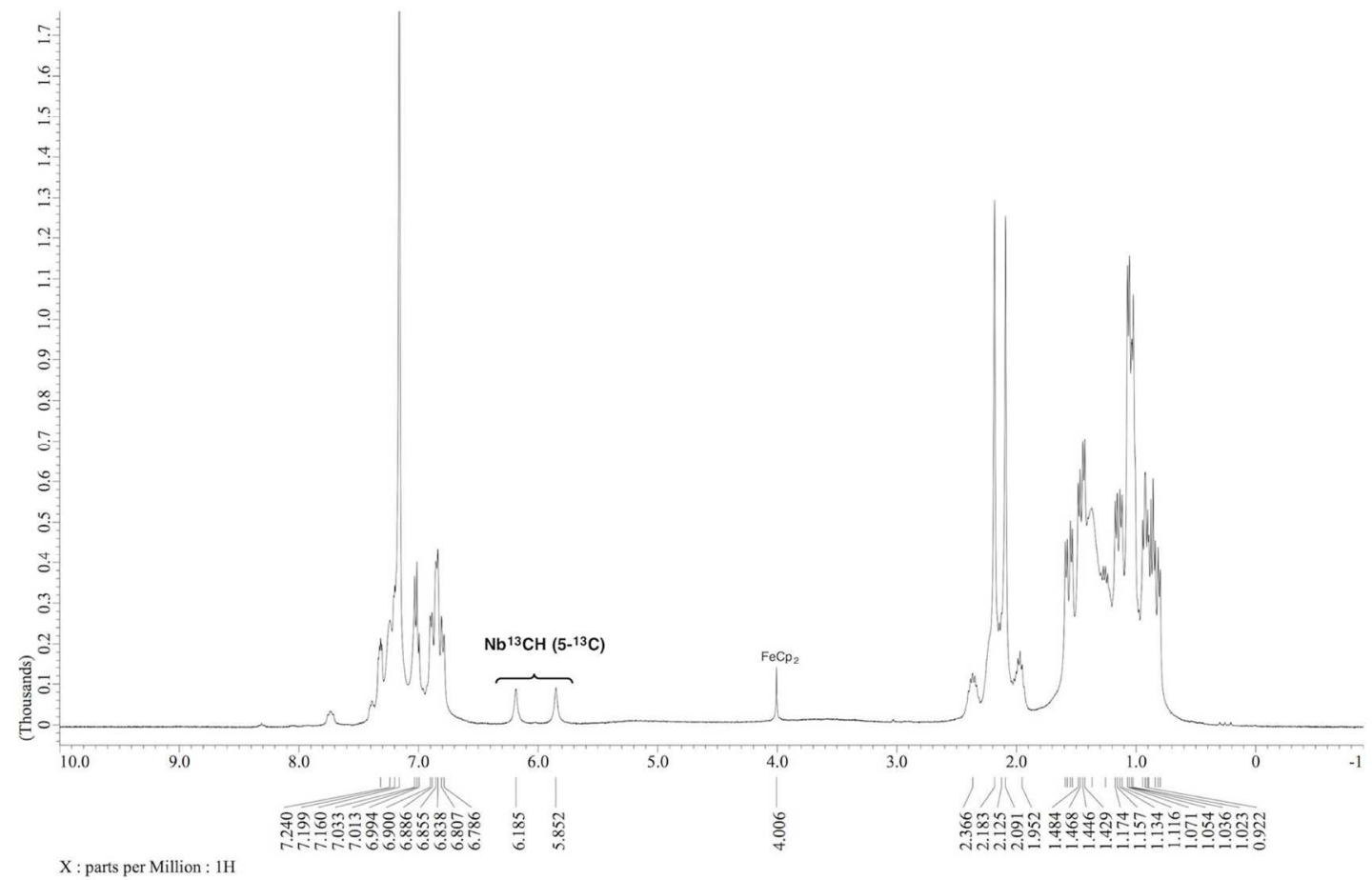

Figure S19. ${ }^{1} \mathrm{H}$ NMR spectrum of $\mathbf{5 -}^{\mathbf{1 3}} \mathbf{C}\left(400 \mathrm{MHz}\right.$, in Benzene- $d_{6}$, at $\left.300 \mathrm{~K}\right)$. 


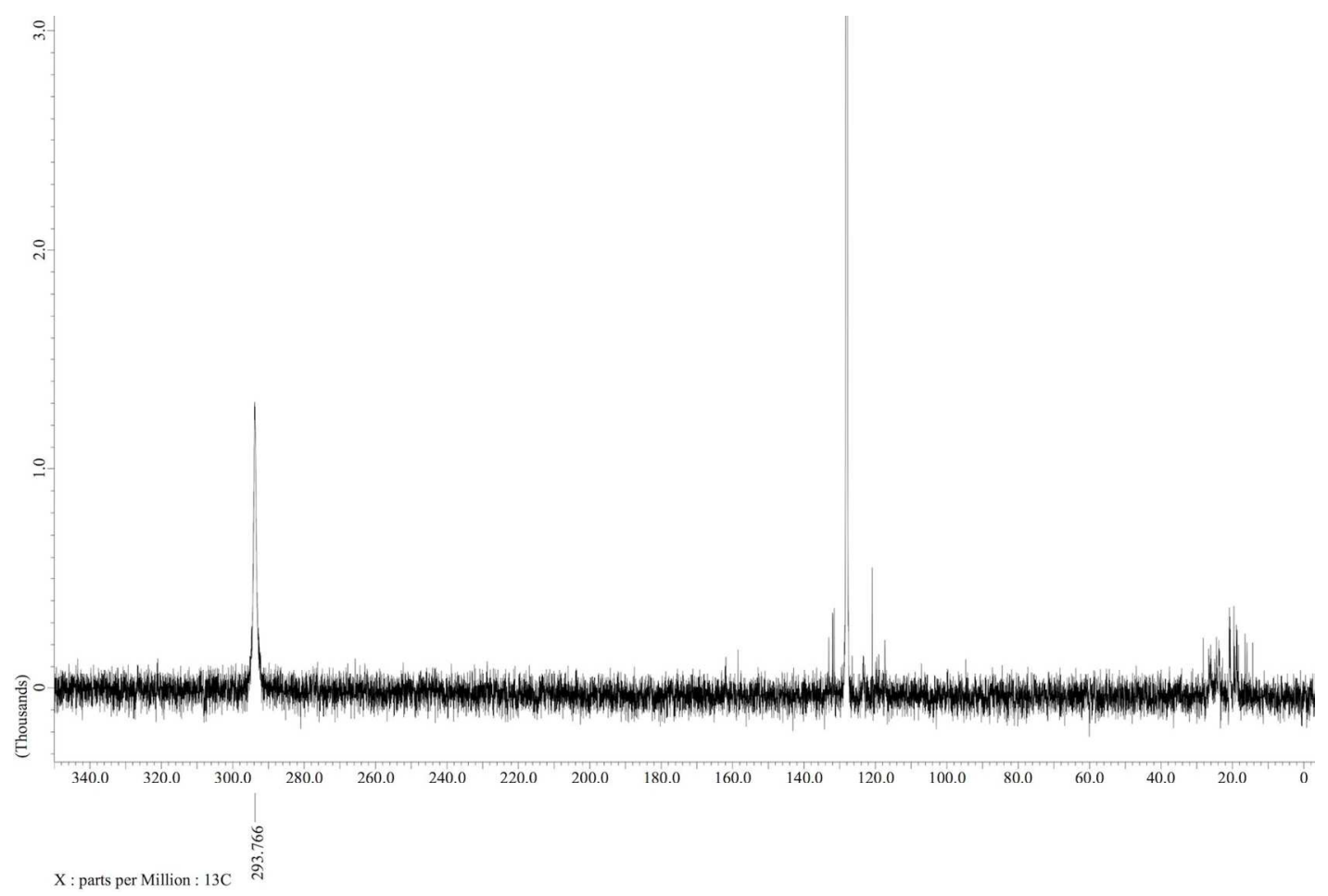

Figure S20. ${ }^{13} \mathrm{C}\left\{{ }^{1} \mathrm{H}\right\}$ NMR spectrum of $\mathbf{5 -}^{\mathbf{1 3}} \mathbf{C}\left(126 \mathrm{MHz}\right.$, in Benzene- $d_{6}$, at $\left.300 \mathrm{~K}\right)$.

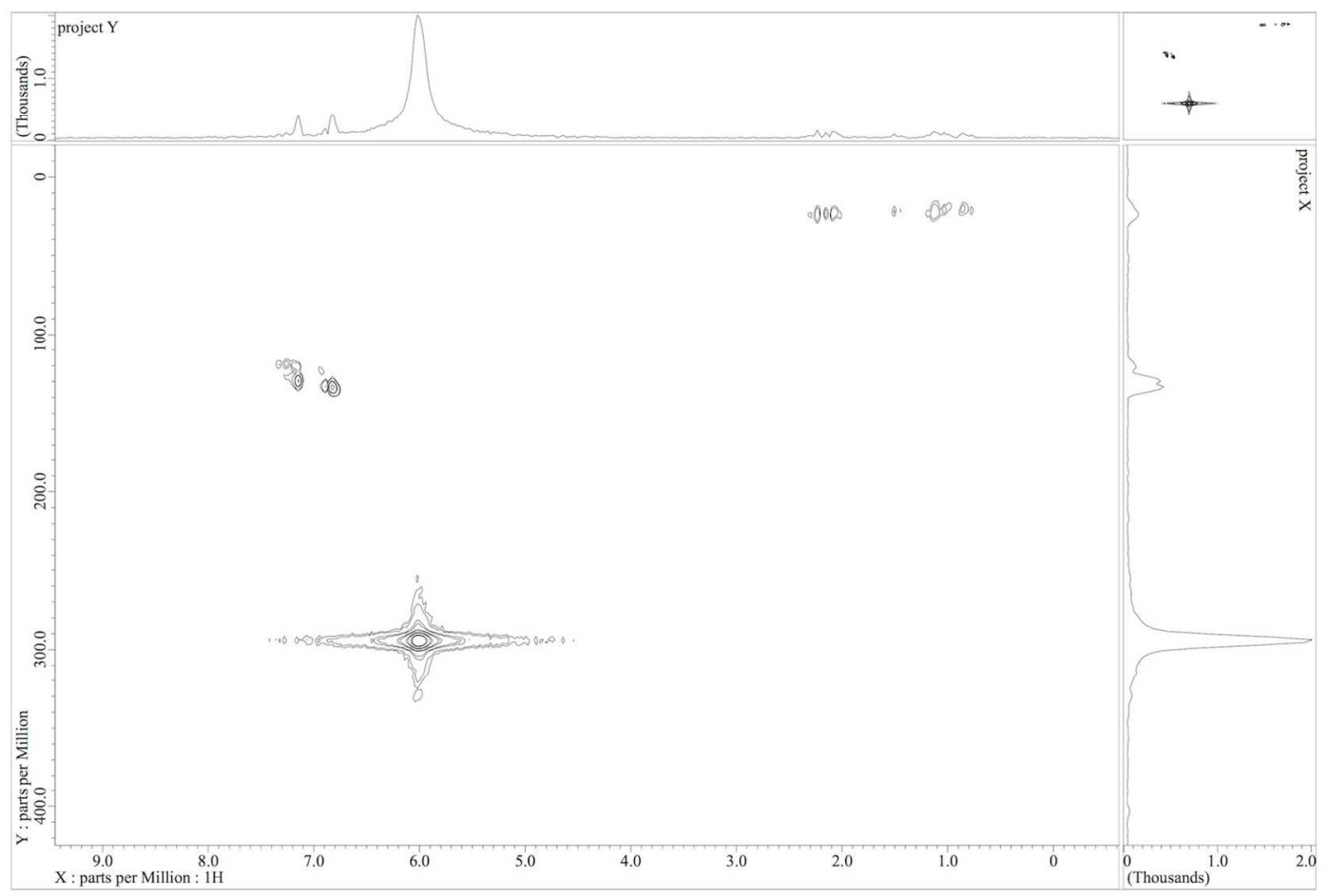

Figure S21. ${ }^{1} \mathrm{H}_{-}{ }^{13} \mathrm{C}$ HMQC spectrum of $\mathbf{5 -}^{\mathbf{1 3}} \mathbf{C}\left(500 \mathrm{MHz}\right.$ in Benzene- $d_{6}$, at $300 \mathrm{~K}, \mathrm{X}$ axis: ${ }^{1} \mathrm{H}, \mathrm{Y}$ axis: ${ }^{13} \mathrm{C}$ NMR). 


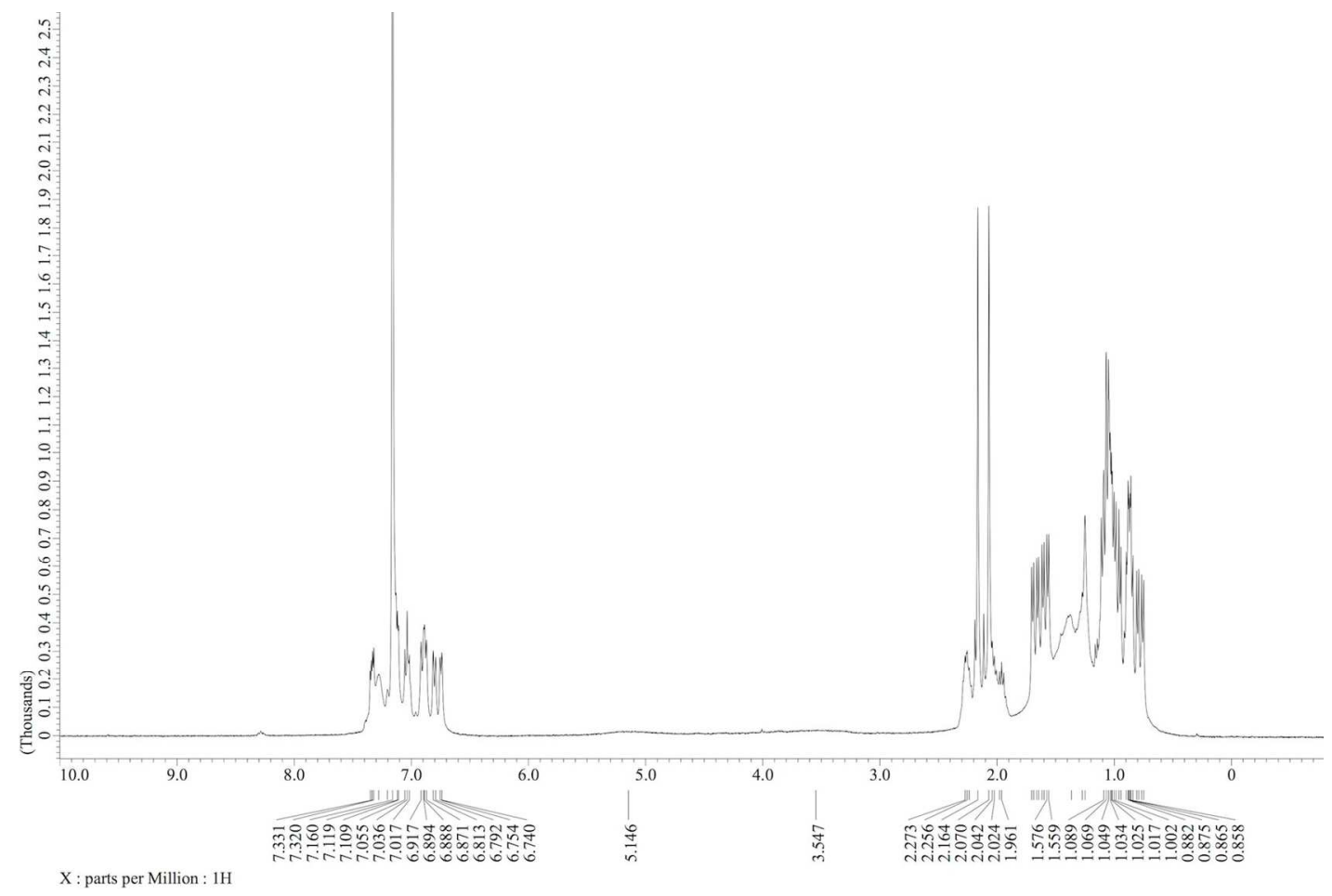

Figure S22. ${ }^{1} \mathrm{H}$ NMR spectrum of $6\left(400 \mathrm{MHz}\right.$, in Benzene- $d_{6}$, at $\left.300 \mathrm{~K}\right)$.

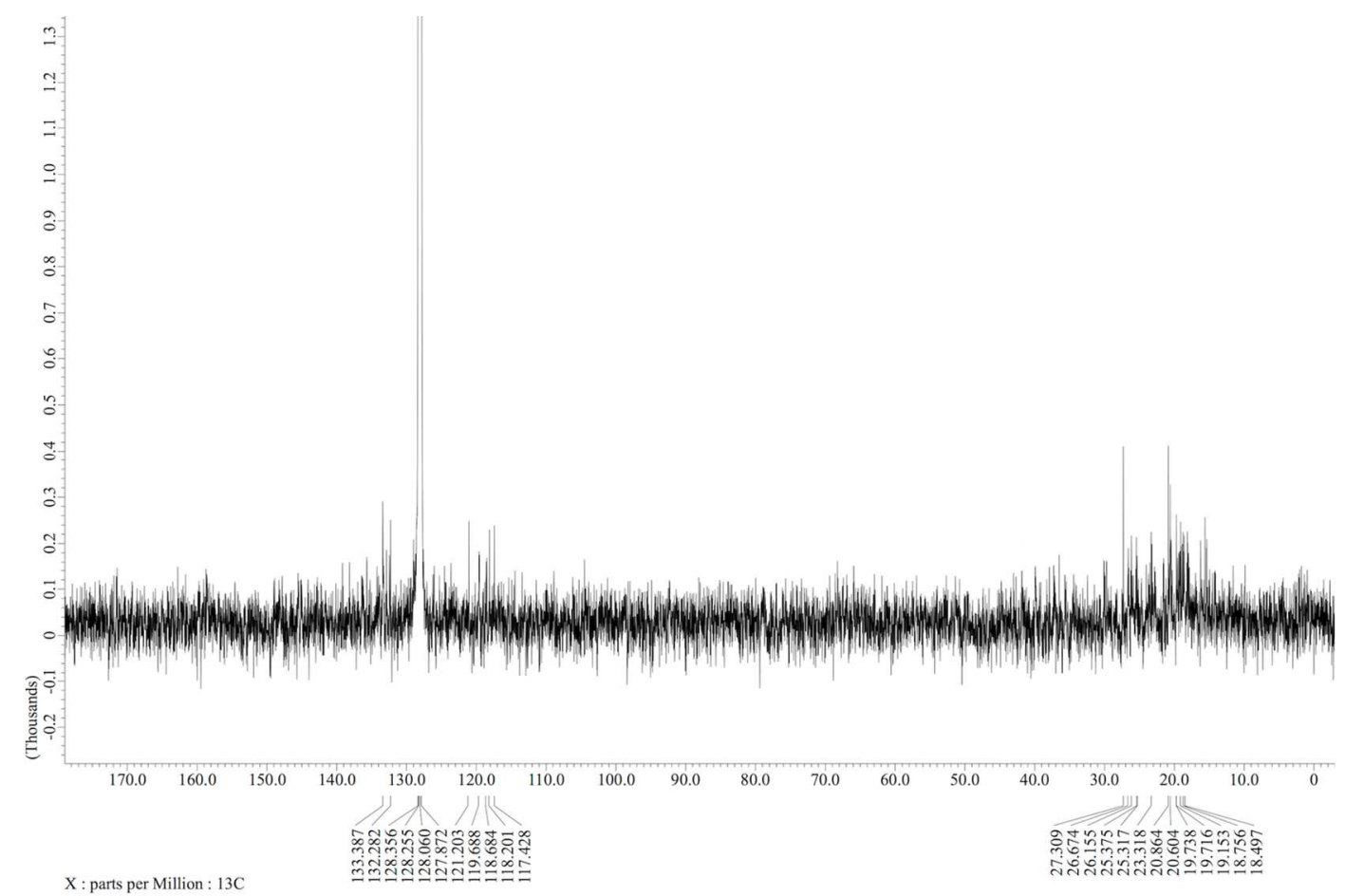

Figure S23. ${ }^{13} \mathrm{C}\left\{{ }^{1} \mathrm{H}\right\}$ NMR spectrum of $6\left(126 \mathrm{MHz}\right.$, in Benzene- $d_{6}$, at $\left.300 \mathrm{~K}\right)$. 


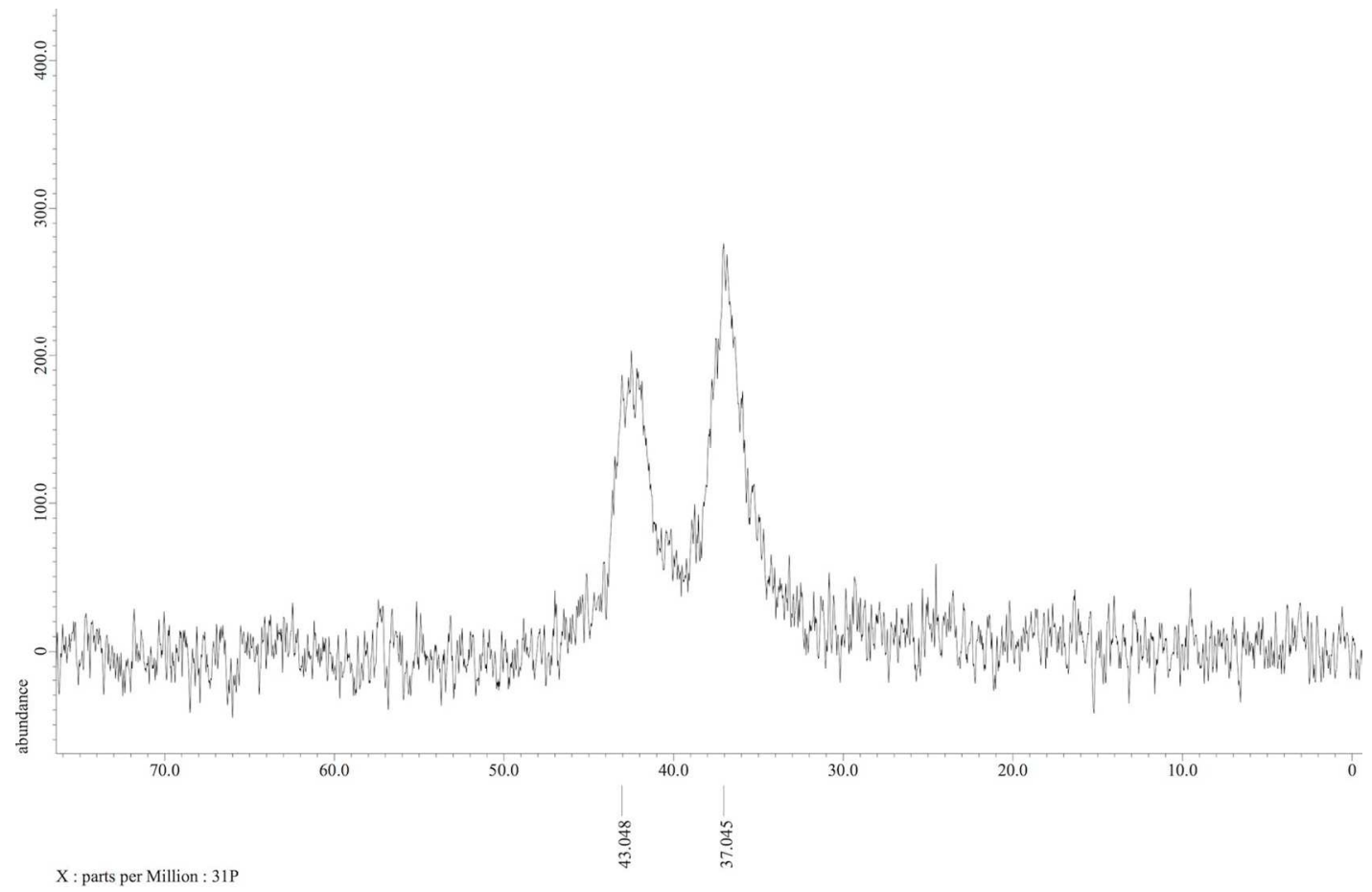

Figure S24. ${ }^{31} \mathrm{P}\left\{{ }^{1} \mathrm{H}\right\}$ NMR spectrum of $6\left(162 \mathrm{MHz}\right.$, in Benzene- $d_{6}$, at $\left.300 \mathrm{~K}\right)$.

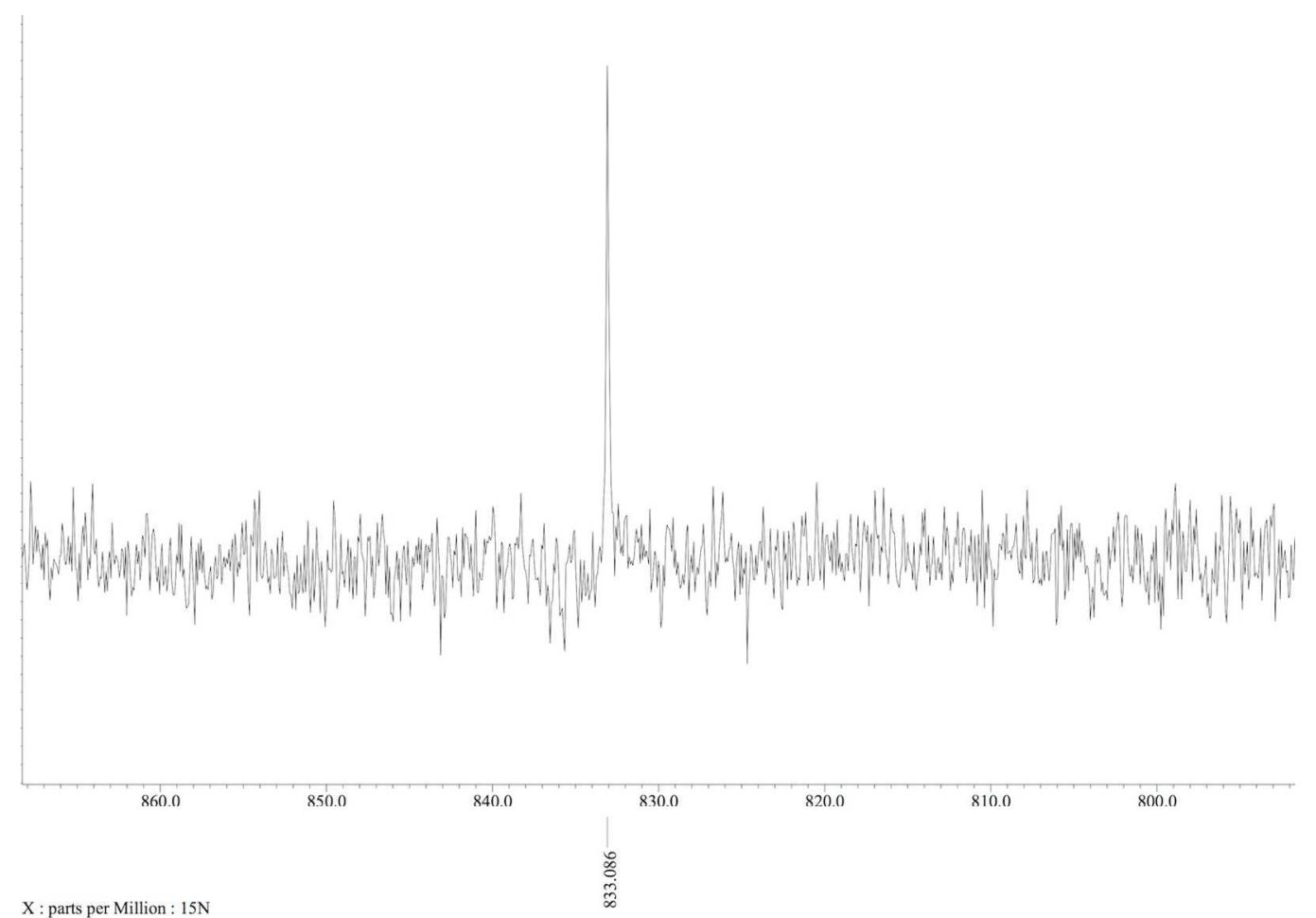

Figure S25. ${ }^{15} \mathrm{~N}$ NMR spectrum of $\mathbf{6}^{-{ }^{15}} \mathbf{N}\left(40.6 \mathrm{MHz}\right.$, in Benzene- $d_{6}$, at $\left.300 \mathrm{~K}\right)$. 


\section{Reaction of 3 with $\mathrm{H}_{2} \mathrm{CPPh}_{3}$}

In a J-Young valve NMR tube, a benzene- $d_{6}$ solution $(0.5 \mathrm{~mL})$ of $\mathbf{3}(20.1 \mathrm{mg}, 22.9 \mu \mathrm{mol})$ was treated with $\mathrm{H}_{2} \mathrm{CPPh}_{3}(7.5 \mathrm{mg}, 27.1 \mu \mathrm{mol})$ at room temperature, resulting in a gradual color change from dark reddish brown to dark green and formation of insoluble material $\left[\mathrm{H}_{3} \mathrm{CPPh}_{3}\right][\mathrm{OTf}]$. After shaking for $10 \mathrm{~min}$ at room temperature, formation of $\mathbf{5}$ quantitatively and $\mathrm{CH}_{4}(0.16 \mathrm{ppm})$ were observed by ${ }^{1} \mathrm{H}$ NMR spectroscopy (Figure S26.) and ${ }^{31} \mathrm{P}\left\{{ }^{1} \mathrm{H}\right\}$ NMR (Figure S27).

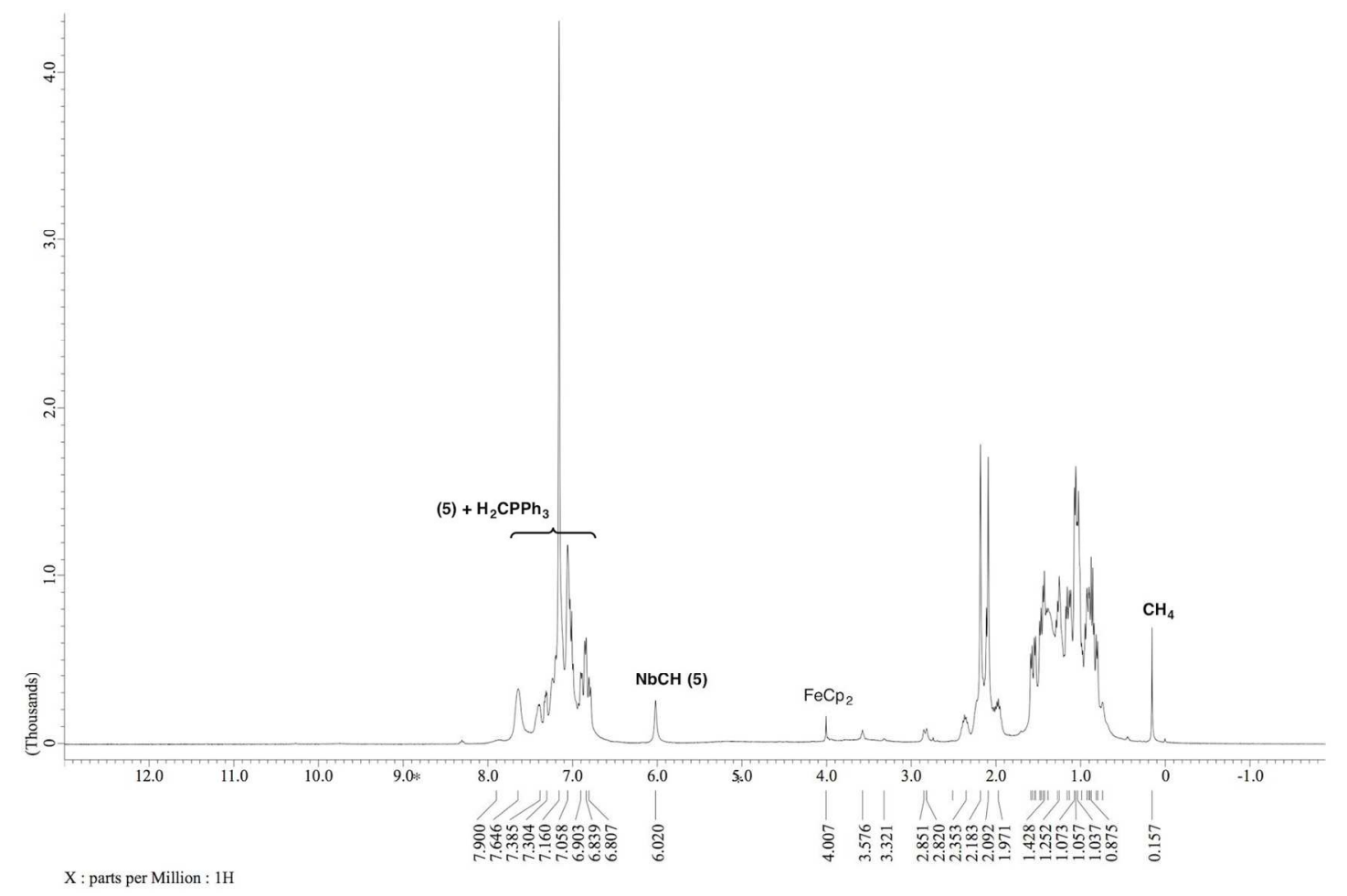

Figure S26. ${ }^{1} \mathrm{H}$ NMR spectrum of the reaction mixture of 3 with $\mathrm{H}_{2} \mathrm{CPPh}_{3}$ at room temperature after $10 \mathrm{~min}$. (400 MHz, in Benzene- $d_{6}$, at $300 \mathrm{~K}$ ). 


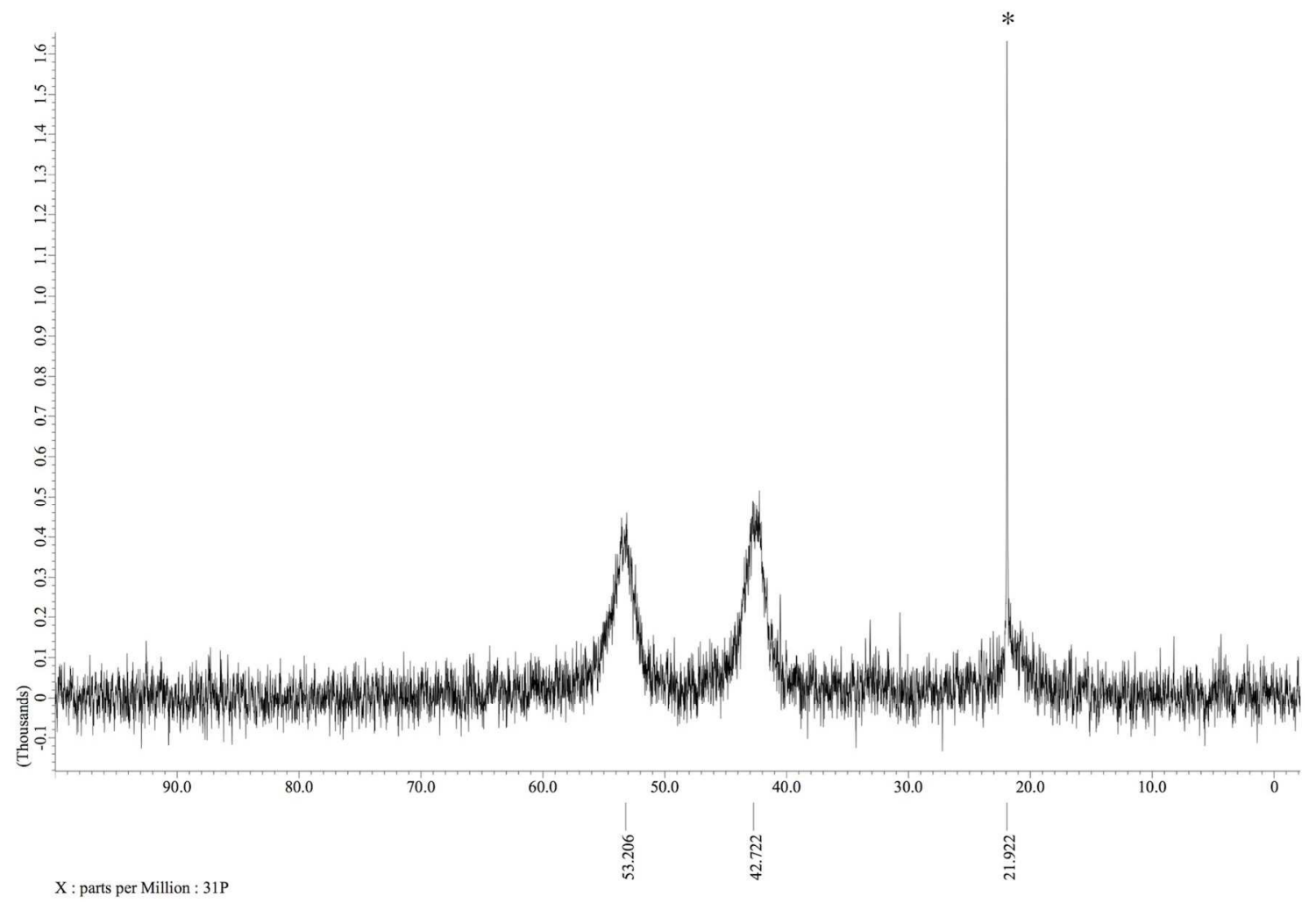

Figure S27. ${ }^{31} \mathrm{P}$ NMR spectrum of the reaction mixture of 3 with $\mathrm{H}_{2} \mathrm{CPPh}_{3}$ at room temperature after $10 \mathrm{~min}$. (162 MHz, in Benzene- $d_{6}$, at $\left.300 \mathrm{~K}\right)$. * : Excessive $\mathrm{H}_{2} \mathrm{CPPh}_{3}$. 


\section{Reaction of 4 with $\mathrm{H}_{3} \mathrm{CMgCl}$}

In a J-Young valve NMR tube, a benzene- $d_{6}$ solution $(0.5 \mathrm{~mL})$ of $4(10.1 \mathrm{mg}, 11.6 \mu \mathrm{mol})$ was treated with $\mathrm{H}_{3} \mathrm{CMgCl}(3.0 \mathrm{M}$ in $\mathrm{THF}, 4.0 \mu \mathrm{L}, 12 \mu \mathrm{mol})$ at room temperature, resulting in a color change from dark yellow to green. After shaking for $15 \mathrm{~min}$ at room temperature, formation of $5(\sim 70 \%), \mathrm{CH}_{4}(0.16 \mathrm{ppm})$, and unidentified paramagnetic species were observed by ${ }^{1} \mathrm{H}$ NMR (Figure S28.) and (PNP) $\mathrm{MgX}\left(\mathrm{X}=\mathrm{Cl}\right.$ or OTf) ${ }^{1}$ was also observed by ${ }^{31} \mathrm{P}\left\{{ }^{1} \mathrm{H}\right\}$ NMR (Figure S29.).

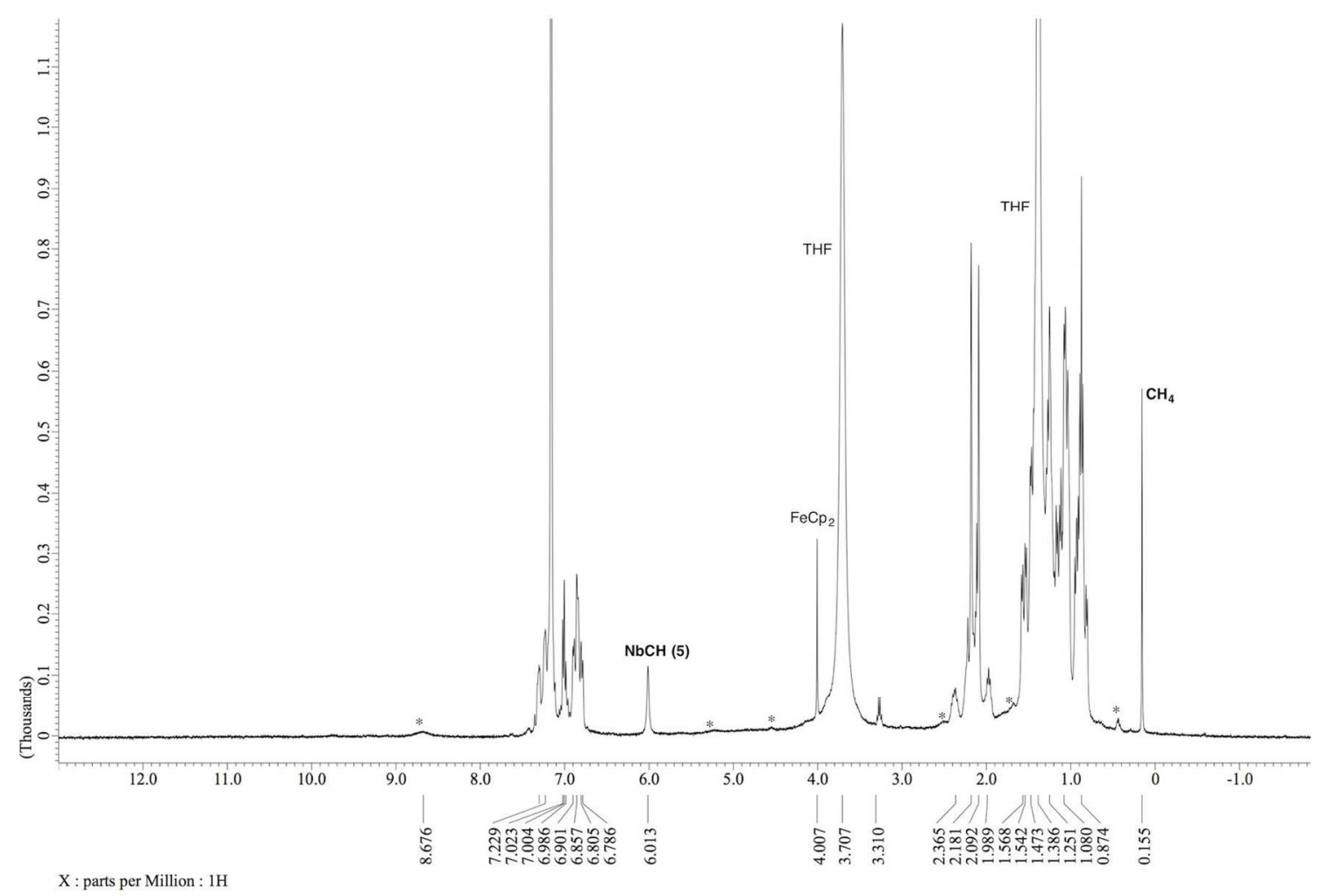

Figure S28. ${ }^{1} \mathrm{H}$ NMR spectrum of the reaction mixture of 4 with $\mathrm{H}_{3} \mathrm{CMgCl}$ at room temperature after $15 \mathrm{~min} .\left(400 \mathrm{MHz}\right.$, in Benzene- $d_{6}$, at $\left.300 \mathrm{~K}\right) .{ }^{*}$ : Unidentified species. 


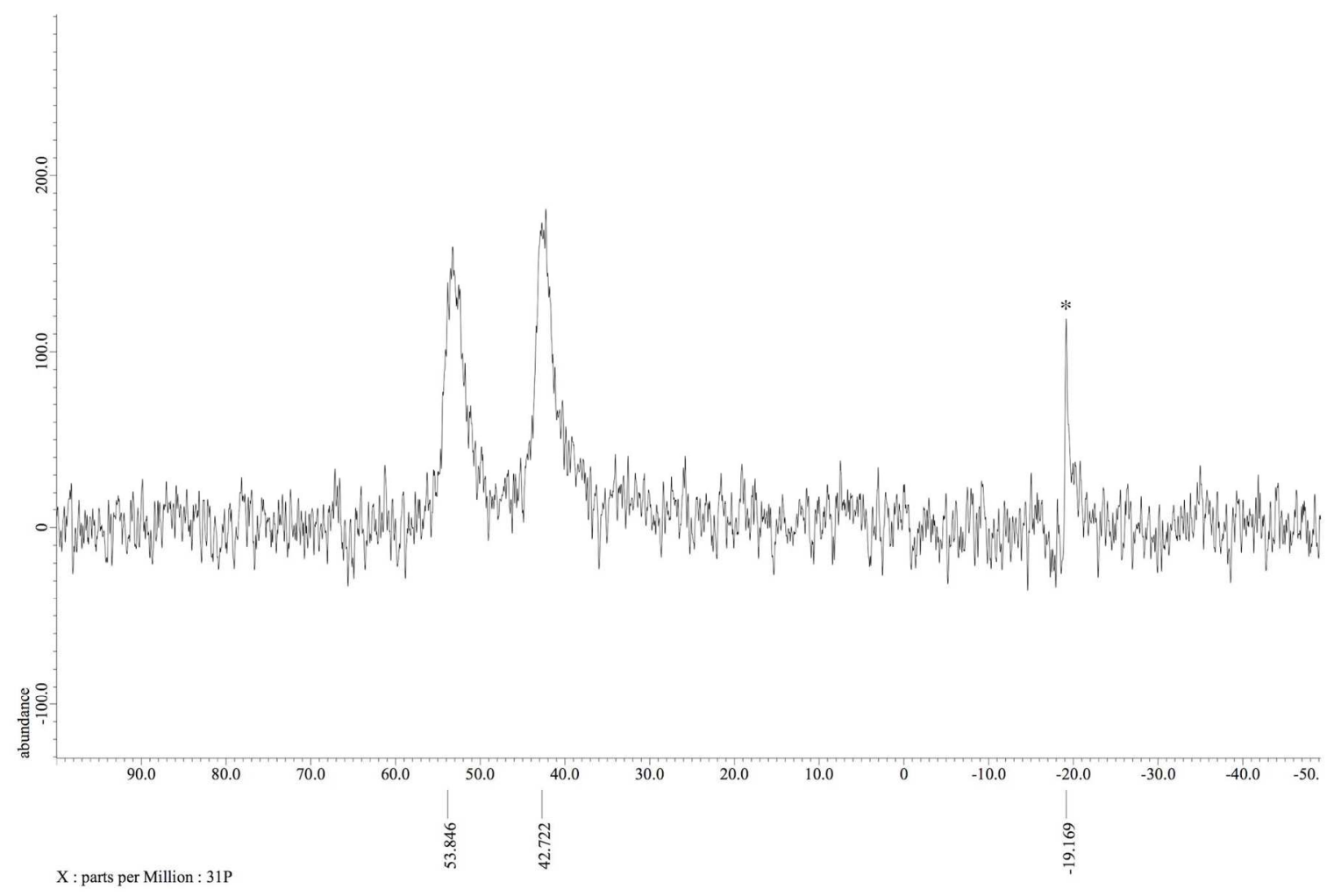

Figure S29. ${ }^{31} \mathrm{P}$ NMR spectrum of the reaction mixture of 4 with $\mathrm{H}_{3} \mathrm{CMgCl}$ at room temperature after $15 \mathrm{~min} .\left(162 \mathrm{MHz}\right.$, in Benzene- $d_{6}$, at $\left.300 \mathrm{~K}\right) .{ }^{*}:(\mathrm{PNP}) \mathrm{MgX}(\mathrm{X}=\mathrm{Cl}$ or OTf). ${ }^{1}$ 


\section{Reaction of 5 with ${ }^{15}$ NCAd}

In a J-Young valve NMR tube, a benzene- $d_{6}$ solution $(0.5 \mathrm{~mL})$ of $5(15.1 \mathrm{mg}, 21.2 \mu \mathrm{mol})$ was treated with ${ }^{15} \mathrm{NCAd}(4.1 \mathrm{mg}, 25.4 \mu \mathrm{mol})$ at room temperature, resulting in a color change from green to reddish brown. After shaking for $10 \mathrm{~min}$ at room temperature, formation of an intermediate A was observed by ${ }^{1} \mathrm{H}$ NMR (8.72 ppm, Figure S30.). After $1 \mathrm{~h}$ at room temperature, the color of the reaction mixture changed to more reddish and formation of $\mathbf{6}$ was observed.

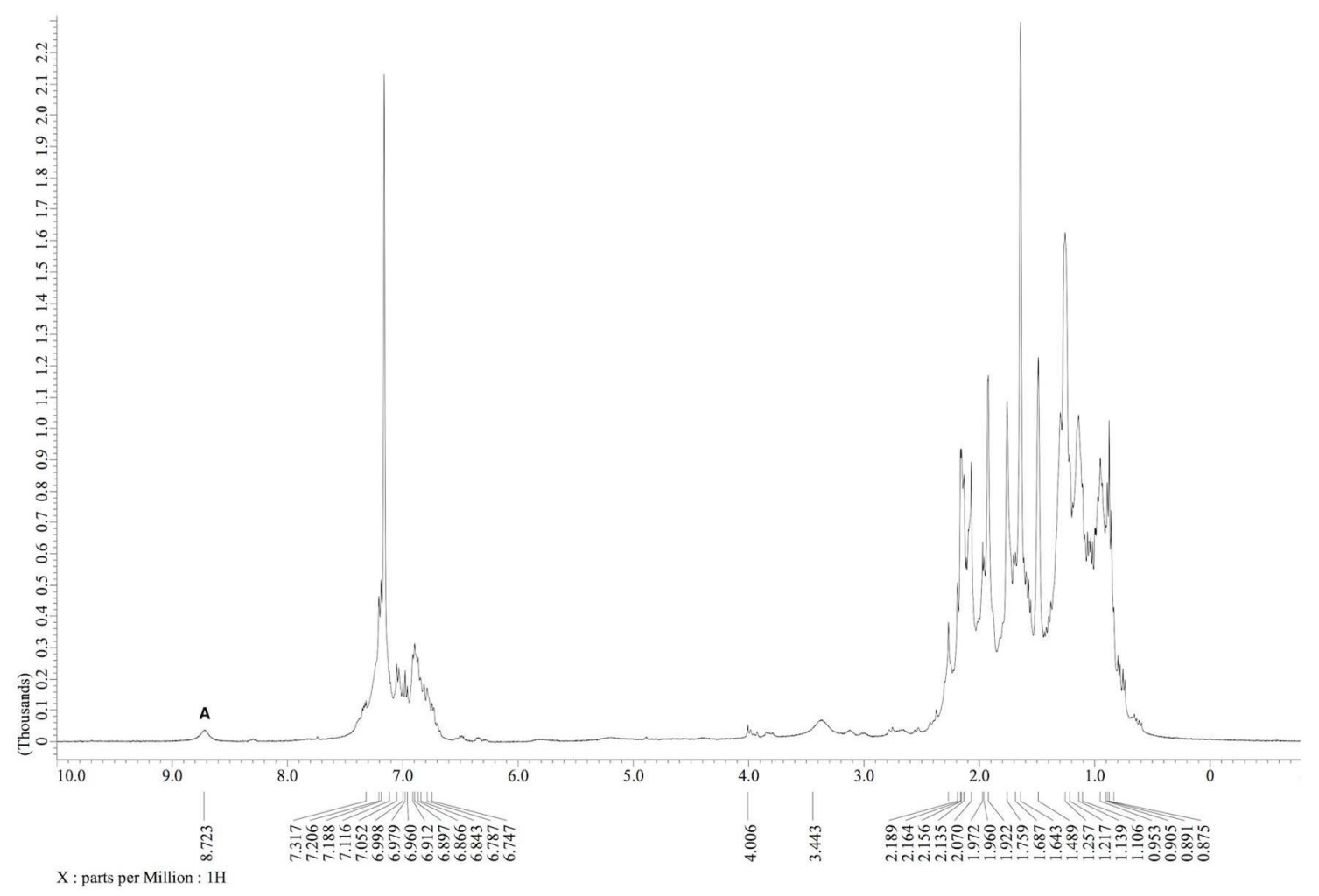

Figure S30. ${ }^{1} \mathrm{H}$ NMR spectrum of the reaction mixture of 5 with ${ }^{15} \mathrm{NC}[1-\mathrm{Ad}]$ at room temperature after $10 \mathrm{~min}$. (400 MHz, in Benzene- $d_{6}$, at $300 \mathrm{~K}$ ). 


\section{Reaction of 5- ${ }^{13} \mathrm{C}$ with ${ }^{15} \mathrm{NC}$ [1-Ad]}

In a J-Young valve NMR tube, a benzene- $d_{6}$ solution $(0.5 \mathrm{~mL})$ of $\mathbf{5 -}^{13} \mathbf{C}(10.1 \mathrm{mg}, 14.2$ $\mu \mathrm{mol})$ was treated with ${ }^{15} \mathrm{NC}[1-\mathrm{Ad}](3.1 \mathrm{mg}, 19.2 \mu \mathrm{mol})$ at room temperature, resulting in a color change from green to reddish brown. After shaking for $10 \mathrm{~min}$ at room temperature, formation of an intermediate $\mathbf{A}-{ }^{13} \mathbf{C}$ was observed by ${ }^{1} \mathrm{H}$ NMR spectrum (8.72 ppm, d, ${ }^{1} J_{\mathrm{CH}}=161 \mathrm{~Hz}$, Figure S31.). After $1 \mathrm{~h}$ at room temperature, formation of $\mathrm{AdC} \equiv{ }^{13} \mathrm{CH}$ was observed by ${ }^{13} \mathrm{C}$ NMR (67.63 ppm, Figure S32.). Overlapping of the ${ }^{1} \mathrm{H}$ NMR signals of $\mathrm{AdC} \equiv{ }^{13} \mathrm{CH}$ and PNP ligand prevents us from observing a doublet of $\mathrm{AdC} \equiv{ }^{13} \mathrm{C} H$.

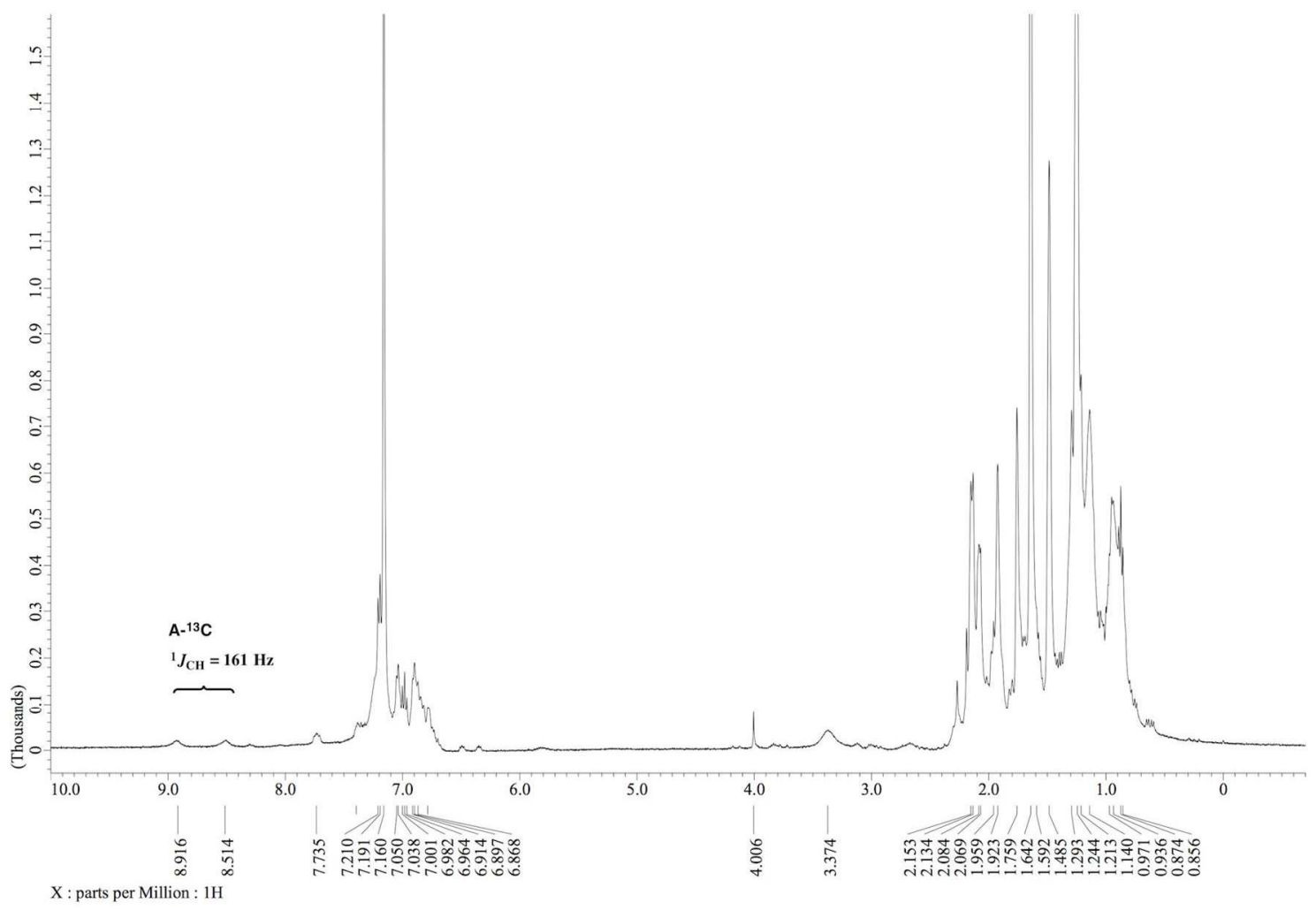

Figure S31. ${ }^{1} \mathrm{H}$ NMR spectrum of the reaction mixture of $5-{ }^{13} \mathbf{C}$ with ${ }^{15} \mathrm{NC}[1-\mathrm{Ad}]$ at room temperature after $10 \mathrm{~min}$. (400 MHz, in Benzene- $d_{6}$, at $300 \mathrm{~K}$ ). 


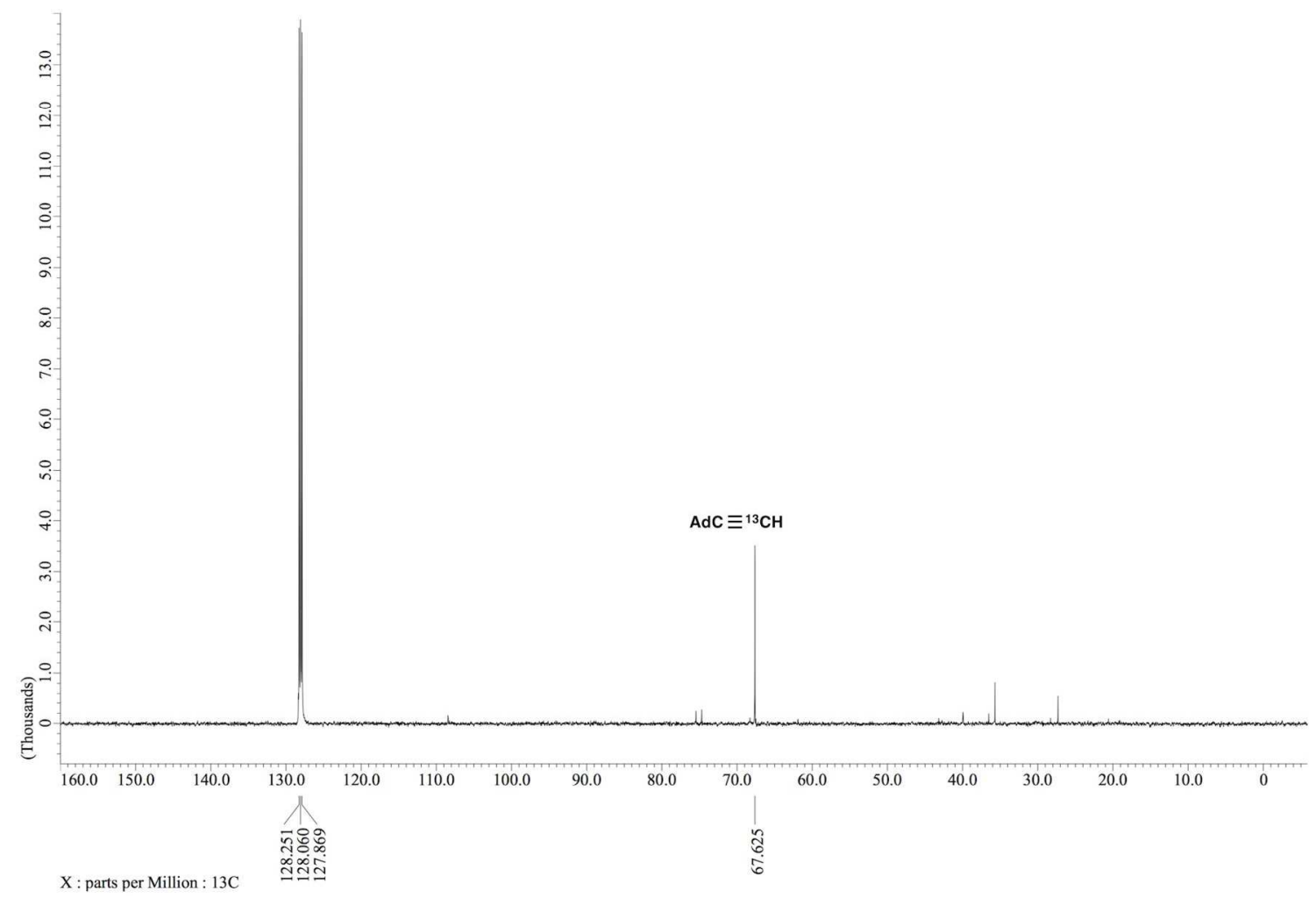

Figure S32. ${ }^{13} \mathrm{C}$ NMR spectrum of the reaction mixture of $5-{ }^{\mathbf{1 3}} \mathbf{C}$ with ${ }^{15} \mathrm{NC}[1-\mathrm{Ad}]$ at room temperature after $1 \mathrm{~h}\left(126 \mathrm{MHz}\right.$, in Benzene- $d_{6}$, at $\left.300 \mathrm{~K}\right)$. 


\section{UV-Vis Spectra}

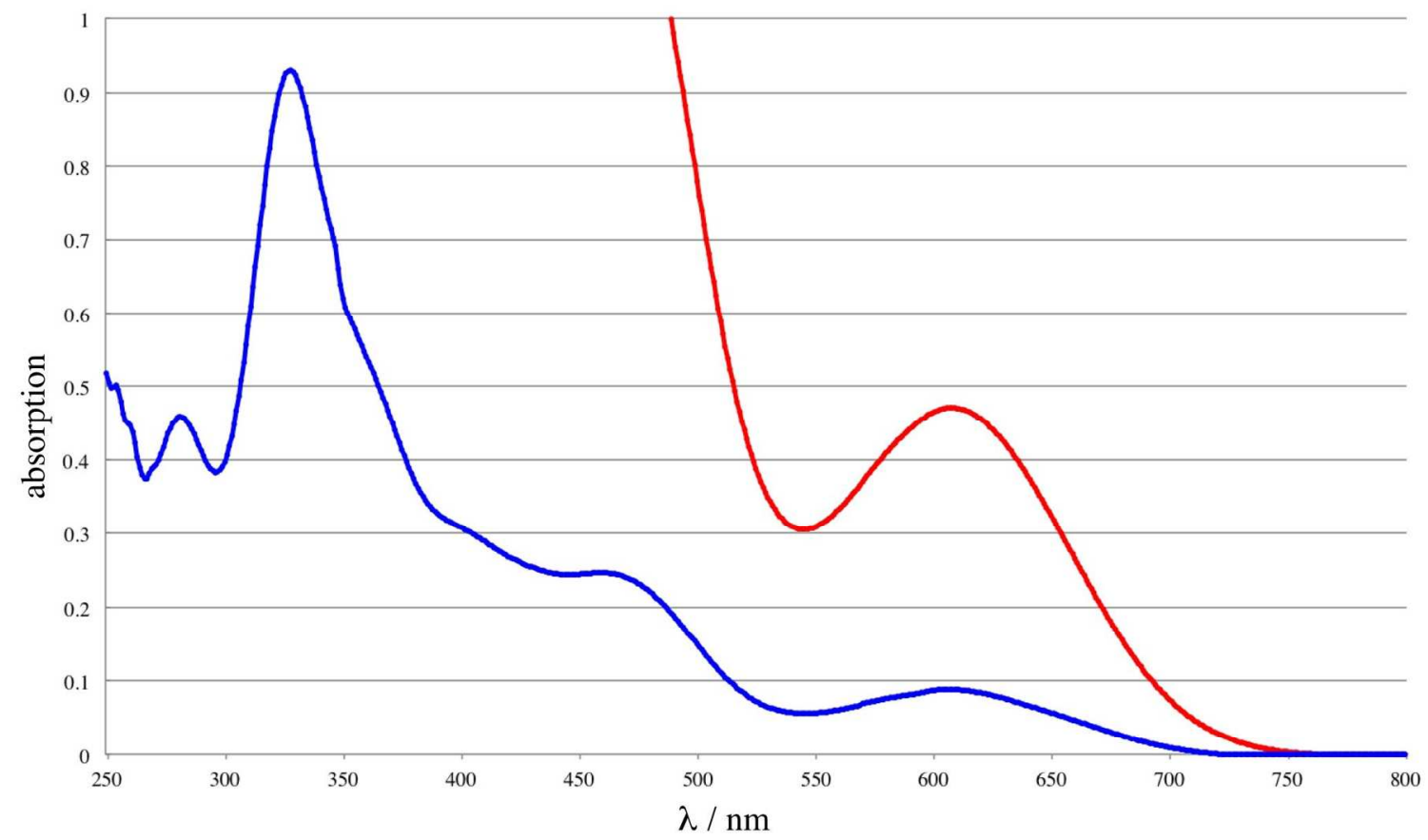

Figure S33. UV-Vis spectrum of 1 (blue; $0.053 \mathrm{mM}$, red; $0.27 \mathrm{mM}$ in hexane, at $300 \mathrm{~K}$ ).

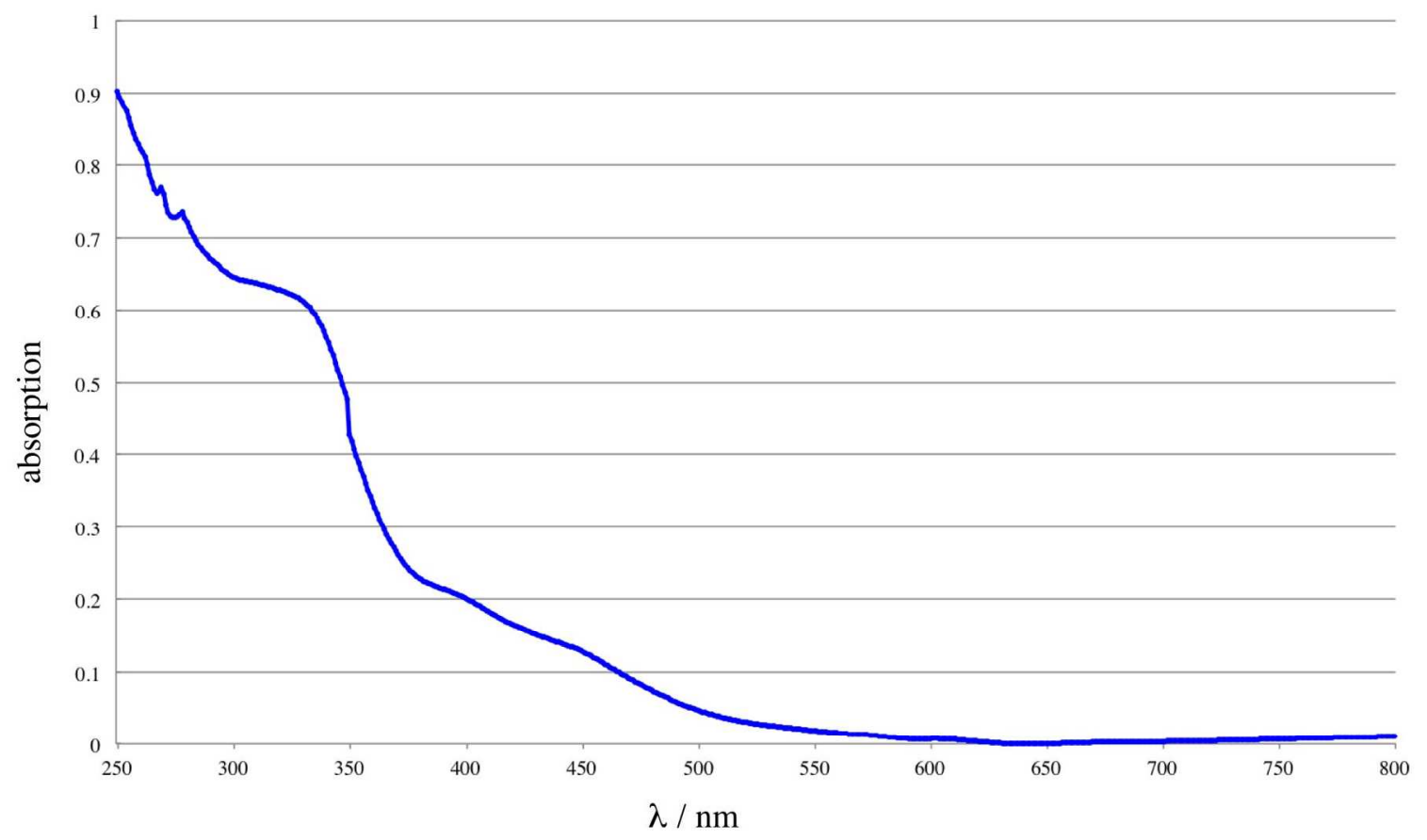

Figure S34. UV-Vis spectrum of $2(0.032 \mathrm{mM}$ in THF, at $300 \mathrm{~K})$. 


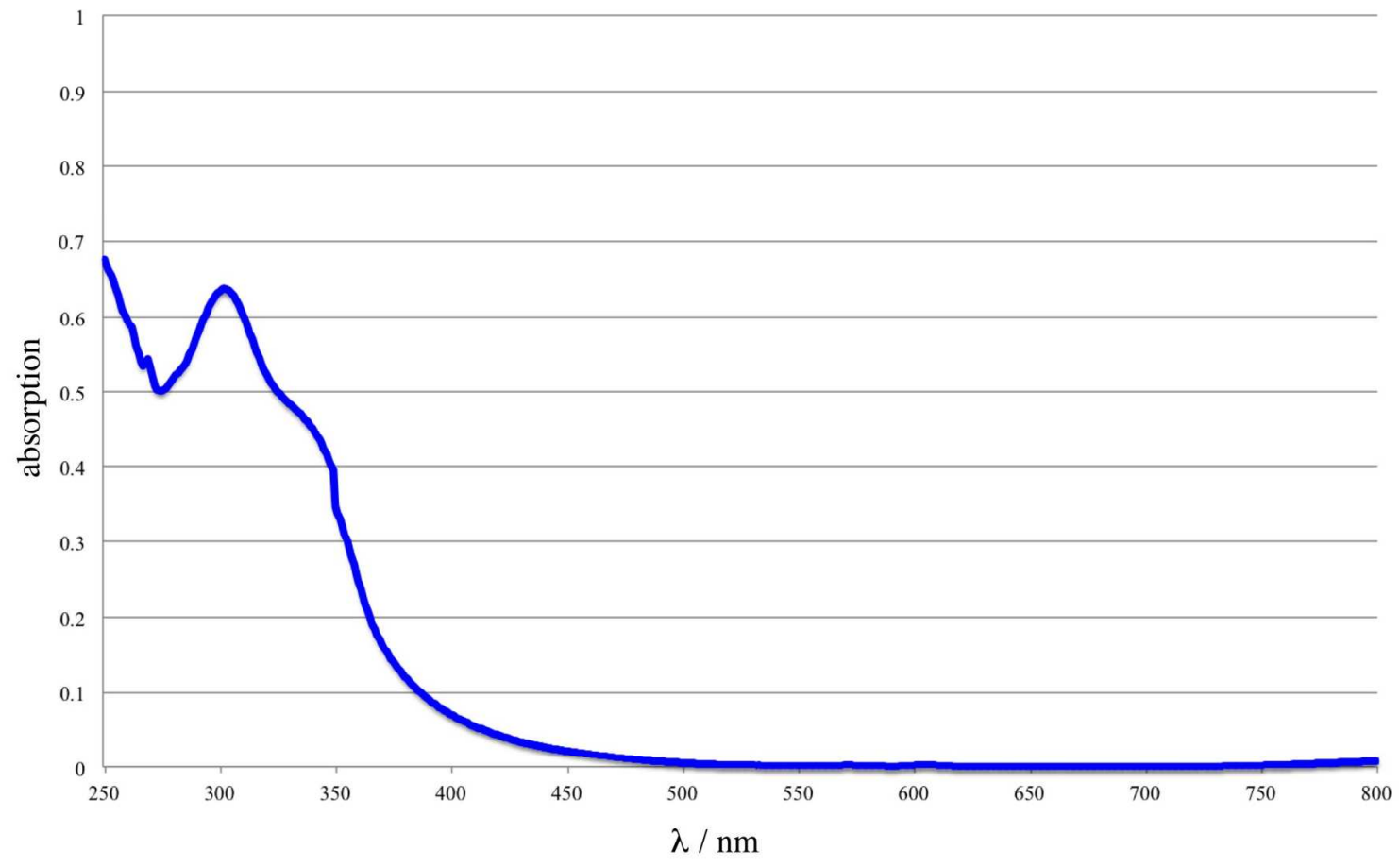

Figure S35. UV-Vis spectrum of $3(0.046 \mathrm{mM}$ in THF at $300 \mathrm{~K})$.

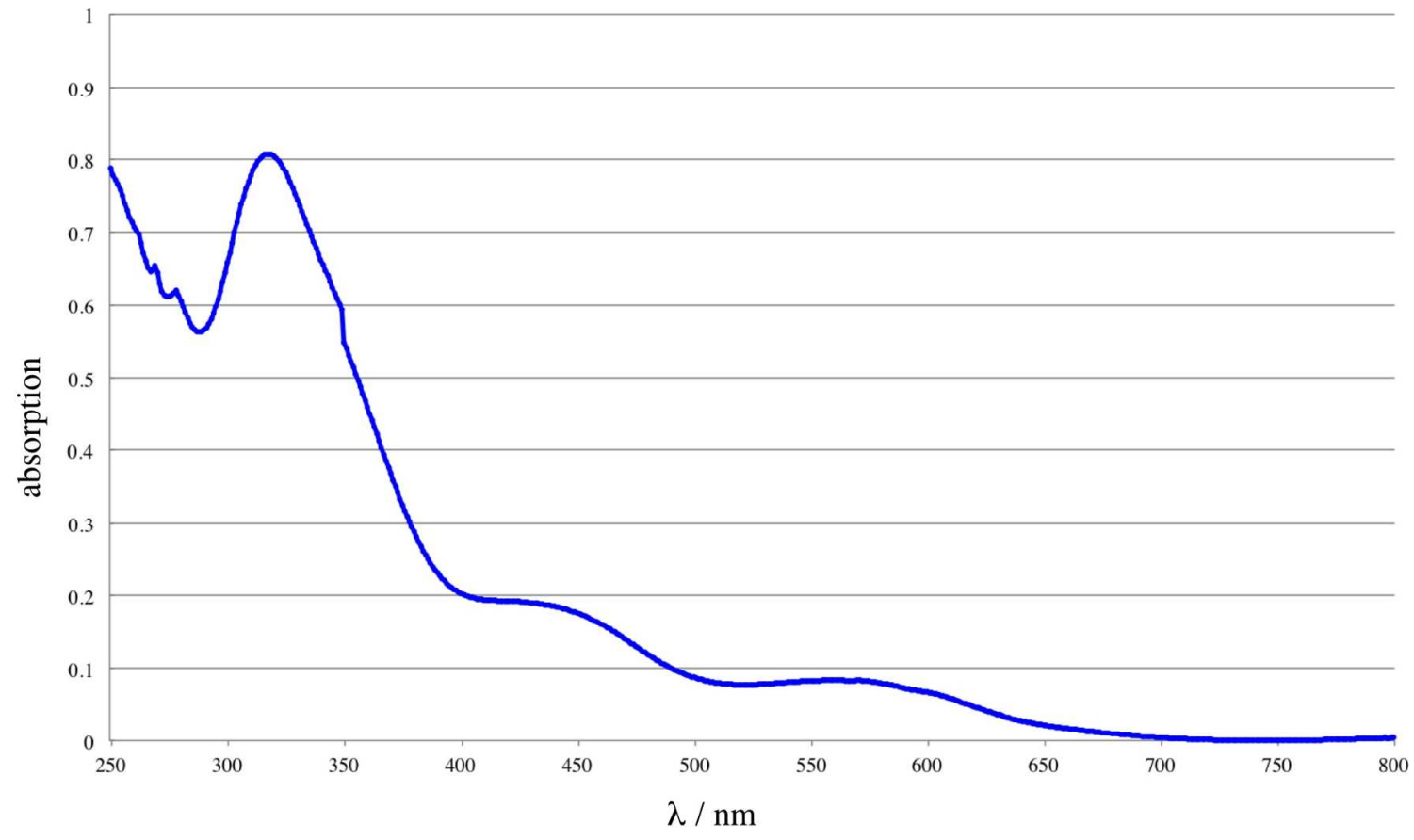

Figure S36. UV-Vis spectrum of $4(0.041 \mathrm{mM}$ in THF, at $300 \mathrm{~K})$. 


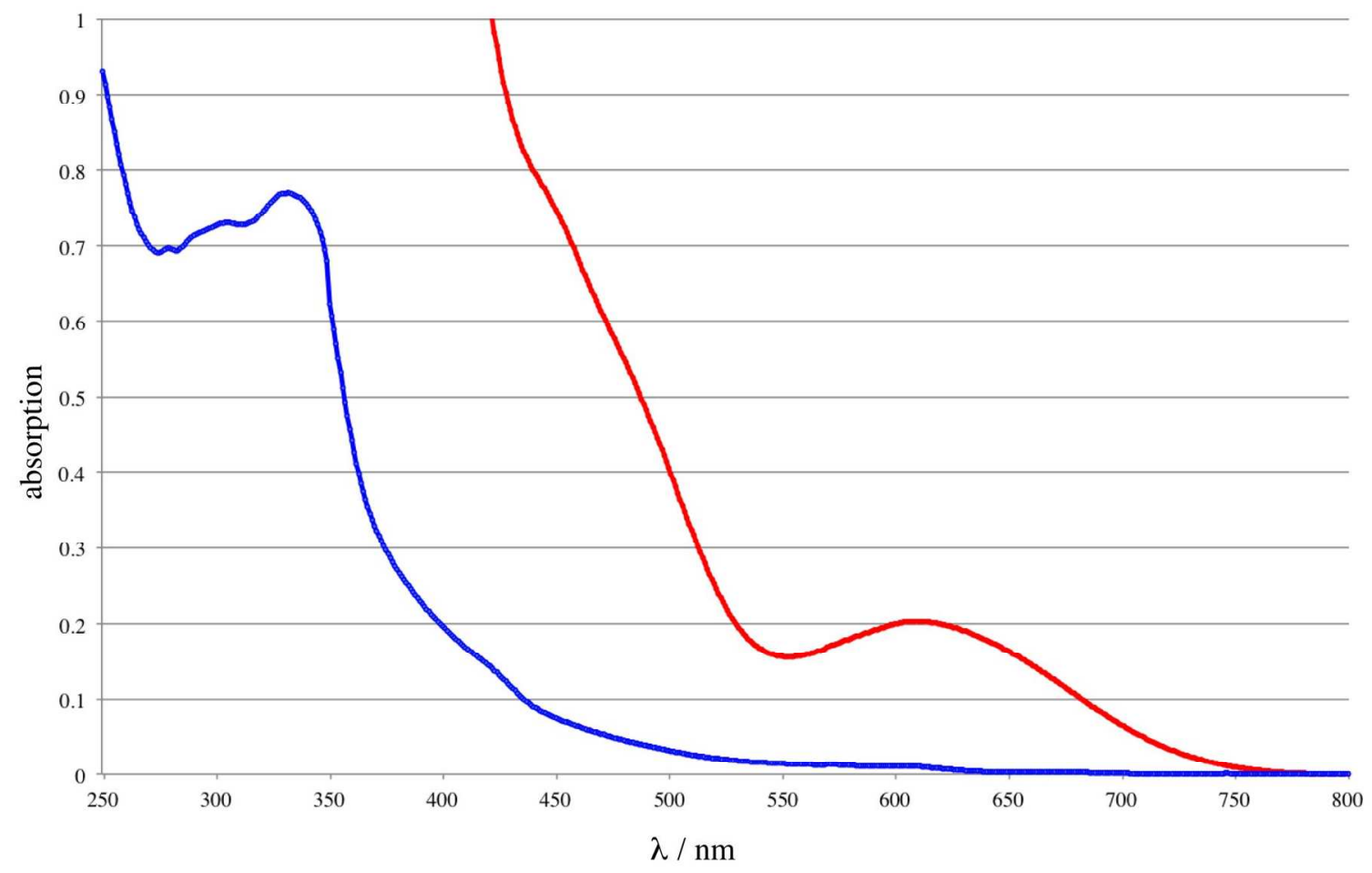

Figure S37. UV-Vis spectrum of 5 (blue; $0.047 \mathrm{mM}$, red; $0.28 \mathrm{mM}$ in hexane, at $300 \mathrm{~K}$ ).

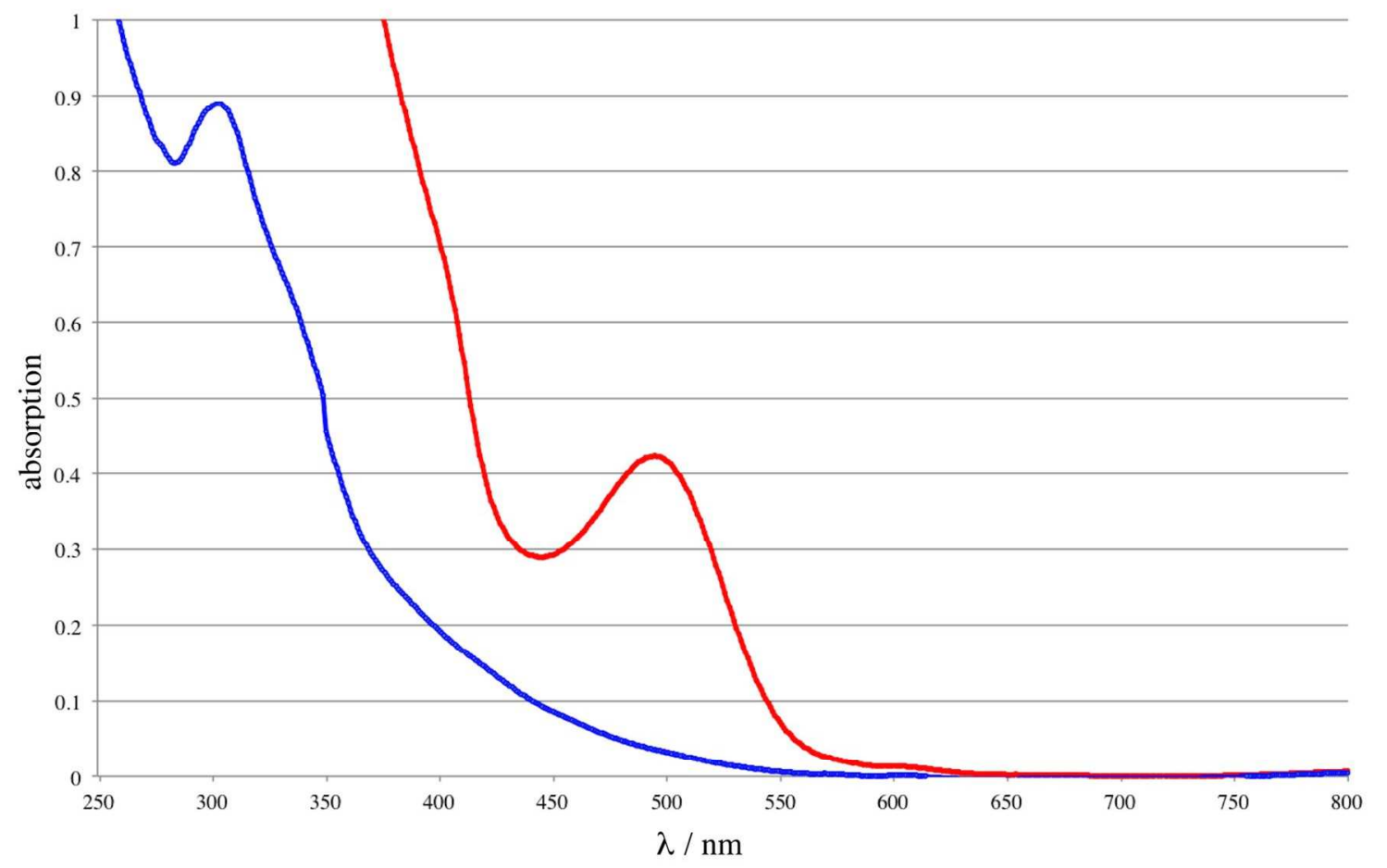

Figure S38. UV-Vis spectrum of 6 (blue; $0.064 \mathrm{mM}$, red; $0.38 \mathrm{mM}$ in hexane, at $300 \mathrm{~K}$ ). 


\section{Cyclic Voltammetry}

Cyclic voltammetry measurement of 2 was carried out using an E2 Epsilon (BAS) autolab potentiostat/galvanostat under control by BAS software. A standard three-electrode cell configuration was employed using a glassy carbon working electrode, a platinum wire counter electrode, and a platinum wire as the reference electrode. $\left[{ }^{\mathrm{n}} \mathrm{Bu}_{4} \mathrm{~N}\right]\left[\mathrm{PF}_{6}\right](0.2 \mathrm{M}$, THF solution) was used as the supporting electrolyte. All electrochemical data are referenced to the $\left[\mathrm{FeCp}_{2}\right] /\left[\mathrm{FeCp}_{2}\right]^{+}$redox couple.

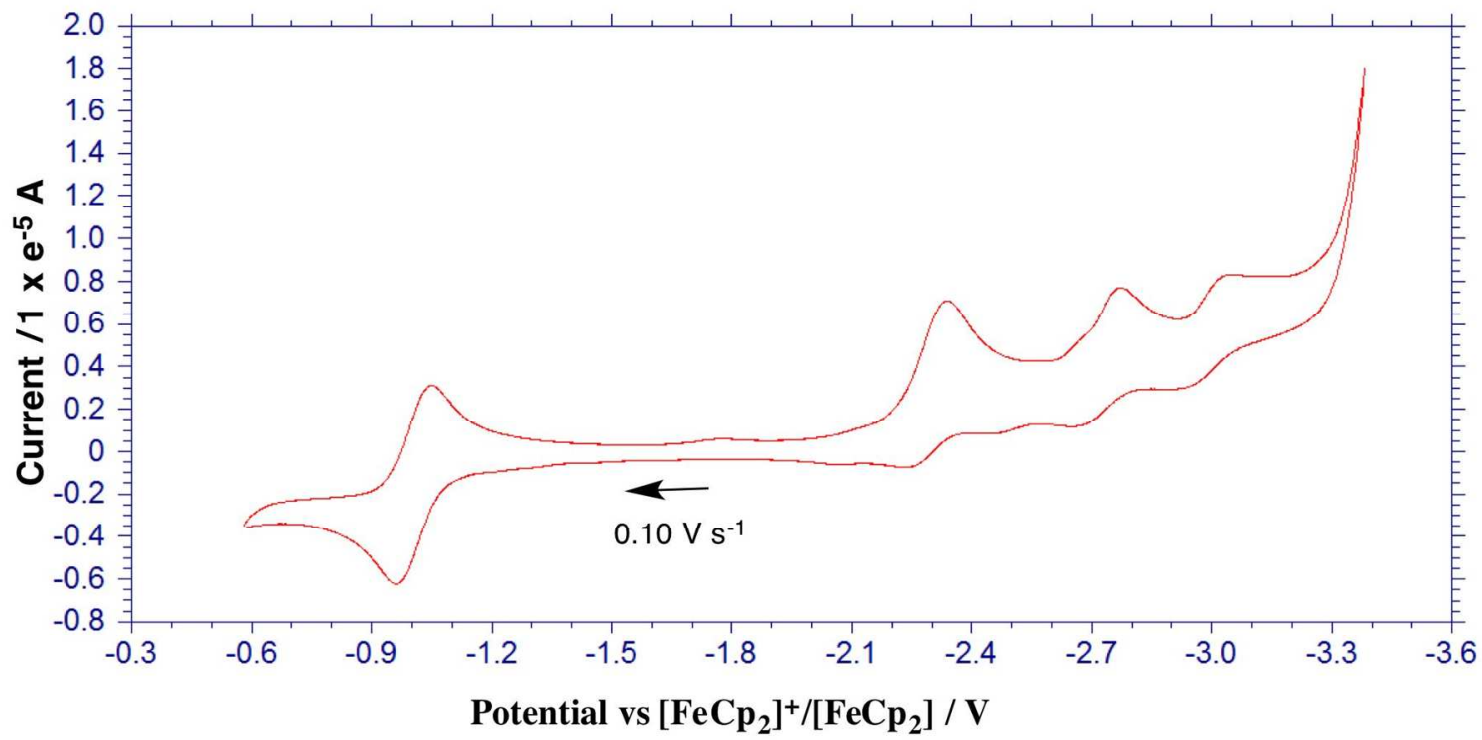

Figure S39. Cyclic Voltammogram of $2\left(0.2 \mathrm{M}\left[{ }^{\mathrm{n}} \mathrm{Bu}_{4} \mathrm{~N}\right]\left[\mathrm{PF}_{6}\right]\right.$ in THF, $0.10 \mathrm{~V} \mathrm{~s}^{-1}$ scan rate, at $300 \mathrm{~K}) . \mathrm{E}_{1 / 2}=-1.01 \mathrm{~V}, \mathrm{E}=-2.34 \mathrm{~V},-2.78 \mathrm{~V},-3.05 \mathrm{~V}$. 


\section{X-ray Crystallography}

Crystallographic data for are summarized Table S1-S5. Suitable crystals for X-ray analysis of 1-5 were placed on the end of a Cryoloop coated in NVH oil. The X-ray intensity data collection was carried out on a Bruker APEXII CCD area detector using graphite-monochromated Mo-K $\alpha$ radiation $(\lambda=0.71073 \AA)$ at $100(1) \mathrm{K}$. Preliminary indexing was performed from a series of thirty-six $0.5^{\circ}$ rotation frames with exposures of 10 seconds. Rotation frames were integrated using SAINT, ${ }^{11}$ producing a listing of non-averaged $F^{2}$ and $\sigma\left(F^{2}\right)$ values which were then passed to the SHELXTL ${ }^{12}$ program package for further processing and structure solution. The intensity data were corrected for Lorentz and polarization effects and for absorption using SADABS. ${ }^{13}$ All calculations were performed using SHELXS $^{14}$ and SHELXL. ${ }^{15}$ The structures were solved by Patterson and Fourier transform methods. All reflections were used during refinement. Non-hydrogen atoms were refined anisotropically and hydrogen atoms were refined using riding models, except for methylidene of $\mathbf{4}$ and methylidyne of $\mathbf{5}$. For $\mathbf{1}$, one of the ${ }^{\mathrm{i}} \mathrm{Pr}$ groups of PNP was disordered over two positions. One site occupied by a hexane molecule was identified in the asymmetric unit. This site contains considerably a disordered hexane molecule and was treated by SQUEEZE as a diffuse contribution. ${ }^{16,17}$ In the void space, a contribution of $712 \mathrm{e}^{-}$per unit cell was found and taken to represent two hexane molecules for each $\mathrm{Nb}$ complex, giving one hexane in the asymmetric unit. For 3, the toluene molecules were disordered over two positions. The toluene molecules were located as a positional disorder of a half toluene and a whole toluene, and the occupacities were refined as 0.67 and 0.33 respectively to represent $2 / 3$ toluene molecules for each $\mathrm{Nb}$ complex. These disordered toluene molecules were fixed with a rigid group model. For 4, the hydrogen atoms on the methylidene ligand were located from a difference map and were refined isotropically. For 5, the hydrogen atom on the methylidyne ligand was located from a final difference map as a $\mathrm{C}-\mathrm{H}$ bond distance of $0.945 \AA$ and was not refined. The isotropic refinement of this hydrogen leads to an 
unrealistically short $\mathrm{C}-\mathrm{H}$ bond distance of $0.83(3) \AA$.

These results were checked using the IUCR's CheckCIF routine. The alerts in the output are related to the disordered groups and crystal solvents. The large values of the second parameter on the SHELXL weighting are due to the poor quality of crystals.

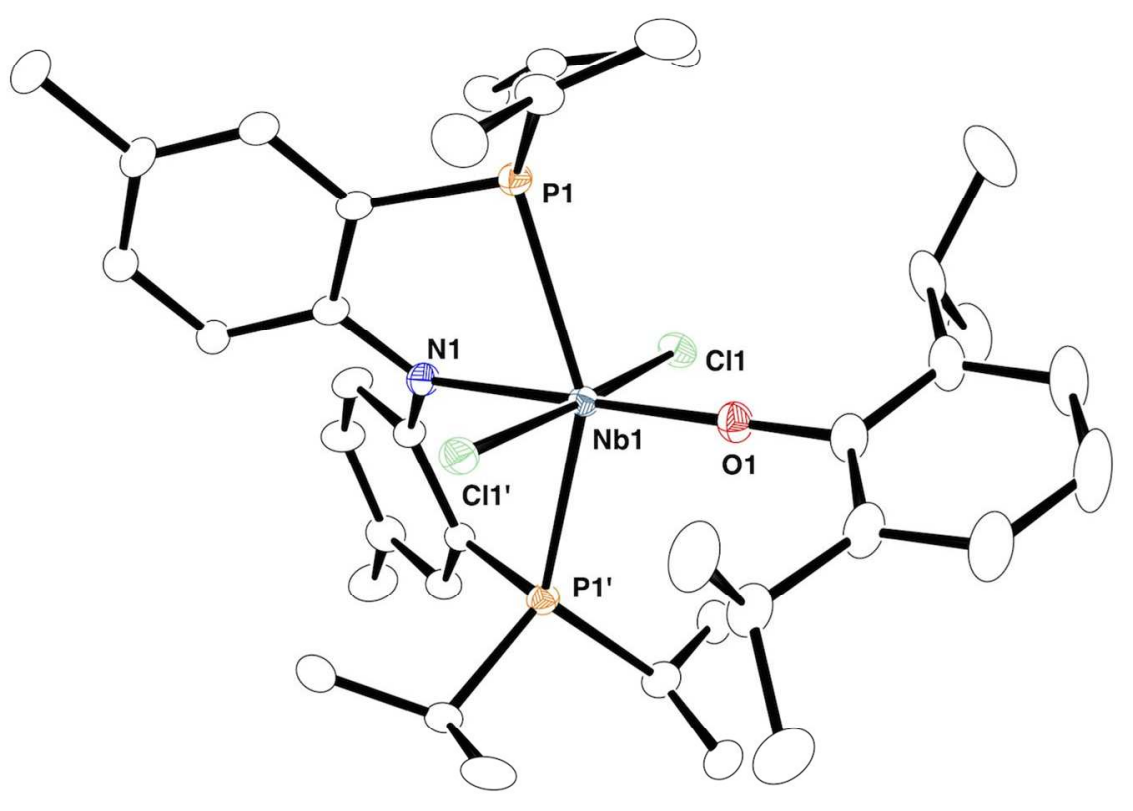

Figure S40. Molecular structure of $\mathbf{1}$ showing thermal ellipsoids at the $35 \%$ probability level. Solvent and $\mathrm{H}$-atoms have been omitted for clarity. 
Table S1. Summary of Structure Determination of 1·(hexane)2

Empirical formula

Formula weight

Temperature

Wavelength

Crystal system

Space group

Cell constants:

$a$
$b$
$c$
$\alpha$
$\beta$
$\gamma$

Volume

Z

Density (calculated)

Absorption coefficient

$\mathrm{F}(000)$

Crystal size

Theta range for data collection

Index ranges

Reflections collected

Independent reflections

Completeness to theta $=27.55^{\circ}$

Absorption correction

Max. and min. transmission

Refinement method

Data / restraints / parameters

Goodness-of-fit on $F^{2}$

Final $\mathrm{R}$ indices $[\mathrm{I}>2 \operatorname{sigma}(\mathrm{I})]$

$\mathrm{R}$ indices (all data)

Largest diff. peak and hole
$\mathrm{C}_{50} \mathrm{H}_{85} \mathrm{NOCl}_{2} \mathrm{P}_{2} \mathrm{Nb}$

941.93

100(1) K

$0.71073 \AA$

Tetragonal

$I 4_{1} / a$ (No. 88)

$13.2018(4) \AA$

$13.2018(4) \AA$

$57.5706(17) \AA$

$90^{\circ}$

$90^{\circ}$

$90^{\circ}$

$10033.8(7) \AA^{3}$

8

$1.247 \mathrm{Mg} / \mathrm{m}^{3}$

$0.445 \mathrm{~mm}^{-1}$

4040

$0.30 \times 0.15 \times 0.02 \mathrm{~mm}^{3}$

1.583 to $27.591^{\circ}$

$-16 \leq \mathrm{h} \leq 17,-17 \leq \mathrm{k} \leq 16,-74 \leq 1 \leq 74$

107366

$5809[R$ (int) $=0.0742]$

$99.5 \%$

Semi-empirical from equivalents

0.7456 and 0.6357

Full-matrix least-squares on $F^{2}$

5809 / 6 / 224

1.285

$R_{1}=0.0740, w R_{2}=0.1567$

$R_{1}=0.0846, w R_{2}=0.1601$

0.668 and -0.738 e. $\AA^{-3}$ 
Table S2. Summary of Structure Determination of $2 \cdot$ (pentane)

Empirical formula

Formula weight

Temperature

Wavelength

Crystal system

Space group

Cell constants:

$a$
$b$
$c$
$\alpha$
$\beta$
$\gamma$

Volume

Z

Density (calculated)

Absorption coefficient

$\mathrm{F}(000)$

Crystal size

Theta range for data collection

Index ranges

Reflections collected

Independent reflections

Completeness to theta $=27.55^{\circ}$

Absorption correction

Max. and min. transmission

Refinement method

Data / restraints / parameters

Goodness-of-fit on $F^{2}$

Final $\mathrm{R}$ indices $[\mathrm{I}>2 \operatorname{sigma}(\mathrm{I})]$

$\mathrm{R}$ indices (all data)

Largest diff. peak and hole
$\mathrm{C}_{45} \mathrm{H}_{75} \mathrm{NOP}_{2} \mathrm{Nb}$

800.91

100(1) K

$0.71073 \AA$

Triclinic

PT (No. 2)

12.3046(12) $\AA$

12.9264(13) $\AA$

$15.7965(15) \AA$

$112.094(5)^{\circ}$

$104.837(5)^{\circ}$

$90.285(5)^{\circ}$

2235.9(4) $\AA^{3}$

2

$1.190 \mathrm{Mg} / \mathrm{m}^{3}$

$0.373 \mathrm{~mm}^{-1}$

862

$0.18 \times 0.08 \times 0.05 \mathrm{~mm}^{3}$

1.449 to $27.587^{\circ}$

$-15 \leq \mathrm{h} \leq 16,-16 \leq \mathrm{k} \leq 15,-20 \leq 1 \leq 20$

56350

$10243[R($ int $)=0.0664]$

$98.9 \%$

Semi-empirical from equivalents

0.7456 and 0.5716

Full-matrix least-squares on $F^{2}$

10243 / 0 / 469

1.023

$R_{1}=0.0436, w R_{2}=0.0976$

$R_{1}=0.0710, w R_{2}=0.1091$

1.173 and -0.934 e. $\AA^{-3}$ 
Table S3. Summary of Structure Determination of $3 \cdot($ toluene) $2 / 3$

Empirical formula

Formula weight

Temperature

Wavelength

Crystal system

Space group

Cell constants:

$a$
$b$
$c$
$\alpha$
$\beta$
$\gamma$

Volume

Z

Density (calculated)

Absorption coefficient

$\mathrm{F}(000)$

Crystal size

Theta range for data collection

Index ranges

Reflections collected

Independent reflections

Completeness to theta $=27.55^{\circ}$

Absorption correction

Max. and min. transmission

Refinement method

Data / restraints / parameters

Goodness-of-fit on $F^{2}$

Final $\mathrm{R}$ indices [I $>2 \operatorname{sigma}(\mathrm{I})]$

$\mathrm{R}$ indices (all data)

Largest diff. peak and hole
$\mathrm{C}_{91.33} \mathrm{H}_{136} \mathrm{~N}_{2} \mathrm{O}_{8} \mathrm{~F}_{6} \mathrm{P}_{4} \mathrm{Nb}_{2}$

1877.80

100(1) K

$0.71073 \AA$

Triclinic

$P \mathrm{~T}$ (No. 2)

$10.4600(7) \AA$

12.8017(10) $\AA$

18.4489(13) $\AA$

$78.432(4)^{\circ}$

$82.776(4)^{\circ}$

$70.576(4) \circ$

$2277.8(3) \AA^{3}$

1

$1.369 \mathrm{Mg} / \mathrm{m}^{3}$

$0.435 \mathrm{~mm}^{-1}$

990

$0.09 \times 0.07 \times 0.07 \mathrm{~mm}^{3}$

1.71 to $27.56^{\circ}$

$-13 \leq \mathrm{h} \leq 13,-16 \leq \mathrm{k} \leq 16,0 \leq 1 \leq 23$

60486

$10106[R($ int $)=0.0726]$

$96.0 \%$

Semi-empirical from equivalents

0.7456 and 0.6213

Full-matrix least-squares on $F^{2}$

10106 / 57 / 575

1.047

$R_{1}=0.0452, w R_{2}=0.0985$

$R_{1}=0.0688, w R_{2}=0.1073$

0.803 and -0.576 e. $\AA^{-3}$ 
Table S4. Summary of Structure Determination of $4 \cdot$ (pentane)

Empirical formula

Formula weight

Temperature

Wavelength

Crystal system

Space group

Cell constants:

$a$
$b$
$c$
$\alpha$
$\beta$
$\gamma$

Volume

Z

Density (calculated)

Absorption coefficient

$\mathrm{F}(000)$

Crystal size

Theta range for data collection

Index ranges

Reflections collected

Independent reflections

Completeness to theta $=27.55^{\circ}$

Absorption correction

Max. and min. transmission

Refinement method

Data / restraints / parameters

Goodness-of-fit on $F^{2}$

Final $\mathrm{R}$ indices $[\mathrm{I}>2 \operatorname{sigma}(\mathrm{I})]$

$\mathrm{R}$ indices (all data)

Largest diff. peak and hole
$\mathrm{C}_{45} \mathrm{H}_{71} \mathrm{NO}_{4} \mathrm{~F}_{3} \mathrm{P}_{2} \mathrm{Nb}$

933.93

100(1) K

$0.71073 \AA$

Triclinic

$P \mathrm{~T}$ (No. 2)

12.2863(12) $\AA$

15.2474(13) $\AA$

15.3656(15) $\AA$

$61.451(4)^{\circ}$

$89.192(5)^{\circ}$

$75.707(4)^{\circ}$

2431.9(4) $\AA^{3}$

2

$1.275 \mathrm{Mg} / \mathrm{m}^{3}$

$0.407 \mathrm{~mm}^{-1}$

988

$0.24 \times 0.20 \times 0.16 \mathrm{~mm}^{3}$

1.520 to $27.691^{\circ}$

$-15 \leq \mathrm{h} \leq 16,-19 \leq \mathrm{k} \leq 19,-19 \leq 1 \leq 19$

60110

$11003[R($ int $)=0.0633]$

$96.7 \%$

Semi-empirical from equivalents

0.7456 and 0.5435

Full-matrix least-squares on $F^{2}$

$11003 / 1 / 538$

1.047

$R_{1}=0.0439, w R_{2}=0.1136$

$R_{1}=0.0531, w R_{2}=0.1220$

0.964 and -1.366 e. $\AA^{-3}$ 


\section{Table S5. Summary of Structure Determination of 5}

Empirical formula

Formula weight

Temperature

Wavelength

Crystal system

Space group

Cell constants:

$a$
$b$
$c$
$\alpha$
$\beta$
$\gamma$

Volume

Z

Density (calculated)

Absorption coefficient

$\mathrm{F}(000)$

Crystal size

Theta range for data collection

Index ranges

Reflections collected

Independent reflections

Completeness to theta $=27.55^{\circ}$

Absorption correction

Max. and min. transmission

Refinement method

Data / restraints / parameters

Goodness-of-fit on $F^{2}$

Final $\mathrm{R}$ indices $[\mathrm{I}>2 \operatorname{sigma}(\mathrm{I})]$

$\mathrm{R}$ indices (all data)

Largest diff. peak and hole
$\mathrm{C}_{39} \mathrm{H}_{58} \mathrm{NOP}_{2} \mathrm{Nb}$

711.71

100(1) K

$0.71073 \AA$

Monoclinic

$P 2{ }_{1} / c$ (No. 14)

$19.8970(13) \AA$

9.6269(7) $\AA$

20.0101(13) A

$90^{\circ}$

$94.974(3)^{\circ}$

$90^{\circ}$

$3818.4(4) \AA^{3}$

4

$1.238 \mathrm{Mg} / \mathrm{m}^{3}$

$0.428 \mathrm{~mm}^{-1}$

1512

$0.29 \times 0.22 \times 0.04 \mathrm{~mm}^{3}$

1.027 to $27.557^{\circ}$

$-25 \leq \mathrm{h} \leq 25,-12 \leq \mathrm{k} \leq 9,-25 \leq 1 \leq 26$

81311

$8792[R($ int $)=0.0361]$

$99.7 \%$

Semi-empirical from equivalents

0.7456 and 0.6767

Full-matrix least-squares on $F^{2}$

8792 / 0 / 411

1.021

$R_{1}=0.0359, w R_{2}=0.0834$

$R_{1}=0.0493, w R_{2}=0.0918$

2.605 and -1.006 e. $\AA^{-3}$ 


\section{References}

[1] (a) Weng, W.; Yang, L.; Foxman, B. M.; Ozerov, O. V. Organometallics 2004, 23, 4700. (b) Ozerov, O. V.; Guo, C.; Papkov, V. A; Foxman, B. M. J. Am. Chem. Soc. 2004, 126, 4792. (c) Fan, L; Foxman, B. M.; Ozerov, O. V. Organometallic 2004, 23, 326.

[2] Tran. B. L.; Pinter, B; Nichols, A. J.; Konopka, F. T.; Thompson, R.; Chen, C.-H., Krzystek, J.; Ozariwski, A.; Tekser, J.; Baik, M.-H.; Meyer, K.; Mindiola, D. J. J. Am. Chem. Soc. 2012, 134, 13035.

[3] Curley, J. J.; Bergman, R. G.; Tilley, T. D. Dalton Trans. 2012, 41, 192.

[4] Pederesen, S. F.; Hartung Jr., J. B.; Roskamp, E. J.; Dragovich, P. S.; Ruffing, C. J.; Klein, B. A. Inorg. Syn. 1992, 29, 120.

[5] Heinrich, D. D.; Staples, R. J.; Fackler Jr., J. P. Inorg. Chim. Acta 1995, 229, 61.

[6] Yousef, R. I.; Walfor, B.; Rueffer, T.; Wagner, C.; Schmidt, H.; Herzog, R.; Steinborn, D. J. Organomet. Chem. 2005, 690, 1178.

[7] Bailey B. C.; Fout, A. R.; Fan, H.; Tomaszeski, J.; Huffman, J. C.; Gary, J. B.; Johnson, M. J. A.; Mindiola, D. J. J. Am. Chem. Soc. 2007, 129, 2234.

[8] Evans, D. F. J. Chem. Soc. 1959, 2003.

[9] Bain, G. A.; Berry, J. F. J. Chem. Educ. 2008, 85, 532.

[10] Kilgore, U. J.; Yang, X.; Tomaszewski, J.; Huffman, J. C.; Mindiola, D. J. Inorg. Chem. 2006, 45,10712 .

[11] SAINT; Bruker AXS Inc.: Madison, WI, USA. 2009.

[12] SHELXTL; Bruker AXS Inc.: Madison, WI, USA, 2009.

[13] Sheldrick, G. M. SADABS; University of Gottingen: Germany, 2007.

[14] Sheldrick, G. M. Acta Crystallogr. 2008, A64, 112.

[15] $R_{1}=\Sigma|| \mathrm{F}_{\mathrm{o}}|-| \mathrm{F}_{\mathrm{c}} \| / \Sigma\left|\mathrm{F}_{\mathrm{o}}\right|, w R_{2}=\left[\Sigma \mathrm{w}\left(\mathrm{F}_{\mathrm{o}}{ }^{2}-\mathrm{F}_{\mathrm{c}}\right)^{2} / \Sigma \mathrm{w}\left(\mathrm{F}_{\mathrm{o}}{ }^{2}\right)^{2}\right]^{1 / 2}, G O F=\left[\Sigma \mathrm{w}\left(\mathrm{F}_{\mathrm{o}}{ }^{2}-\mathrm{F}_{\mathrm{c}}{ }^{2}\right)^{2} /(\mathrm{n}-\right.$ p) $]^{1 / 2} ;$ where $n=$ the number of reflections and $\mathrm{p}=$ the number of parameters refined.

[16] Spek, A. L. Acta Cryst. 2009, D65, 148.

[17] van der Sluis, P.; Spek, A. L. Acta Cryst. 1990, A46, 194. 